\title{
'MASTER \\ ASSESSMENT OF \\ BLACK LIQUOR RECOVERY BOILERS
}

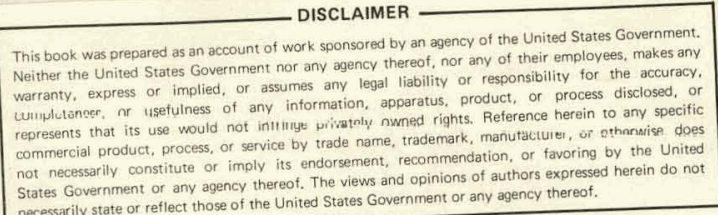

States Government or any agency thereof. The views and opin

PREPARED FOR

THE UNITED STATES DEPARTMENT OF ENERGY

DIVISION OF MAGNETOHYDRODYNAMICS

CONTRACT NO. 01-78-ET 11058.000

May/1979

PREPARED BY

GILBERT/COMMONWEALTH

ENGINEERS/CONSULTANTS

READING, PA 


\section{DISCLAIMER}

This report was prepared as an account of work sponsored by an agency of the United States Government. Neither the United States Government nor any agency Thereof, nor any of their employees, makes any warranty, express or implied, or assumes any legal liability or responsibility for the accuracy, completeness, or usefulness of any information, apparatus, product, or process disclosed, or represents that its use would not infringe privately owned rights. Reference herein to any specific commercial product, process, or service by trade name, trademark, manufacturer, or otherwise does not necessarily constitute or imply its endorsement, recommendation, or favoring by the United States Government or any agency thereof. The views and opinions of authors expressed herein do not necessarily state or reflect those of the United States Government or any agency thereof. 


\section{DISCLAIMER}

Portions of this document may be illegible in electronic image products. Images are produced from the best available original document. 
This report was prepared as an account of work sponsored by the United States Government. Neither the United States nor the United States Department of Energy, nor any of their employees, nor any of their contractors, subcontractors, or their employees, makes any warranty, expressed or implied, or assumes any legal liabilicy or responsibility for the accuracy, completeness or usefulness of any information, apparatus, product or process disclosed, or represents that its use would not infringe privately-owned rights. Mention of commercial products, their manufacturers, or their suppliers in this publication does not imply or connote approval or disapproval of the product by Gilbert Associates, Inc. or the U. S. Department of Energy. 
List of Figures

List of Tables

iv

Executive Summary

V

1.0 INTRODUCTION AND SUMMARY

1.1 Introduction

1.2 Similarities

1.3 Differences

1.4 Cost Comparison

1.5 Recommendations

2.0 COMPARISON OF BLACK LIQUOR AND MHD SYSTEMS

2.1 Review of Black Liquor Technology Applied to MHD

2.2 Comparison

3.0 BLACK LIQUOR RECOVERY BOILERS

3.1 Recovery Process

3.2 Boiler Design

3. 3 Corrosion

3.4 Field Operation and Experience

3.5 Boiler Explosion

3.6 Heating Surface Protection

References

Appendix A - Black Liquor Boiler Installation Lists

$A-2$

Appendix B - Corrosion in Black Liquor. Boilers 
FIG. NO.

\section{LIST OF FIGURES}

IIITLE PAGE

PHYSICAL STATE OF COMPLEX SULFATES AS A

FUNCTION OF TEMPERATURE AND THE CORROSION OF. AUSTENITIC ALLOYS.

A TYPICAL MHO SYSTEM FLOW DIAGRAM II

CORROSION OF CARBON STEEL IN CHLORINE AND 15 HYDROGEN CHLORIDE.

PROCESS FLOW DIAGRAM OF A TYPICAL KRAFT PULP AND 18 PAPER MILL.

$\begin{array}{ll}\text { KRAFT RECOVERY PROCESS } & 19\end{array}$

TYPICAL RECOVERY UNIT SHOWING CHEMICAL REACTIONS 22 AND WHERE THEY OCCUR

TYPICAL RECOVERY UNIT CORROSION. $\quad 25$

CORROSION RATE VS. METAL TEMPERATURE FOR CARBON 28 STEEL (SA-226).

TYPE 304 STAINLESS STEEL CORROSION RATE. 28

TYPE 304 STAINLESS STEEL WEIGHT GAIN VS. 29 TEMPERATURE.

HARDNESS PEAKS OF TYPE 309 CARBON STEEL. 29

EFFECT OF FURNACE GAS COMPOSITION ON CORROSION. - B-5

EFFECT OF SODIUM CHLORIDE ON. THE MELTING POINT B-5 OF SMELT.

COMPARISON OF SUPERALLOY. PERFORMANCE IN 90\% B-6 $\mathrm{Na}_{2} \mathrm{SO}_{4}-10 \% \mathrm{NaCl}$ CRUCIBLE TEST AT $927^{\circ} \mathrm{C}$ (1700.6F).

COMPARISON OF SUPERALLOY PERFORMANCE IN $75 \%$ $\mathrm{Na} \mathrm{SO}_{4}-25 \% \mathrm{NaCl}$ SALT SHOWER TEST AT $900^{\circ} \mathrm{C}$ (i652 $\mathrm{F}$ ). 


\section{LIST OF TABLES}

TABLE NO.

1

2

3

4

5

6

7
TITLE

PAGE

BLACK LIQUOR BOILER AND MHD SYSTEM GAS CONSTITUENTS

BLACK LIQUOR BOILER AND MHD SYSTEM DESIGN PARAMETERS

BLACK LIQUOR BOILER AND MHD SYSTEM HEAT TRANSFER SURFACE DESIGN DETAILS

METAL LOSS IN THICKNESS OF CORROSION

SPECIMENS IN COMBUSTION GAS WITH UNSEEDED COAL AND IN COMBUSTION GAS WITH COAL SEEDED WITH POTASSIUM CARBONATE.

ANALYSIS OF TYPICAL BLACK LIQUOR

CORROSION RATES ON SA-192 AT $700^{\circ} \mathrm{F}$

WASTAGE OF SA-192 AT $700^{\circ} \mathrm{F}$.
20

26

6

8

9

13

27 


\section{EXECUTIVE SUMMARY}

In the paper making industry, pulpwood chips are digested and cooked to provide the pulp going to the refining and paper mills. Black liquor residue, containing the dissolved 7 ignin binder from the chips, with a concentration of 12 to 16 percent solids, is further concentrated to 62 to 65 percent solids and mixed with salt cake, Sodium Sulfate $\left(\mathrm{Na}_{2} \mathrm{SO}_{4}\right)$. The resulting concentrate of black liquor serves both as a fuel for generating steam in the boiler and also as the mother liquid from which other process liquors are recovered and recycled.

Because the black liquor fuel contains high alkali concentrations, 18.3 percent sodium, 3.6 percent sulfur an amount typical of midwestern bituminous coal, and measurable amounts of silica, iron oxides and other species, the black liquor boiler experience was reviewed for application to MHD boiler technology.

Direct comparison of salient features of black liquor boiler and MHD boiler design are:

1. High alkali concentrations in the combustion gases

- Carry over of Sodium ( $\mathrm{Na}$ ) in the black liquor boiler is about 0.2 percent by weight of combustion gases compared to 1.0 percent Potassium ( $K$ ) in the MHD boiler. Corrosion and thermodynamic behavior of $\mathrm{K}$ and $\mathrm{Na}$ are, similar under the same concentrations and operating states.

2. Particulate loading

- Particulate loading in the MHD combustion gases is about 4 times as high as for the black liquor combustion gases, 77 grains mass flow rate compared to 18 . About one tenth of the loading in the MHD cycle is acidic slag particles. 


\section{Operating States}

- MHD gases enter the radiant boiler at $3650^{\circ} \mathrm{F}$ compared to $2800^{\circ} \mathrm{F}$ for the black liquor boiler (and $3400^{\circ} \mathrm{F}$ for conventional coal fired boilers).

- MHD employs fuel rich combustion to limit NOx formation. The resultant reducing atmosphere is corrosive to metal and refractory materials and exists through a high temperature air heater in direct fired systems and through the secondary radiant furnace in the separately fired systems. (This extensive reducing zone occurs because excess air cannot be added until an available injection point is reached after gas temperatures are below $2600^{\circ} \mathrm{F}$, otherwise the recombustion could. produce additional NOX). Reducing atmosphere in the black liquor boiler occurs only at the hearth (furnace bottom) where maximum reduction of $\mathrm{NA}_{2} \mathrm{SO}_{4}$ to $\mathrm{N}_{2} \mathrm{~S}$ is desired.

o. Gas temperatures are restricted to $1700^{\circ} \mathrm{F}$ into the black. liquor superheater. This temperature level is high enough to produce superheated and reheat steam and low enough to reduce the concentration of molten salt carryover from the radiant furnace. In the MHD cycle the temperature level into the superheater may be as high as $2400^{\circ} \mathrm{F}$ and the level does not drop to $1700^{\circ} \mathrm{F}$ until the exit from the reheater.

- The highly corrosive molten range of the sodium salts in the black. Tiquor boiler is from $1800^{\circ} \mathrm{F}$ and $1600^{\circ} \mathrm{F}$. Potassium salts in the MHD cycle have more complex constituents and the molten range of temperature is higher and more extensive, but the most severe corrosive range extends from $2100^{\circ} \mathrm{F}$ to $1950^{\circ} \mathrm{F}$. In addition, molten range for the corrosive (acidic) slag extends "from $3200^{\circ} \mathrm{F}$ to $2200^{\circ} \mathrm{F}$. Since there are operational overlaps of areas which can be contacted by molten alkalies or molten acidic salts material selection is made more 
difficult in the MHD design.

0 Steam temperatures in the black liquor boiler do not exceed $850^{\circ} \mathrm{F}$ and pressures are 1500 psig. Coal fired MHD/steam cycles where system efficiency is of paramount importance provide superheat and reheat steam to $1000^{\circ} \mathrm{F}$ at higher pressures.

- Combustion gas velocities in the black liquor boiler are in a 15 to 20 feet per second range. In the MHD radiant boiler velocities which are restricted to allow dwell time for NOx to revert to $\mathrm{N}_{2}$ and $\mathrm{O}_{2}$ are at 50 feet per second. Because of cost and performance requirements for MHD boilers, velocities in the other boiler sections approach conventional velocities of 100 feet per second. These higher velocities plus the s.lag content make MHD combustion gases more erosive than those in the black liquor boiler.

Black liquor boiler design has adopted the following techniques for successful operation of black liquor boilers:

1. In the high temperature, $1800^{\circ} \mathrm{F}$, reducing atmosphere at the hearth, a combination of sacrificial studs implemented on diffusion coated tubes, hard face welding protection, "Sandvik" bimetallic tubes, and refractory coating are employed. Compared to carbon tubes with a metallic coating, the increased cost factors for diffusion coating is 5 , hard face welding or studs with refractory is 10 , and composite tubing is 15 .

2. Water cooled deflectors are installed to limit the high temperature impact of the erosive gases on superheater surface. Large pitch, 12 inch lateral spacing, and in-line array to lessen impact area reduce slag buildup. Platen" weld protection reduces erosion and inhibits buildup of slag so that interlocking between adjacent tubes is avoided. Retractable, half length soot blowers allow 
easy access to tube surface and increase effectiveness in removing tube deposits.

3. Since the black liquor boiler is a process boiler which also produces plant steam, design features can emphasize utility rather than performance. Input is usually around 300 MWth and even on a relative basis the thermal duty of the furnace is low since combustion gases at the maximum temperature of $2800^{\circ} \mathrm{F}$ have to maintain sufficient temperature and enthalpy to superheat steam to $850^{\circ} \mathrm{F}$ downstream. Compared to subbituminous coal, the black liquor contains three times the amount of increased $\mathrm{Na}$ compounds: This excess lowers the melting point of slag by $300^{\circ} \mathrm{F}$. Resulting slagging and fouling in the furnace reduce the effectiveness of the heat transfer surface. In addition, the lower gas temperature in the black liquor furnace reduces the radiative heat transfer (by about 50\%) compared to the conventional furnace. For these reasons, heat transfer in the black liquor furnace is about one tenth that of modern conventional furnaces. (MHD furnace unit heat transfer is predicted for first generation MHD. plants to be about one third that of modern conventional practice.) Economizer thermal duty, as another design example, is restricted so that outlet gas temperatures are above the condensation of sulfur acids which could cause corrosion.

Review of factors influencing design of the black liquor boiler places it intermediate in difficulty compared to conventional boiler design and MHD boiler design. The increased severity of MHD operating parameters is evidenced in the following table: 
TABLE A

Parameter

Gas flame temperature, ${ }^{0} \mathrm{~F}$

Gas inlet to superheater, ${ }^{\circ} \mathrm{F}$

Alkali content, $\% w$

Particulate loading grains

$F t^{3}-\mathrm{sec}$

Molten zone, ${ }^{0} F$

(highly corrosive)

Steam conditions, ${ }^{\circ} \mathrm{F}$, Psig

Reducing Zone

(highly corrosive)

System Size, MWt

Major Design Objectives

\begin{tabular}{|c|c|c|}
\hline $\begin{array}{l}\text { Black Liquor } \\
\text { Boiler } \\
\end{array}$ & $\begin{array}{c}\text { Conventional } \\
\text { Boiler } \\
\end{array}$ & $\begin{array}{l}\text { MHD } \\
\text { Boiler }\end{array}$ \\
\hline 2800 to 3000 . & 3400 & 3700 \\
\hline 1700 & 2200 & 2445 \\
\hline $0.15(\mathrm{Na})$ & traces & $1.0(K)$ \\
\hline 18 & 7 to 10 & 77 \\
\hline 1600 to 1800 & $\begin{array}{l}2400 \text { to } 3100 \\
(\text { slag })\end{array}$ & $\begin{array}{l}1950 \text { to } 2100(\mathrm{Ki} \\
2200 \text { to } 3200(\mathrm{Si})\end{array}$ \\
\hline 850,1500 & 1000,2400 & 1000,2000 to 4000 \\
\hline Hearth & NA & $\begin{array}{l}\text { Topping side substan- } \\
\text { tial section of boilers }\end{array}$ \\
\hline 300 & to 2000 & 2000 \\
\hline Process & Power prod. & Power prod. \\
\hline
\end{tabular}


The protective techniques and design features which allow successful commercial operation for the black liquor boilerare valid but only as starting points for design of analogous MHD boilers.

The successful design of black liquor boilers provides confidence that the additional steps to satisfactory MHD boiler design can be accomplished technically. Increased cost per square foot of surface for the MHD boilers plus the increased surface requirements for a given duty will create economic challenges. Recent advancements in boiler design for conventional as well as.specialized applications, with major application to improved availability, add assurance that if commercial applicability for MHD boilers exists, design problems can be solved. 
SECTION 1.0

INTRODUCTION AND SUMMARY

\section{$1.1 \quad$ INTRODUCTION}

Black liquor is the residual concentrated liquid resulting from cooking pulpwood in an alkaline solution as part of the Kraft (sulfate) process of paper making. In recovery furnaces, heat energy from the combustion of organic liquor constituents is used to produce steam, and inorganic constituents are recovered as molten smelt. The corrosive black liquor recovery furnace may have design application to the Magnetohydrodynamic (MHD) components exposed to corrosive high temperature operating conditions. The report surveys and assesses black liquor design practices and experiences as they might apply to MHD components.

\subsection{SIMILARITIES}

Commercially operating black liquor recovery boilers and the open cycle MHD system boilers have in common high concentrations of alkali metals in the flue gas. In addition, high corrosion rates in the furnace and slag removal from heating surfaces are major problems for both systems.

The following black liquor boiler. design features have been employed to remain operable in the corrosive-erosive environment:

- Sacrificial pin-studs spaced 1/2 inch circumferentially (Ref. 1), on dual wall tubes with a diffusive metallic coating of chromium and aluminum-chromium

- A water cooled furnace screen to shield the superheater from high flue gas temperatures

- Use of a "platen" type, self-drainable, vertical, parallel flow superheater and reheater with a minimum lateral tube spacing of 12 inches. The wider lateral tube spacing is about three times that in the conventional subbituminous coal-fired unit. The platen type membrane wall may prevent the "keying" of the slag, and wider lateral tube spacing may lessen fouling and increase effectiveness of the soot blower. 
- Half-length, retractable, steam soot blowers to remove deposits

\subsection{DIFFERENCES}

The following differences between the systems may constrain direct application to MHD systems:

- A substantially higher MHD plasma temperature of $3650^{\circ} \mathrm{F}\left(2283^{\circ} \mathrm{K}\right)$ compared to the flue gas temperature of $2800^{\circ} \mathrm{F}\left(1811^{\circ} \mathrm{K}\right)$ in the black liquor furnace (at the secondary and tertiary air zones)

- A higher heat absorption rate in the MHD radiant boiler compared to the black liquor furnace (ratio of 3 to 1 )

- The higher steam pressure and temperature conditions ( 3500 or 2400 psig/ $1000^{\circ} \mathrm{F} / 1000^{\circ} \mathrm{F}$ ) proposed by different contractors for the MHD system compared to those in the black liquor system (1500 psig/ $875^{\circ} \mathrm{F}$ )

- Additional corrosive deposits in the MHD system as iron oxides $\left(\mathrm{Fe}_{2} \mathrm{O}_{3}, \mathrm{Fe}_{3} \mathrm{O}_{4}\right)$ and potassium-iron trisulfates $\left[\mathrm{K}_{3} \mathrm{Fe}\left(\mathrm{SO}_{4}\right)_{3}\right]$

\subsection{COST COMPARISON}

Since a detailed cost comparison is out of the scope of this study, this section contains only brief, generalized comparisons. Considering a carbon steel tubing with metallic coating as the base coat, diffusion coating costs about five to six times as much, hard face welding or studs with refractory at 10 to 15 times, and composite tubing 11 to 21 times (Ref. 1).

\subsection{RECOMMENDATIONS.}

The black liquor boiler is an intermediate step from conventional boilers to MHD boilers. Turndown, corrosion, and cost increases of black liquor boilers compared to conventional boilers would be analogous to those in going from black liquor boilers to MHD boilers. 
Further study of the use of black liquor recovery boiler technology in the MHD system is warranted. To select proper alloys to resist oxidation and corrosion attack, more accurate thermochemical calculations using the Joint Army-Navy-Air Force (JANAF) tables and melting point data on MHD slag are required. In these calculations, governing factors would be temperature, $\mathrm{CO} / \mathrm{CO}_{2}$ ratio, $\mathrm{SO}_{2}$ content, and combustion gas pressure.

Alternate approaches for MHD design such as gas quenching to eliminate corrosion and adherence problems due to molten seed should also be investigated. (Ref. 2) 


\section{SECTION 2.0}

\section{COMPARISON OF BLACK LIQUOR AND MHD SYSTEMS}

\subsection{REVIEW OF BLACK LIQUOR TECHNOLOGY APPLIED TO MHD}

For reference, Appendix A contains black liquor boiler installation lists from the three leading manufacturers: Babcock and Wilcox Company $(B \& W)$, Combustion Engineering (CE), and Copeland Systems Incorporated subsidiary of Foster Wheeler Development Corporation (FW). Based on these lists, $B \& W$ has the most relevant experience. In addition, they have designed the largest capacity unit with the highest steam pressure and temperature (1500 psig/8750 F) located at the Union Camp Corporation, Franklin, Virginia, with a firing rate of 1,200 tons/day of sulfate liquor. The consulting engineer on this unit was C.T. Main, Inc. CE has the widest black liquor boiler design experience of all the Engineering Test Facility. (ETF) contractors or subcontractors. Their ETF downstream component design reflects black liquor boiler design by low heat absorption rate in the furnace; wider convection surface lateral spacing; three separate furnaces: slag recovery, seed recovery, and final oxidation. Their configurations resemble the three zones in the black liquor furnace: drying, reducing, and oxidizing.

The FW MHD design reflects black liquor boiler design only in the low furnace heat absorption rate (20 percent of the conventional coal-fired value) and a roof-fired, secondary furnace construction which is standard FW furnace design practice for low heating value fuels such as black liquor whose gross heating value is only $6,600 \mathrm{Btu} / \mathrm{lb}$. FW does not appear to have considered the effect of potassium salts $\left(\mathrm{K}_{2} \mathrm{CO}_{3}\right.$, $\mathrm{K}_{2} \mathrm{SO}_{4}$ ) in their design calculations.

In general, both conceptual designs (AVCO/CE, GE/FW) meet ETF operational goals as defined in their respective design criteria documents. In the CE design, the location of the low temperature air 
heater (LTAH), the effect of air leakage (to the gas side) on the seed/slag system, most of the selected tube metals, and the separation of dry seed (from slag). at the unbalanced operating conditions should be investigated further. The condensation of seed in the flue gas depends directly upon variables such as partial pressure of potassium compounds, inlet and outlet flue gas and air temperatures, uniform distribution of air to the vertical air heater panels, gas-to-air weight ratio, and predicted-to-actual heat transfer rate. These variables are difficult to define analytically at unbalanced operating conditions, and the design of the recovery furnace will need test verification.

In the FW design as applied to MHD, the following need verification: (1) the flue gas distribution from the spoiler to the radiant boiler, (2) plasma leakage through the dividing wall openings to the "unfired" secondary cavity, (3) the streamlined gas flow distribution at the radiant boiler exit, and (4) the superheater's performance under the variable thermal loads.

\subsection{COMPARISON}

The black liquor boiler hearth furnace and MHD radiant boiler operate with reducing atmospheres, and sodium $(\mathrm{Na})$ and potassium (K) have similar chemical properties. Table 1 presents the gas constituents for the two systems. Under equal concentrations and the same physical state, potassium compounds are more chemically active and less thermally active (due to higher melting point) than sodium counterparts. While the volatility of potassium sulfate $\left(\mathrm{K}_{2} \mathrm{SO}_{4}\right)$ is not as high as sodium sulfate $\left(\mathrm{Na}_{2} \mathrm{SO}_{4}\right)$, it is highly volatile compared to other constituents in coal ash. In addition, the ratio of potassium-to-sodium in the coal ash or tube deposit is significant. Potassium has a greater tendency to form complex, molten sulfates which are more corrosive than their sodium counterparts. 
TABLE 1

BLACK LIQUOR BOILER AND MHD SYSTEM GAS CONSTITUENTS

\begin{tabular}{|c|c|}
\hline $\begin{array}{l}\text { BLACK LIQUOR BOILER } \\
\text { Furnace Hearth Area }\end{array}$ & $\begin{array}{l}\text { MHD SYSTEM } \\
\text { Radiant Boiler Inlet }\end{array}$ \\
\hline $\begin{array}{l}\mathrm{CO}, \mathrm{SO}_{2}, \mathrm{SO}_{3} \\
\mathrm{Na}_{2} \mathrm{O}, \mathrm{Na}_{2} \mathrm{~S}(\mathrm{solid}), \mathrm{NaCl} ; \\
\mathrm{KOH} \\
\mathrm{H}_{2} \mathrm{O}, \mathrm{H}_{2} \mathrm{~S}\end{array}$ & $\begin{array}{l}\mathrm{CO}, \mathrm{SO}_{2}, \\
\mathrm{~K}_{2} \mathrm{O}(\mathrm{solid}), \mathrm{KCl}, \\
\quad- \\
\mathrm{H}_{2} \mathrm{O}\end{array}$ \\
\hline $\begin{array}{l}\text { Superheater Inlet } \\
\mathrm{CO}, \mathrm{SO}_{2}, \mathrm{SO}_{3} \\
\mathrm{Na}_{2} \mathrm{SO}_{3}, \mathrm{Na}_{2} \mathrm{SO}_{4} \\
\mathrm{Na}_{2} \mathrm{CO}_{3}, \mathrm{NaCl}\end{array}$ & $\begin{array}{l}\text { Superheater } \\
\mathrm{CO}, \mathrm{SO}_{2}, \\
\mathrm{~K}, \mathrm{~K}_{2} \mathrm{SO}_{4} \text { (1 iquid) } \\
\mathrm{KCl}, \mathrm{KOH} \\
\mathrm{K}_{2} \mathrm{O} \text { (solid) }\end{array}$ \\
\hline
\end{tabular}

To control fouling and corrosion in the convection surface, a platen type ("pencil" weld) surface with wide lateral tube spacing (minimum 12 inches) is adopted by all the black liquor boiler manufacturers. The lateral tube spacing for coal-fired boilers, black liquor boilers, and MHD-ETF (AVCO and CTE) boiler designs are shown in Figure 1.

Design parameters for a typical black liquor boiler and a number of MHD systems (Gilbert Baseline Plant, ETF-AVCO/CE and GE/FW) are shown on Table 2, and heat transfer surface design details are tabulated on Table 3. Systems operate under positive pressures, and the moisture content is practically the same (about 5 percent by weight). Flue gas temperatures are significantly higher in the MHD system than those in the black liquor boiler. Higher flue gas temperature and the presence 


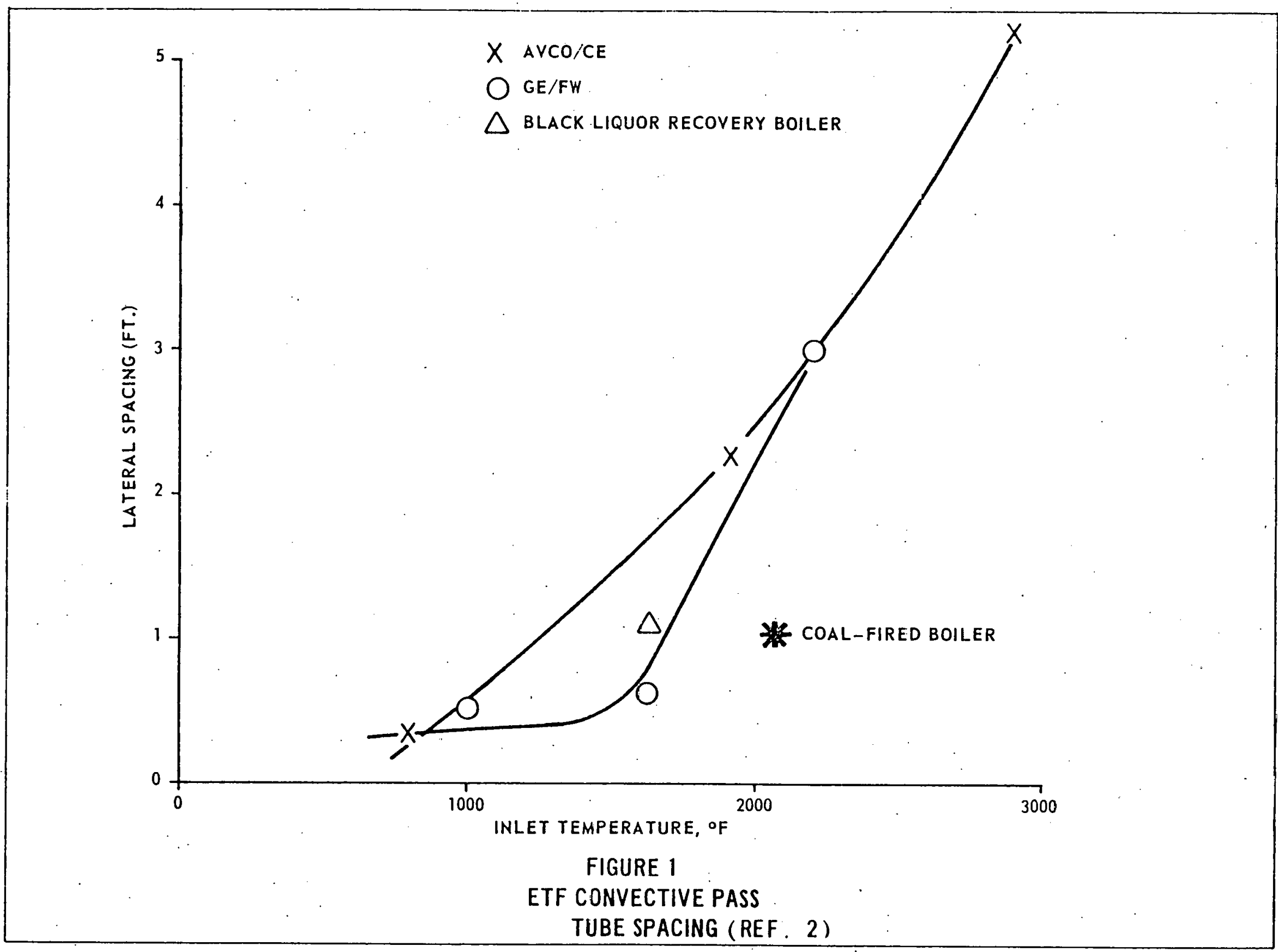




\section{TABLE 2}

\section{BLACK LIQUOR BOILER AND MHD SYSTEM DESIGN PARAMETERS}

№.

Thermal Input, W

2 Steam Pressure/Temperature, $\mathrm{Paig} /{ }^{\circ} \mathrm{P} /{ }^{\circ} \mathrm{F}$

3 Purnace Hear Llberacion Rate,

4 Furnace Heat Release Rate, $\mathrm{Btu} / \mathrm{ft}^{2} / \mathrm{hr}$

5 Heat Plux $\mathrm{Btu} / \mathrm{ft}^{2} / \mathrm{hr}$

6 Heat Absorption In the Purnace, $B t u / \mathrm{ft}^{2} / \mathrm{hr}$

7 Purnace Cross-Sectional Area ft $\times \mathbf{f t}$

8 Purnace Width, ft

9 Furnace Residence Time, seconds

10 Radiant. Boller/Furnace Refractory Material

11 Maximum Flue Gas Temperature in the Radiant Boiler and Furnace, ${ }^{\circ} \mathbf{F}\left({ }^{\circ} \mathrm{K}\right)$

12 Flue Gas Temp. Entering Superheater, $1700(1200)$ ${ }^{\circ}\left({ }^{\circ} \mathrm{K}\right)$

13 Particulate Loading Entering Particulate Loading Entering
Superheater, grains $/ \mathrm{ft}^{2} / \mathrm{sec}$.

14 Flue Gas Temperature Leaving Superheater, ${ }^{\circ} \mathrm{F}\left({ }^{\circ} \mathrm{K}\right)$

15 Ash Pusion Temperature, ${ }^{\circ} \mathbf{P}$

16 Melting Point, ${ }^{\circ} \mathrm{F}\left({ }^{\circ} \mathrm{K}\right)$ of $\mathrm{K}_{2} \mathrm{CO}$ (under reduc ing zone) $\mathrm{K}_{2} \mathrm{SO}_{4}$ $\mathrm{Na}_{2} \mathrm{CO}_{3}$

18

-

$1300(977) \quad 2080(1411)$

$1450 / 1061) \quad 2220(1483)$

$1645(1169)$

1955 (1341)

$1563(1123) \star \star \star *$
$1625(1158) \star \star \star *$

MUID
AVCO/CR
BASLINE
(REV E) $\quad \begin{gathered}\text { ETF DRSIGN } \\ 2500^{\circ} \text { F AIR }\end{gathered}$

271.5

$3690 / 1000 /-$

$1250 / 950 /-$

5,570

$1,150,550$

405,400

29,000

$20.8 \times 20.8$

20.8

2.0

98\% MgO Base + High Magneala Typé

Bubble Alumina ( $3 \mathrm{kn}$. th.)

3650(2283)

3725 (2325)

Finishing Superheater 2940 (1888) Primary Superheate 0 (811)

77

$800(700)$

$2220(1488)$

$1645(1169)$

$1955(1341)$

:

AVCO/CE
ETF DES IGN
$3000^{\circ}$ P AIR

1250/950/-

5,645

$1,160,800$

415,050

29,350

$20.8 \times 20.8$

20.8

2.0

High Magnegla Type

(3 ta. th.)

$3700(2311)$

F $\ln 1$ shtng 2915(1875) Primary S

77

$775(686)$

2220 (1488)

1645(1169) 1955(1341)

- \begin{tabular}{cc} 
GE/FW & GL/FW \\
ETR DESIGN & ETP DESIGN \\
STEAM \\
MID/STEAM BOTTOMING \\
\hline
\end{tabular} 250.0

$3500 / 1000 / 1000$ $2400 / 943 / 1000 *$

2,310

650,150

301,000

15,175

$18.0 \times 36.0$

18

2.0

H.H. Ruby

3126 (1992)

2111(1428)

2915 (1875)

7

$1140(888)$

$2220(1488)$

1645 (1169) $1955(1341)$

:
175.0

$3500 / 1000 / 1000$ At throttle condition 2400/943/1000*

2,745

744,300

$303, \div 25$

17,500

$29.5 \times 36.0$

29.5

2.0

H. N. Ruby

$3175(2020)$

$2060(1366)$

$1495(1086)$

$2220(1488)$

$16.45(1169)$ $1955(1341)$
REMARKS

$*_{A H}$ ateam/volume of the furnace

Inlet thermal energy/furnace cross-sectional area

* $\Delta \mathrm{H}$ gas/furnaze cross sectional area

$\star \Delta H$ steam/prajected area

* $\Delta H$ a change in enthalpy in $B t u / h r$.

$\star *=40,000 \mathrm{Btu} / \mathrm{ft}^{2} / \mathrm{hr}$ at the burner porta

$* * *=$ Under oxidizing zone 
TABLE 3

BLACK LIQUOR BOILER AND MHD SYSTEM HEAT TRANSFER SURFACE DESIGN DETAILS

No.

Vertical Gas Velocity, $\mathrm{ft} / \mathrm{sec}$ Tube Material

Tube 0.0.-in., Thickness-in., Spacing-in.
Radiant Boiler/Furnace

BLACK LIQUOR

SYSTEM

\section{0}

SA-226, STUD.

2.0/N.A. $/ 3.5$

Superficial Gas Velocity, It./sec Tube Material

Tube 0.D.-in., Thickness-in.,

lateral and longitudinal

spacing-in.

Superheater (Parallel Flow) Superficial Gas Velocity, $t / \mathrm{sec}$. Tube Material

Tube 0.0.-in., Thickness-in.,

lateral and longitudinal spacing-in.

Reheater (Counter Flow)

Superficial Gas Velocity, ft/sec. DO NOT EXIST

Tube Material

Tube O.D.-in. , Thickness-in.,

lateral and iongitudinal

spacing-in.

5 - Boiler Bank

Superficial Gas Velocity, $\mathrm{ft} / \mathrm{sec}$.

Tube 0 - in. Thickness-in.

$-192$

Tube 0.D.-in., Thickness-in.

lateral and
spacing-in.

6 Economizer (Counter Flow)

Superficial Gas Velocity, $\mathrm{ft} / \mathrm{sec}$. Tube Material

Tube 0.D.-in:, Thickness-in.,

lateral and longitudinal

(SA-209, T-1)

3/N.A. $/ 24 \& 3.5$

10
$(S A-209, T-1)$
$(S A-213, T-11)$

2.5/N.A. /1283

(BASELINE-REV:F)

SA-213, T-22 STUD.

2.0/0.33/4.0

DO NOT EXIST

AVCO/CE

$S A-213,304$ S.S.

2. $0 / 0.55 / 12 \& 3$

50
$S A-213,304$ S.S.

3. $5 / 0.20 / 986$

DO NOT EXIST

2/N.A. $/ 684$

spacing-in.

NOIE: N.A. $=$ NOT AVAILABLE
ETF DESIGN

N. A

Aminized SA-210C

$1.25 /$ N.A. $/ 1.75$

DO NOT EXIST

DO NOT EXIST

TF DESICN

15

SA- $213, \mathrm{~T}-22$

$1.5 / 00.25 / 1.75$

COUNTER FLOW

N.A.

N.A.

$S A-213, T P-304 H$

$T-22, T-11, S A-209$

$T-1, S A-210 A 1$ SA-178

Initial Superheater

$.2 / N . A .14 .584 .5$

Intermediate Superheater

. $2 /$ N. A. / 13. $5 \& 4.5$

Finishing Superheater

$\therefore 2 /$ N. A. $/ 62.584$

DO NOT EXIST

N.A.

$S A-213, T P-316 \mathrm{H}$

$\mathrm{SA}-213, \mathrm{~T}-22$

$2 / 0.165 / 7.5 \& 2.75$

DO NOT EXIST

DO NOT EXIST

N.A.

SA-178A

$2 / N . A$. . 4.584.5

SA-209, T-14

$2 / 0.257 / 6 \& 4$

N.A.

$S A-210, A-1$

$2 / 0.165 / 4 \& 4$ $\frac{\text { High Pressure }}{N . A}$

Low Pressure 
of a liquid hydroxide $(\mathrm{KOH})$ downstream of the superheater exit at $2060^{\circ} \mathrm{F}\left(1400^{\circ} \mathrm{K}\right)$ and a liquid chloride (KCl) downstream of the reheater exit at $1590^{\circ} \mathrm{F}\left(1139^{\circ} \mathrm{K}\right)$ significantly increases corrosion rates. Also, the flue gas entrance velocity to the MHD radiant boiler is about eight times that in the black liquor furnace, resulting in a higher erosion rate. A typical MHD system flow diagram is shown in Figure 2.

In the MHD system, most of the previous chemical equilibrium composition (CEC) calculations have ignored the effects of tube materials on the gas constituents. Based on CEC (Ref. 4), the $\mathrm{pH}$ classifications of gas and slag in the MHD systems are as follows:

\begin{tabular}{|l|c|c|c|}
\cline { 2 - 4 } \multicolumn{1}{c|}{} & Diffuser Exit & Radiant Boiler Exit & $\begin{array}{c}\text { Low Temperature } \\
\text { Heater Exit }\end{array}$ \\
\hline $\begin{array}{l}\text { Gas } \\
\text { Slag }\end{array}$ & $\begin{array}{l}\text { neutral } \\
\text { acid }\end{array}$ & $\begin{array}{l}\text { alkaline } \\
\text { neutral }\end{array}$ & $\begin{array}{l}\text { alkaline } \\
\text { neutral }\end{array}$ \\
\hline
\end{tabular}

Acidic silica condenses before alkaline components and produces an increasingly alkaline gas and slag on cooling. In the MHD system, actual chemical reactions between acids and bases form less volatile products and more slag products with complex composition than those predicted by the CEC computer program under equilibrium composition. Big Sky Rosebud subbituminous coal generates a 'lignitic' type ash. With a $2160^{\circ} \mathrm{F}\left(1455^{\circ} \mathrm{K}\right)$ initial deformation temperature (IDT) and $2465^{\circ} \mathrm{F}$ $\left(1625^{\circ} \mathrm{K}\right.$ ) hemisperical softening temperature (HT); corrosion associated with the formation of metal sulfides is not expected on the surface of the radiant boiler tubes. On the contrary, the surface of the boiler tubes will probably act as a chill surface which will condense solid mixtures of $\mathrm{K}_{2} \mathrm{SO}_{4}, \mathrm{~K}_{2} \mathrm{CO}_{3}$, and $\mathrm{KCl}$, clogging the radiant furnace with bulk deposits. As deposits continue to build up, the thermal conductivity through the deposits will drop until the temperature on the surface of the deposit increases to the melting point of the salts. 


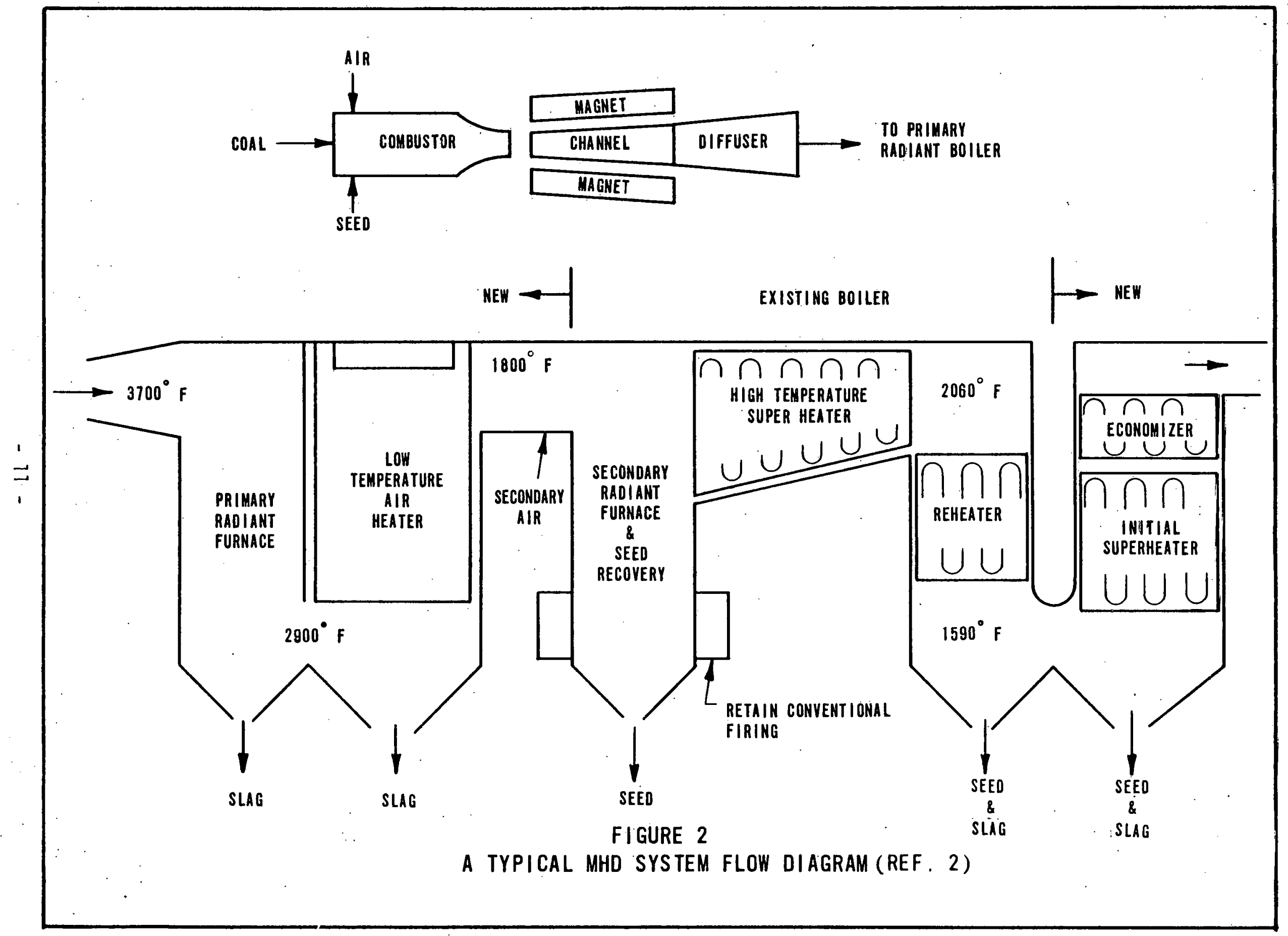


At this point, any further material condensing out will be a liquid runoff, and no further buildup. will occur. According to Rosa's model, when the slag viscosity becomes about 1.5 poise, the shear forces of the gas stream will cause a slag flow. An equilibrium slag thickness is predicted, ranging between 0.43 and $2.8 \mathrm{~mm}$ with respective surface temperatures of $3680^{\circ} \mathrm{F}\left(2300^{\circ} \mathrm{K}\right)$ and $3590^{\circ} \mathrm{F}\left(2250^{\circ} \mathrm{K}\right)$. Under full load operating conditions, the maximum slag layer thickness in the radiant boiler is expected to be about $1 \mathrm{~mm}$. (Ref. 5).

In the MHD radiant boiler and on convection surfaces such as the superheater and reheater, with 95 percent stoichiometric air, formation of elemental sulfur $(S)$ at a temperature of about $3500^{\circ} \mathrm{F}\left(2200^{\circ} \mathrm{K}\right)$ is not possible, although 22.0 percent (by weight) of carbon dioxide $\left(\mathrm{CO}_{2}\right)$ and 0.09 percent (by weight) sulfur dioxide $\left(\mathrm{SO}_{2}\right)$ are present. Corrosion rates of various tube materials ( $3 / 4 \mathrm{in}$. length schedule 40 pipe - 1.05 in. 0.D. or 1 in. welded tubing), with seeded (4.4 percent by weight of $\mathrm{K}_{2} \mathrm{CO}_{3}$ in coal) and unseeded Rosebud Montana coal are tabulated in Table 4.

For the lignitic type ash, fouling on the convection surface will depend directly upon the total percentage of sulfates. $\left(\mathrm{Na}_{2} \mathrm{SO}_{4}\right.$ and $\mathrm{K}_{2} \mathrm{SO}_{4}$ ) in the ash. In the MHD system, the percentage of these sulfates by weight in the total ash is about 84 percent, so that severe fouling can be expected (the high percentage of $\mathrm{K}_{2} \mathrm{SO}_{4} ; 83.22$ percent by weight, is due to seed addition). Steam tubes (mostly located in the superheater, made up of SA-213, 304, or equivalent) operating with a maximum external wall temperature of $1200^{\circ} \mathrm{F}\left(922^{\circ} \mathrm{K}\right)$ will act as a cold trap for the potassium and sodium compounds. These constituents will condense on fly ash particles and remain as liquid on the heat transfer surfaces. They will react chemically with fly ash, flue gas, and other deposits to form bonded deposits resulting in additional heat transfer resistance. In the superheater, seed condensation will be substantially complete, and initial deposition on the tubes will form a 
TABLE 4

METAL LOSS IN THICKNESS OF CORROSION SPECIMENS IN COMBUSTION GAS WITH UNSEEDED COAL AND IN COMBUSTION GAS WITH COAL SEEDED WITH
Metal Loss (c)

While Burning

Unseeded Coal

ARadius in in.

1800

1800

1800

2100

2100

2100

2100

2500

2500

2500

2500 (a)

0.0000

0.0025

0.0000

0.0055

0.0000

0.0000

0.0015

0.0035

0.0000

(a) POTASSIUM CARBONATE (REF. 6 )

\section{Material}

Carbon steel (A 106)

Croloy 2-1/4

Croloy 5

446 SS

406 SS

316 SS

310 SS

310 SS

Nickel

Incone $]$

Haynes 25

POTASSIUM CARBONATE (REF. 6)

(a) Cooling air failure caused loss of specimen.

(b) Completely oxidized after 50 hours.

(c) Duration of test: 83 hours.

(d) Duration of test: 100 hours.
Metal Loss (d)

While Burning

Seeded Coal,

$\triangle$ Radius in in.

0.0075

0.0015

0.0075

0.0000

0.0035

0.0000

0.0000

(b)

(b)

(b)

0.0005 
solid coating. Any subsequent deposition will be in the form of low viscosity liquid seed with an interface temperature around $1905^{\circ} \mathrm{F}$ $\left(1315^{\circ} \mathrm{K}\right)$.

In the MHD system, the presence of potassium chloride (KCl) is less than 0.02 percent by weight (not significant to the melting point of slag). However, the pitting effect due to the formation of potassium sulfate $\left(\mathrm{K}_{2} \mathrm{SO}_{4}\right)$ is strongly dependent upon the amount of $\mathrm{KCl}$ present. The following reactions are predicted over the range of temperature:

$$
2 \mathrm{KCl}+\mathrm{SO}_{2}+1 / 2 \mathrm{O}_{2}+\mathrm{H}_{2} \mathrm{O} \rightarrow \mathrm{K}_{2} \mathrm{SO}_{4}+2 \mathrm{HCl}
$$

(only at low temperature)

This chloride then reacts with the tube metal as follows:

$$
\mathrm{Fe}+2 \mathrm{HCl} \rightarrow \mathrm{FeCl}_{2}+\mathrm{H}_{2}
$$

Although elemental chlorine has not been recorded in the MHD CEC run (Ref. 14), it may play a role in the corrosion reaction. Metal oxides $\left(\mathrm{Fe}_{2} \mathrm{O}_{2}\right)$ on the tube surface may catalyze the reaction:

$$
4 \mathrm{FeCl}_{2}+3 \mathrm{O}_{2} \rightarrow 2 \mathrm{Fe}_{2} \mathrm{O}_{3}+4 \mathrm{Cl}_{2}
$$

Under a reducing atmosphere, $\mathrm{Fe}_{2} \mathrm{O}_{3}$ will probably be converted to $\mathrm{Fe}_{3} \mathrm{O}_{4}$. The mixed oxide and molten salt layers limit the availability of oxygen and retain chlorine and sulfur within the adherent scale. The corrosion rates of carbon steel in the presence of chlorine and hydrochloric acid are shown in Figure 3.

The melting points of potassium pyrosulfates $\left(\mathrm{K}_{2} \mathrm{~S}_{2} \mathrm{O}_{7}\right)$ and potassium bisulfate $\left(\mathrm{KHSO}_{4}\right)$ are $575^{\circ} \mathrm{F}\left(575^{\circ} \mathrm{K}\right)$ and $415^{\circ} \mathrm{F}\left(486^{\circ} \mathrm{K}\right)$, respectively, and, even at high temperatures, the following electrochemical reactions are predicted: 


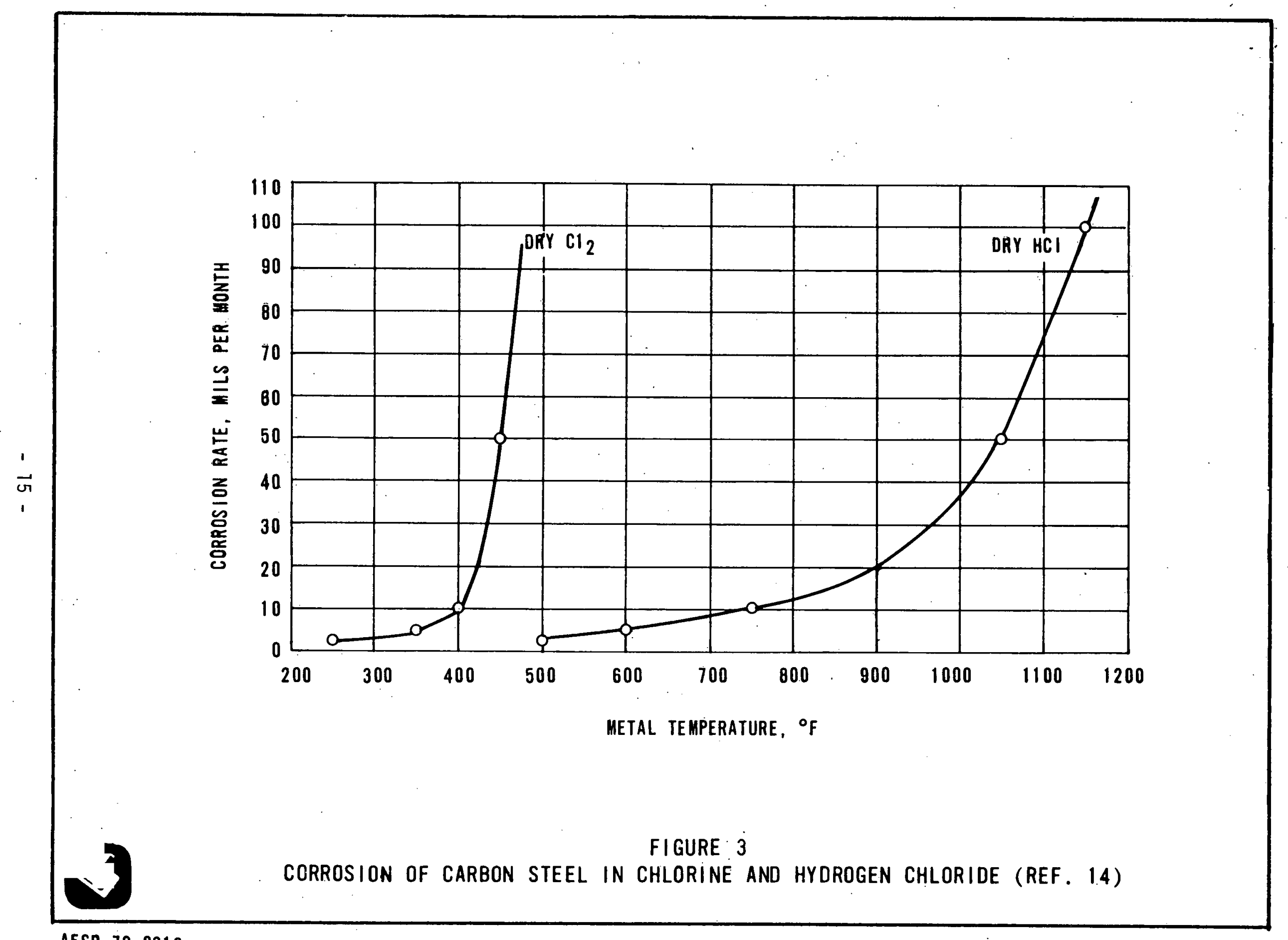




$$
\begin{aligned}
& \mathrm{Fe}_{2} \mathrm{O}_{3}+3 \mathrm{~K}_{2} \mathrm{~S}_{2} \mathrm{O}_{7} \rightarrow 2 \mathrm{~K}_{3} \mathrm{Fe}\left(\mathrm{SO}_{4}\right)_{3} \text { (potassium-iron trisulfates) } \\
& \mathrm{Fe}_{2} \mathrm{O}_{3}+3 \mathrm{~K}_{2} \mathrm{SO}_{4}+3 \mathrm{SO}_{3} \rightarrow 2 \mathrm{~K}_{3} \mathrm{Fe}\left(\mathrm{SO}_{4}\right)_{3}
\end{aligned}
$$

These complex sulfates, which form corrosive deposits, then react with the tube metal as follows:

$$
2 \mathrm{~K}_{3} \mathrm{Fe}\left(\mathrm{SO}_{4}\right)_{3}+6 \mathrm{Fe} \rightarrow 3 / 2 \mathrm{FeS}+3 / 2 \mathrm{Fe}_{3} \mathrm{O}_{4}+\mathrm{Fe}_{2} \mathrm{O}_{3}+3 / 2 \mathrm{SO}_{2}
$$




\section{SECTIION 3.0}

\section{BLACK LIQUOR RECOVERY BOILERS}

\subsection{RECOVERY PROCESS}

Figures 4 and 5 are simplified process flow diagrams of typical Kraft (sulfate) pulp and paper mill processes. The function of the recovery unit is the reduction of sodium sulfate $\left(\mathrm{Na}_{2} \mathrm{SO}_{4}\right)$ in the black liquor to sodium sulfide $\left(\mathrm{Na}_{2} \mathrm{~S}\right)$ in the furnace. In the recovery furnace, heat obtained from the combustion of the organic liquor constituents dissolved from the wood is used for the production of steam, and the inorganic sodium constituents in the liquor are recovered as molten smelt.

The logs entering the Kraft pulp and paper mill are first debarked (1), reduced to chips (2), and charged into a digester ( 3 ), where they are cooked under pressure in a steam-heated, aqueous, digestion solution of sodium hydroxide $(\mathrm{NaOH})$ and sodium sulfide $\left(\mathrm{Na}_{2} \mathrm{~S}\right)$, known as "white liquor" or "cooking liquor." In the cooking operation, the lignin that binds the cellulose fibers of the wood is dissolved.

After cooling, the cellulose fibers, now called pulp or brown stock, are separated from the spent cooking liquor in the pulp washers (4). The pulp may go through several fiber refining and bleaching processes before being sent to the paper machine. The spent cooking liquor containing the lignin is called black liquor. As the dilute or weak black liquor (15-18 percent dissolved solids) comes from the washers, it is concentrated (45-50 percent dissolved solids) in a multiple effect evaporator (5) by the use of steam. The concentrated or "strong" black liquor then passes to the recovery unit $(6,7$, and 8$)$. It is further concentrated to "heavy" black liquor in a direct contact evaporator (6) using the sensible heat of the flue gas (62-65 percent dissolved solids). The heavy black liquor then goes to the mix 


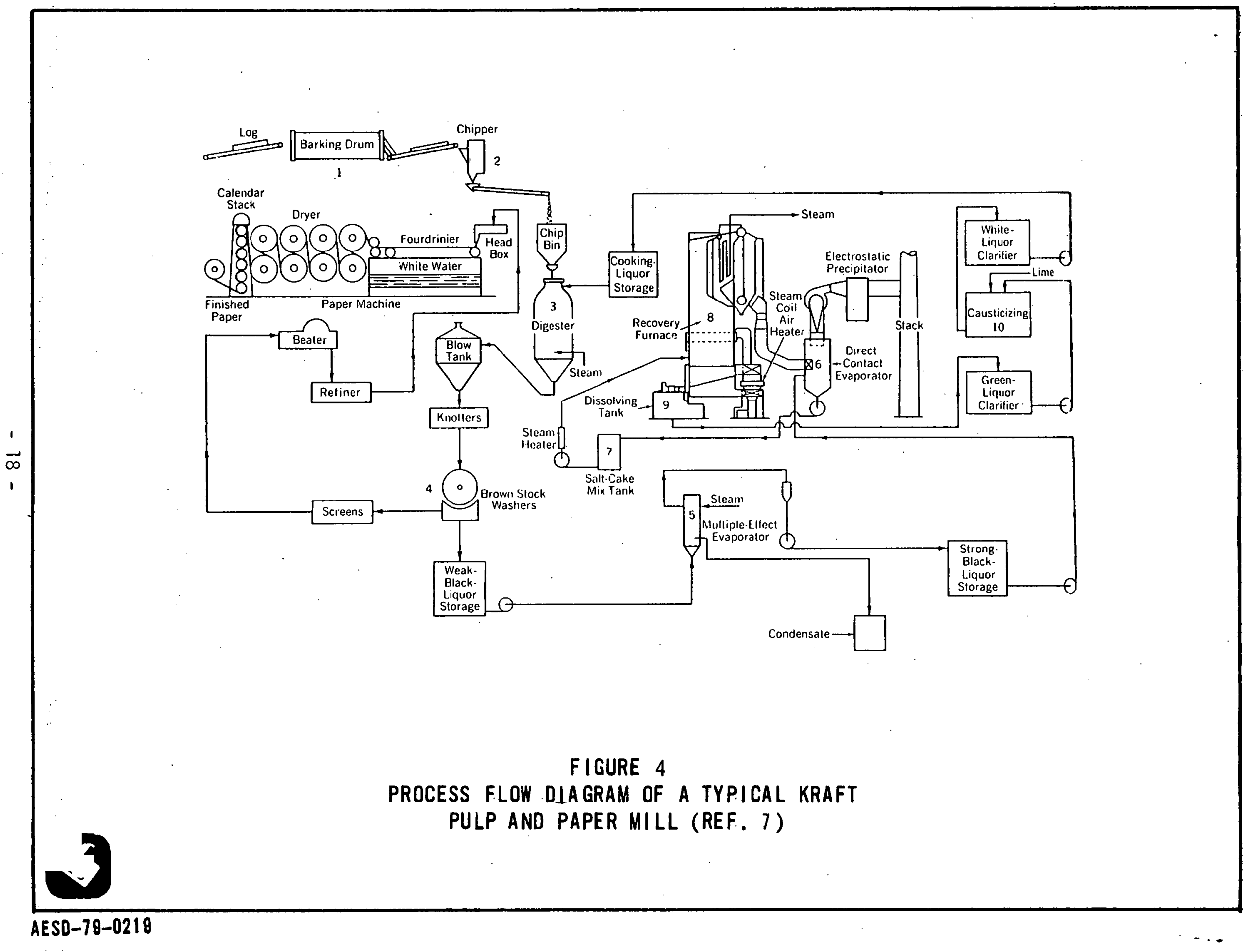




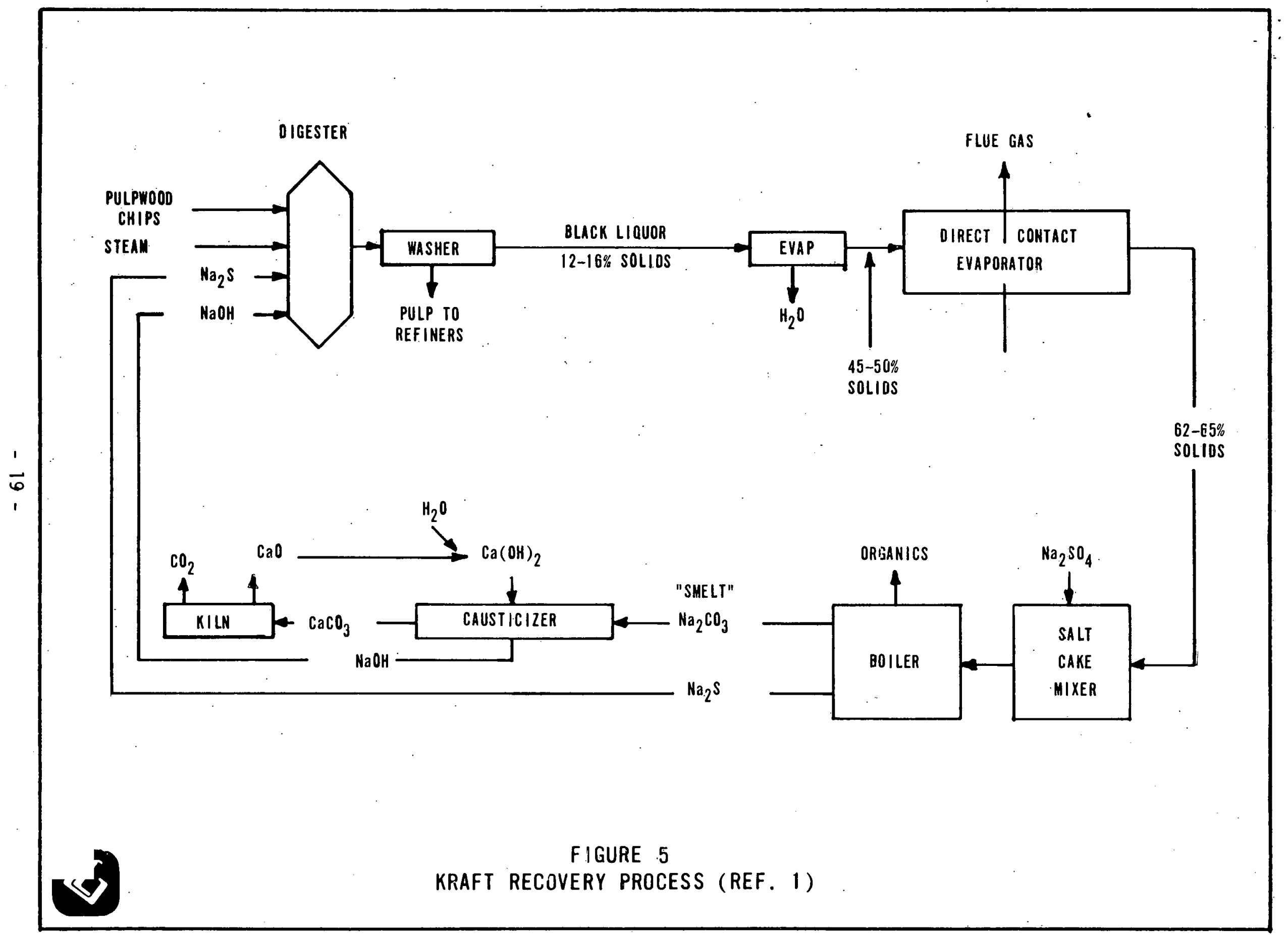


tank (7) where sodium sulfate (salt cake) is mixed with the liquor to make up for the chemical losses in the system. Chemical ash recovered from the boiler hoppers and the fume collector following the direct contact evaporator are returned to the liquor cycle. The heavy black liquor with its salt cake burden is heated to lower its viscosity and pumped to the recovery furnace. (8). In the furnace, the heavy black liquor is sprayed on the walls for dehydration prior to final combustion of the dried char. Sodium sulfide $\left(\mathrm{Na}_{2} \mathrm{~S}\right)$ is tapped from the furnace and dissolved in water in the dissolving tank (9) to form "green liquor." The green liquor is subjected to a causticizing treatment (10) with slaked lime $\mathrm{Ca}(\mathrm{OH})_{2}$, to convert the sodium carbonate to sodium hydroxide. The sodium sulfide remains unchanged. The liquor, now known again as white liquor, is then ready for reuse as cooking liquor in the digester (3).

\subsection{BOILER DESIGN}

In black liquor, organic sulfur compounds are present in combination with sodium sulfide, sodium carbonate, sodium sulfate, salt, silica, traces of lime, iron oxide, alumina, and potash. An approximate analysis of a typical black liquor is shown in Table 5.

TABLE 5

ANALYSIS OF TYPICAL BLACK LIQUOR

\begin{tabular}{|l|c|c|c|}
\hline Element & Inorganic & Organic & $\begin{array}{c}\text { Total Black Liquor } \\
\text { Solids }\end{array}$ \\
\hline & & & \\
$\mathrm{Na}$ & 18.3 & - & 18.3 \\
$\mathrm{~S}$ & 3.6 & - & 3.6 \\
$\mathrm{C}$ & 0.4 & 42.2 & 42.6 \\
$\mathrm{H}$ & 0.5 & 21.7 & 3.6 \\
$\mathrm{~N}$ & 10.0 & $\underline{0.2}$ & 31.7 \\
Total & - & 67.2 & 0.2 \\
& 32.8 & & 100.0 \\
& & Gross Heating Value $=6,600 \mathrm{Btu} / 1 \mathrm{~b}$. \\
\hline
\end{tabular}


The black liquor at $\left(200^{\circ} \mathrm{F}\right.$ ) and combustion air (15 percent excess air at $280^{\circ} \mathrm{F}$ ) are fired in the furnace at an approximate ratio of 1 to 5.3 by weight. The total air is distributed as 40 percent primary air, 30 percent secondary air, and 30 percent tertiary air (B\&W design) or 50 to 60 percent of the total air as primary air and the balance as secondary air (CE design). Typical recovery unit chemical reactions and their points of occurrence are shown in Figure 6 . The reactions listed occur simultaneously in each of the zones.

In the recovery furnace, a drying zone is required, so that the residual water in the black liquor can be evaporated as the first step in the drying process. The controlled reducing atmosphere at the hearth burns dehydrated char falling from the walls to effect a maximum reduction of sodium sulfate to sulfide in the smelt. Typical gas temperatures $\left({ }^{\circ} \mathrm{F}\right)$ at various points in the unit are:

\begin{tabular}{|l|c|}
\hline$\because \ldots$ Location & $O_{F}$ \\
\hline & \\
Primary Air Port Level & $1800-2200$ \\
Secondary Air Port Level & $2500-2800$ \\
Tertiary Air Port Level & $2500-2800$ \\
Superheater Inlet & $1700-1750$ \\
Boiler Bank Inlet & $1150-1300$ \\
Boiler Bank Outlet & $700-800$ \\
Economizer Outlet & $550-600$ \\
Cyclone Evaporator Outlet & 325 \\
\hline
\end{tabular}




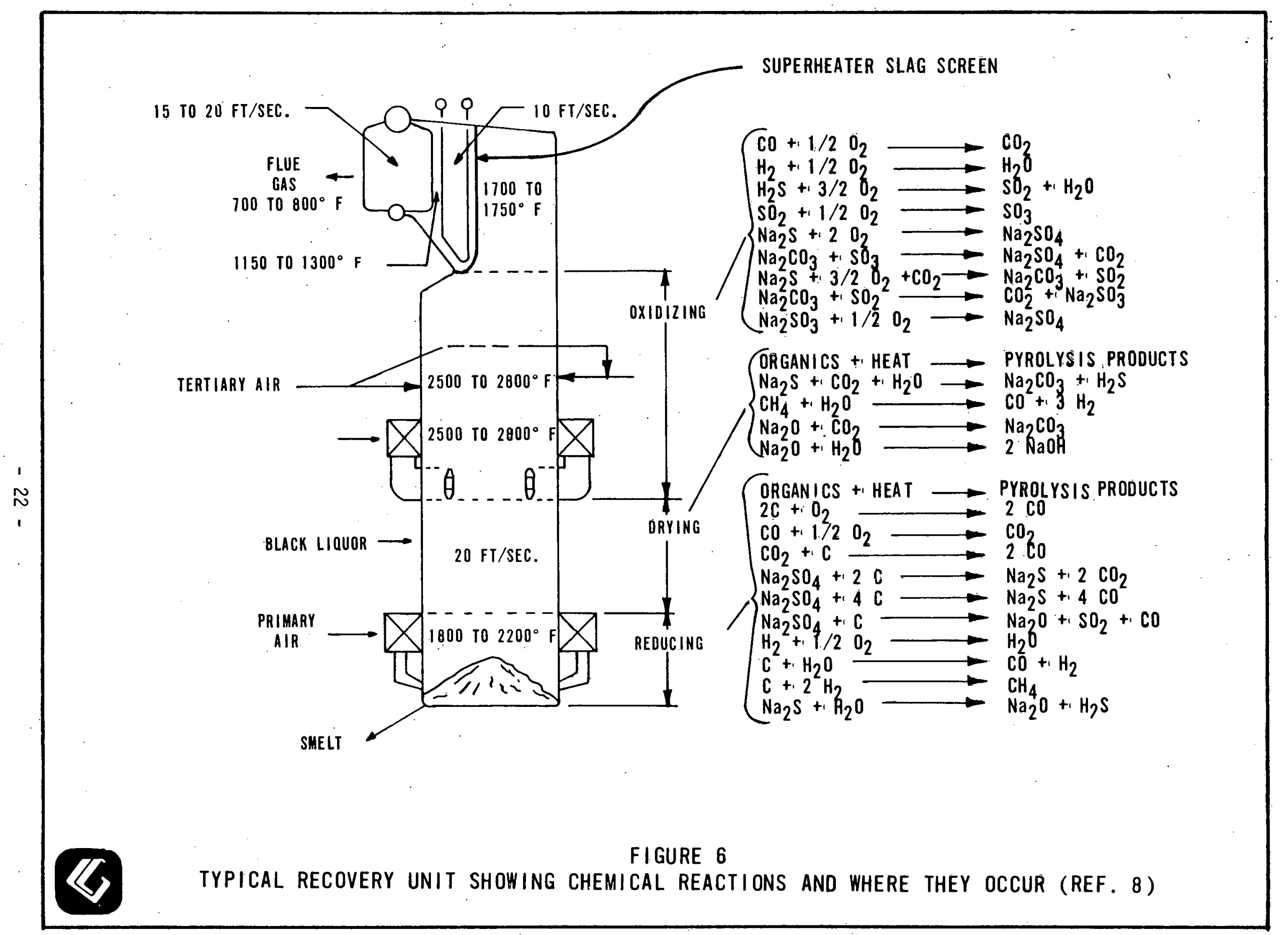


Velocities (feet/sec.) through the unit are in the order of:

\begin{tabular}{|l|c|}
\hline Location & Feet per sec \\
\hline & \\
Furnace & 20 \\
Superheater & 10 \\
Boiler Bank & $15-20$ \\
Economizer & $20-35$ \\
\hline
\end{tabular}

The dried black liquor collects as char on the hearth, forming a pile to which a controlled amount of air (primary air) is supplied. This determines the amount of heat released in this section and the composition of the gas atmosphere. Sufficient heat must be released to maintain an incandescent char bed, furnish the heat required for endothermic reactions, smelt the inorganic chemicals, supply heat to the drying process, and allow for the heat absorbed by the furnace walls. The water cooled furnace walls fabricated from carbon steels (SA-192 or SA-226) are protected from corrosion as described in Section 3.6, "Heating Surface Protection." Under steady state conditions, the furnace wall tube mean metal temperature will be about $100^{\circ} \mathrm{F}\left(55^{\circ} \mathrm{K}\right)$ higher than the inside water temperature.

Black liquor is an extremely poor fuel because of its high ash content and low ash fusion temperature (approximately $1450^{\circ} \mathrm{F}$ ). Large furnaces produce the low gas temperature (approximately $1700^{\circ} \mathrm{F}$ ) needed in the superheater. This low gas temperature weakens the corrosion attack, reduces the fly ash carryover, and facilitates the operation of the soot blower. Superheaters are normally arranged for parallel flow of gas and steam. When steam temperatures are above $825^{\circ} \mathrm{F}$, the superheater reqires alloys, such as SA-209, T-1 and SA-213, T-11. 
Superheaters supplying lower temperature steam utilize carbon stee 1 tubes such as SA-192 and SA-226. The parallel flow superheater arrangement keeps the hottest gas in contact with the coolest metal, reducing metal wastage due to corrosion.

The economizers are vertical, bare tube, modular type, baffled to establish cross-flow of gases. To avoid external corrosion (due to formation of sulfuric acid, $\mathrm{H}_{2} \mathrm{SO}_{4}$ ), the effectiveness of the economizer is kept low. For high sulfur ( 3.6 percent by weight) black liquor, the mean metal temperature is 1 imited to about $250^{\circ} \mathrm{F}$.

Retractable steam soot blowers are continuously in use when a modern recovery unit is operated at or near rated capacity, and, consequentiy, no hand lancing is required to keep gas passages open. However, as load increases from partial load to full load on a unit, mechanical entrainment of ash and sublimation of sodium compounds increase and invariably lead to cleaning problems. In addition to excessive quantities of ash in the flue gas, velocities and temperatures at all points in the unit are increased, and ash deposits become more difficult to remove. All the furnace designs incorporate a sloping floor to minimize smelt pool formation. (Ref. 2)

\section{$3.3 \quad$ CORROSION}

Corrosion in the black liquor boiler occurs in the furnace at the "hearth" zone ( $0.03 \mathrm{in} / \mathrm{yr}$ or $0.76 \mathrm{~mm} / \mathrm{yr}$ ) near the window face of the furnace wall tubes and at the upper parts of the furnace $(0.01 \mathrm{in} / \mathrm{yr}$ or $0.25 \mathrm{~mm} / \mathrm{yr}$ ). Figure 7 charts these corrosion rates. Since flue gas temperature entering the superheater is 1 imited to $1700^{\circ} \mathrm{F}$, corrosion rates in the convection surface zones (the superheater and boiler bank) are minimum. The corrosion rates measured on carbon steel (SA-192) samples at $700^{\circ} \mathrm{F}$ (with both synthetic smelt and actual unit smelt) 


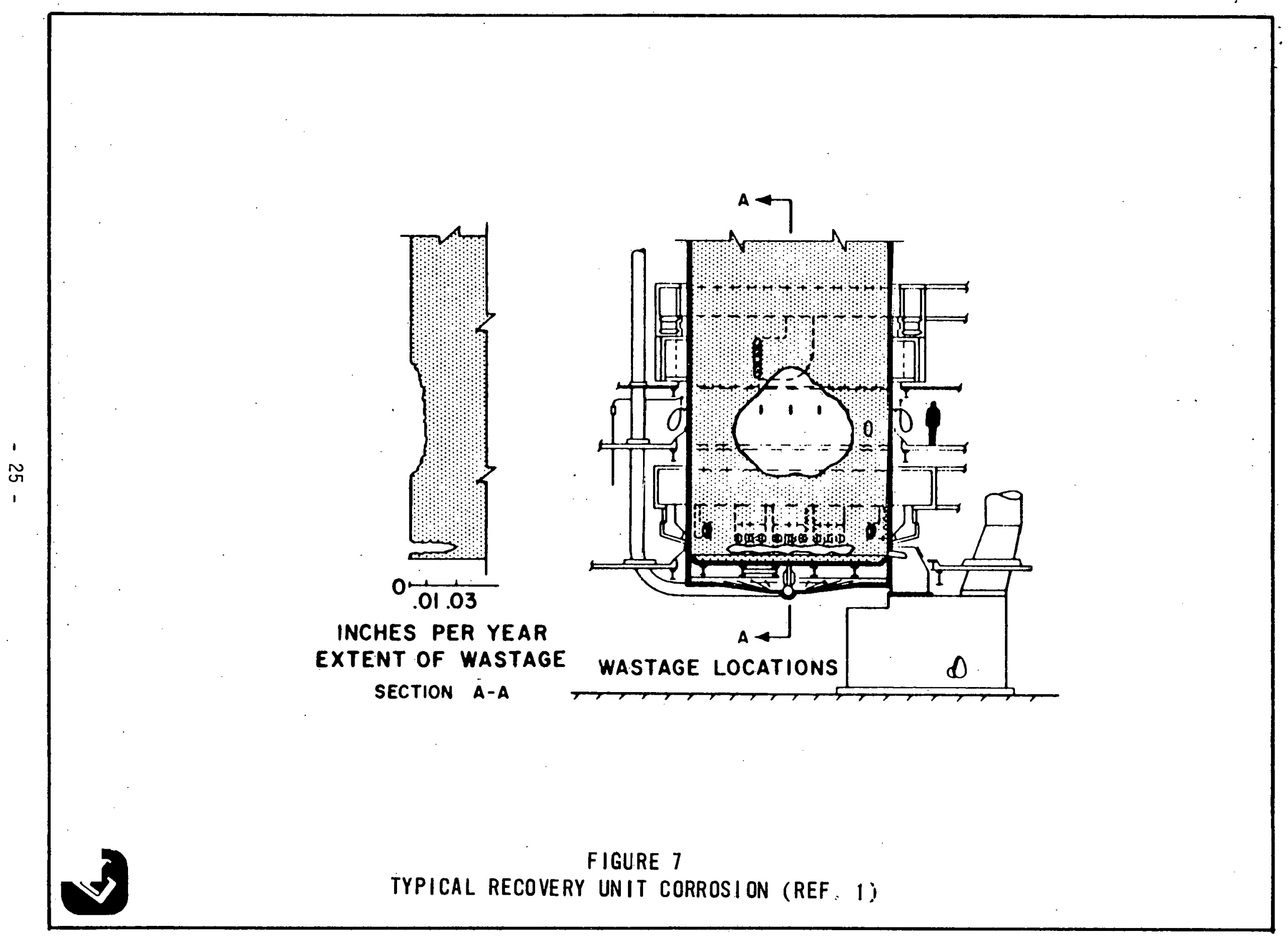

AESD-79-0223 
obtained from a unit operating with 22 percent sodium chloride in various furnace atmospheres, i.e., air, nitrogen, and carbon dioxide are listed below:

TABLE 6

CORROSION RATES ON SA-192 AT $700^{\circ} \mathrm{F}$ (REF. 1 )

\begin{tabular}{|c|c|c|}
\hline Atm. & $\begin{array}{c}\text { Synthetic Smelt } \\
\text { (Weight loss/week) }\end{array}$ & $\begin{array}{c}\text { Actual Unit Smelt } \\
\text { (Weight loss/week) }\end{array}$ \\
\hline $\mathrm{N}_{2}$ & $28.7 \times 10^{-6} \mathrm{lb} / \mathrm{in}^{2}\left(2.0 \mathrm{mg} / \mathrm{cm}^{2}\right)$ & $52.9 \times 10^{-6} \mathrm{lb} / \mathrm{in}^{2}\left(3.7 \mathrm{mg} / \mathrm{cm}^{2}\right)$ \\
Air & $30.9 \times 10^{-6} \mathrm{lb} / \mathrm{in}^{2}\left(2.1 \mathrm{mg} / \mathrm{cm}^{2}\right)$ & $50.7 \times 10^{-6} \mathrm{lb} / \mathrm{in}^{2}\left(3.5 \mathrm{mg} / \mathrm{cm}^{2}\right)$ \\
$\mathrm{CO}_{2}$ & $29.4 \times 10^{-6} \mathrm{lb} / \mathrm{in}^{2}\left(10 \mathrm{mg} / \mathrm{cm}^{2}\right)$ & $90.5 \times 10^{-6} \mathrm{lb} / \mathrm{in}^{2}\left(6.3 \mathrm{mg} / \mathrm{cm}^{2}\right)$ \\
\hline
\end{tabular}

Corrosion rate is strongly affected by skin metal temperature, type of atmosphere (reducing or oxidizing), gas constituents, and tube metal composition. It is further complicated by operating pressures, high velocities, and erosive particle impingement. The corrosive gases and saits contain low melting $\mathrm{NaCl}$ and sulfur compounds such as sodium sulfate $\left(\mathrm{Na}_{2} \mathrm{SO}_{4}\right)$, sodium thiosulphate $\left(\mathrm{Na}_{2} \mathrm{SO}_{3}\right)$, and sodium pyrosulphate $\left(\mathrm{Na}_{2} \mathrm{~S}_{2} \mathrm{O}_{7}\right)$. Gases, such as sulfur dioxide $\left(\mathrm{SO}_{2}\right)$, sulfur trioxide $\left(\mathrm{SO}_{3}\right)$, hydrochloric acid ( $\mathrm{HCl})$, and chlorine $\left(\mathrm{Cl}_{2}\right)$, play a major role in the corrosion process. Appendix $B$ contains a detailed description of corrosion in black liquor boilers.

\subsubsection{Material Test Results}

Laboratory test results of the wastage of a carbon steel (SA-192) sample $(1-1 / 2 \times 1-1 / 2$ bar $)$ kept at $700^{\circ} \mathrm{F}(644 \mathrm{~K})$ for one week are tabulated below: 


\section{TABLE 7}

WASTAGE ON SA-192 AT $700^{\circ} \mathrm{F}$ (REF. 1)

Carbon steel tubes (at the primary zone)

Carbon steel tubes (1iquid spray gun area)

Carbon steel with chromium

Carbon steel with chromium + aluminum

Compound tubes (304 s.s. over carbon steel)

410 stainless stee $]$

Weld overlay tubes*
$0.03 \mathrm{in} / \mathrm{yr}(0.76 \mathrm{~mm} / \mathrm{yr})$

$0.01 \mathrm{in} / \mathrm{yr}(0.25 \mathrm{~mm} / \mathrm{yr})$

no measurable wastage

no measurable wastage

$0.0026 \mathrm{in} / \mathrm{yr}(0.066 \mathrm{~mm} / \mathrm{yr})$

$0.0026 \mathrm{in} / \mathrm{yr}(0.066 \mathrm{~mm} / \mathrm{yr})$

$0.039 \mathrm{in} / \mathrm{yr}(0.99 \mathrm{~mm} / \mathrm{yr})$

*Tubes with extra welding material on the surface.

In a simulated recovery furnace, corrosion rate versus metal temperature data for carbon steel $(S A-226)$ is shown in Figure 8.

Type 304 stainless steel has exhibited the best resistance to corrosion and is virtually corrosion-free in the range of $110^{\circ} \mathrm{F}\left(316^{\circ} \mathrm{K}\right)$ to $950^{\circ} \mathrm{F}$ $\left(783^{\circ} \mathrm{K}\right)$, as shown in Figures 9 and 10 . Type 304 stainless stee provides satisfactory protection from gas and smelt corrosion due to the formation of a tight and firm surface film containing sulfides and oxides of iron, chromium, and nickel. Firmness of the film is sufficient to resist mechanical actions within the furnace, and tightness of the film is adequate to minimize diffusion of corrodents through the film, thus limiting the corrosion rate to a low value of 1 to 1.5 mills per year. Higher alloyed steels offer no better protection against fireside corrosion.

Type 309 stainless steel applied as a flame sprayed protection layer does not have the necessary mechanical strength to stand up to the stresses used by firebox and temperature cycling. Type 309 stainless steel is applied as a weld overlay on a carbon steel tube and forms a martensitic zone. This zone, with its associated hardness peaks, acts as a stress raiser. These hardness peaks are shown in Figure 11 (Ref. 10). 


\section{FIGURE 8}

CORROSION RATE VS. METAL TEMPERATURE

\section{FOR CARBON STEEL (SA-226) (REF. 3)}

RATE OF METAL LOSS

MILLIMETER/YR.

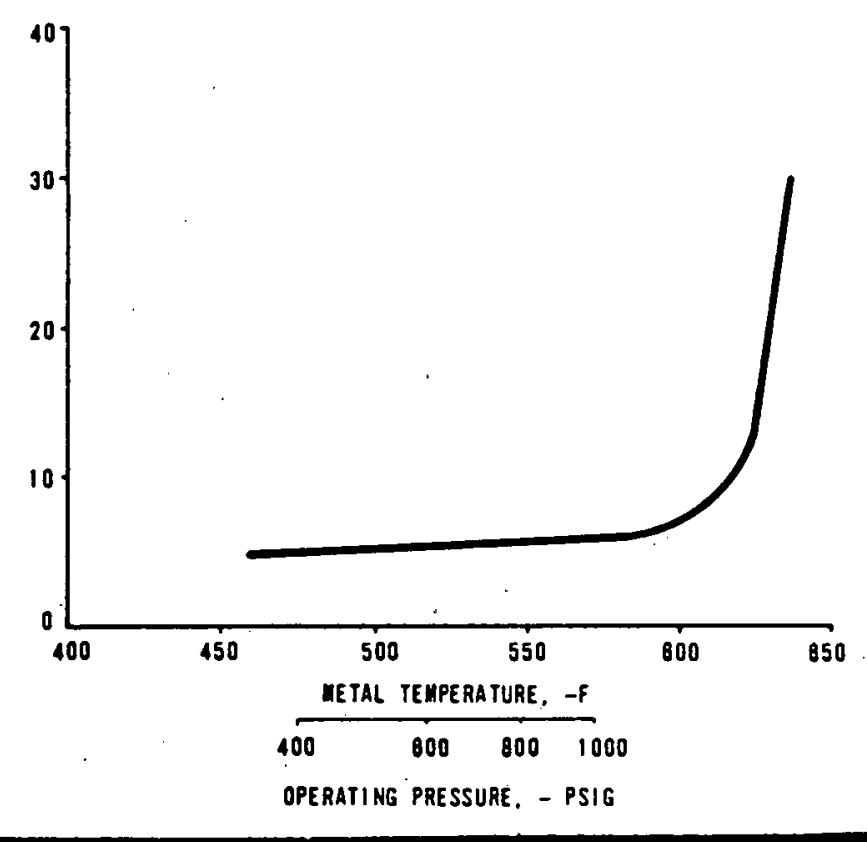

FI GURE 9

TYPE 304 STAINLESS STEEL CORROSION RATE (REF. 10)

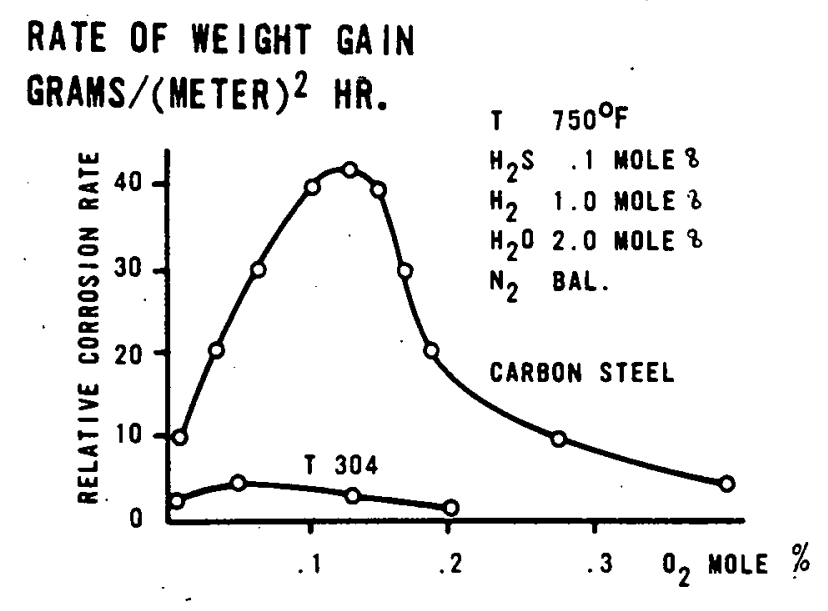

AESD-79-0225 


\section{FIGURE 10}

TYPE 304 STAINLESS STEEL WEIGHT GAIN VS. TEMPERATURE (REF. 10)

RATE OF- WEIGHT GAIN

GRAMS/(METER $)^{2}$ HR.

$\mathrm{H}_{2} \mathrm{~S}$

U. 1 VOL.?

AESO-78-0228

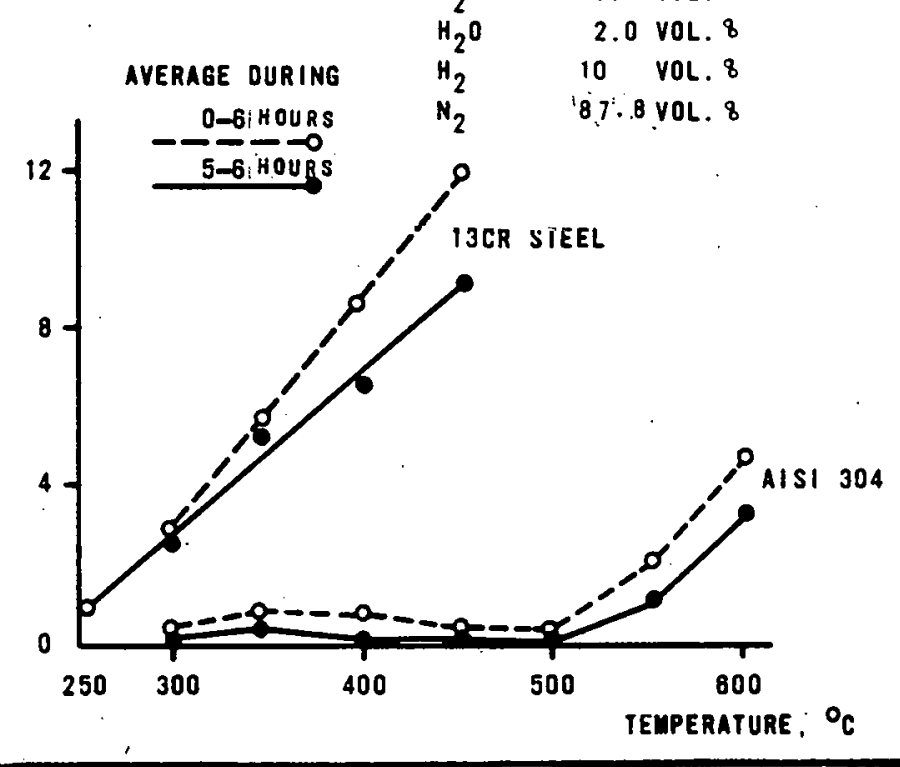

FIGURE 11

HARONESS PEAKS OF TYPE 309 CARBON STEEL (REF. 10)

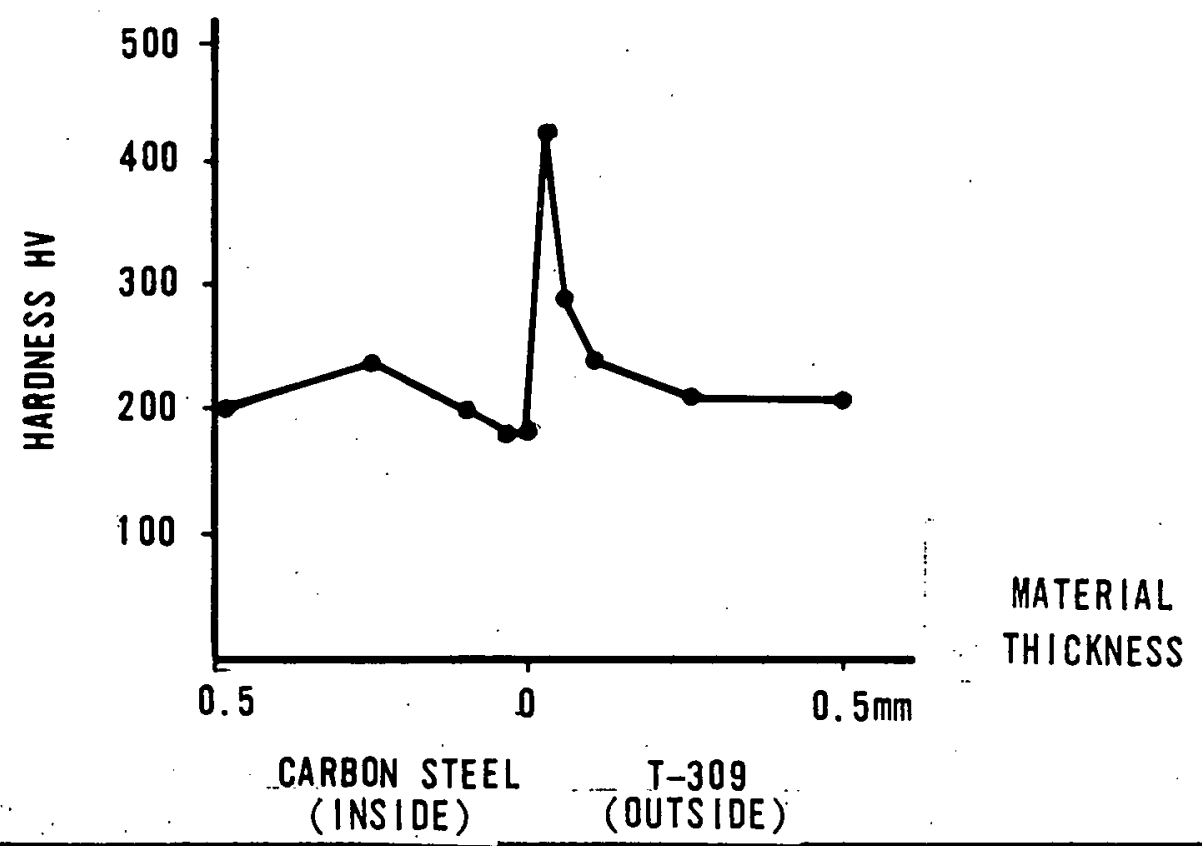

AESD-79-0227 (INSIDE) 


\subsection{FIELD OPERATION AND EXPERIENCE}

Several paper companies were contacted to determine user experience in the field. The major problem areas were corrosion of the waterwall tubes in the lower part of the furnace and fouling in the superheater sections. The possibility of explosions occurring due to smelt/water reactions caused by tube leakage in the lower furnace dictates frequent boiler inspections. The majority of users inspect boilers twice annually, with one company inspecting three times annually. Inspection shutdowns require three to four days (minimum) for inspection alone. During the shutdown water/steam tubes are inspected utilizing ultrasonic and radiographic techniques. Occasionally, the front rows of superheater tubes require cleaning due to the buildup of hard deposits formed by molten/sticky salts during load fluctuations. Most users keep superheater.slag screen entrance temperatures in the 1400$1600^{\circ} \mathrm{F}$ range to limit buildup problems, but occasional shutdowns are required. (The inlet gas temperatures to the superheater are not monitored, but settings are established by monitoring superheater exit gas temperatures.)

In contrast to the practice followed by most users, the Hudson Pulp \& Paper Company (Palatka, Florida) has a relatively new CE boiler (1250 psi, $900^{\circ} \mathrm{F}$ steam) that is operated at rated load continually. At load conditions, slag screen entrance temperature is $1900^{\circ} \mathrm{F}$, and superheater entrance temperature is $1650^{\circ} \mathrm{F}$ (CE design values). The boiler was operated from December 1976 to December 1977 with no shutdowns. During the inspection period, hard deposit layers were removed from the slag screen and the initial bank of superheater tubes, which would indicate that liquid smelt had been present on the tubes during operation. No fouling problems were encountered during the one year operational period, but the reason this could not be determined from the users or from the manufacturer. The superheater and soot blower design does not differ markedly from older designs that reportedly have fouling problems. 
To minimize furnace waterwall tube corrosion, the industry feels that duplex tube configurations are necessary for steam pressures in excess of $850 \mathrm{psi}$. The "Sandvik" dual wall tube is the industry choice; the "Sandvik" tube consists of a carbon steel inside tube for pressure carrying and a 316 stainless steel outside shell for corrosion resistance.

\subsection{BOILER EXPLOSION}

The smelt/water chemical reactions in the unique environment of the recovery boiler produce rapid generation of steam and are potentially explosive. The sequence of chemical reactions resulting in catastrophic explosions is not yet known.

The various causes of smelt/water explosions are (Ref. 11):

- firing weak black liquor or chemical solutions

- using water in an unsafe manner

- overheating pressure parts

o adding heavy black liquor to smelt bed

o using air lances improperly

- corrosion and erosion

o leaking smelt

- leaking water cooled parts

To prevent explosion, the following precautions are recommended (Ref. 12):

- maintenance of oxygen and combustible analyzers

- proper use of air lances

- thorough periodic checking of the furnace from the standpoint of erosion and corrosion

- monitored auxiliary fuel burners

o application of boiler feedwater treatment system 
- maintenance of liquor pump and standby pump, so that the load can be immediately picked up (otherwise condensate is formed in a direct contact secondary liquor heater)

o accurate measurement of percent solids fired

- ensuring that the smelt bed is adequately cooled before water washing of boiler to facilitate fireside inspection or repair

- use of an auxiliary fuel firing facility

- design of good control and instrumentation systems to rapidly drain the recovery boiler under emergency conditions to a level 8 feet above the bottom ( 8 feet depth of water will avoid the overheating and thermal stresses set up in dry not lubes due to the hot char and the smelt bed)

- opening of a vent valve, following a time delay of 2 minutes longer than the time to drain to the 8 feet level as described above (the objective of this precaution is to reduce the flow of water in the event there is a pressure part failure below the 8 feet level.)

\section{$3.6 \quad$ HEATING SURFACE PROTECTION}

The commercial methods of water cooled wall construction to protect it from corrosion are as follows:

- A sacrificial, pin studded tube (up to tertiary windbox level) is used to reduce the potential for corrosion by retaining a solidified layer of smelt adjacent to the tube. This provides a position barrier to the fluid smelt, elemental sulfur, and corrosive gases of the hearth zone. Sometimes, B\&W PCO "KROMIGHT-GUN" refractories (at $1500^{\circ} \mathrm{F}$, refractory's average temperature, thermal conductivity, $12 \mathrm{Btu} / \mathrm{sq} . \mathrm{ft}, \mathrm{hr},{ }^{\circ} \mathrm{F} / \mathrm{in}$ ) are also applied.

o Metallic coatings with chrome steel (13.5 percent $\mathrm{Cr}$ ) are applied to sand blasted tube walls. 
- Application of multiple coats of flame spraying with nickel aluminide $\left(\mathrm{Ni}_{3} \mathrm{Al}_{4}\right), 300$ series stainless steel and aluminum (respectively from inside to outside layers).

- Spray coating with chromium nickel titanide plasma.

- Application of diffusion coatings of chromium and aluminum chromium.

- Providing hard face welding protection over the lower 6 to 9 feet hearth zone.

- The use of "SANDVIK" bimetallic compound tubes, fabricated from carbon steel inside for pressure carrying and 315 stainless steel outside for $\mathrm{NaCl}$ corrosion resistance; approximate thickness ratfo of carbon steel to stainless steel required is 4-to-1, especially when the steam pressures are in excess of 850 psig.

The success of each of the above methods depends upon operating conditions and quality of the manufacturing process.

To control fouling and corrosion in the superheater surface, a platen type ("pencil" weld) surface with wide lateral tube spacing (minimum 12 inches) is adopted by all the manufacturers. The technique of tangent tube construction minimizes the projected surface area perpendicular to the gas flow and, as a result, reduces the fouling and erosion/corrosion problem. (Ref. 1). The platen type tube surface prevents the circular $\left(360^{\circ}\right)$ formation of slag (keying) and, thus, makes it easier to remove slag by soot blowers. 


\section{REFERENCES}

1. Plumley, A. L. Dr. and W. R. Roczniak. Recovery Unit Waterwall Protection: A C-E Status Report. Windsor, CT, C-E Inc. Paper presented at British Columbia Black Liquor Recovery Boiler Advisory Comm. Meeting, Vancouver, Br. Columbia, November 5, 1974.

2. Mechanical Technology Incorporated - Commercial Boiler Systems and Cyclone Separator Technology for MHD. Report \# MTI 78 TRI12.

3. Plumley, A. L. Dr., J. Jonakin and Dr. R. E. Vuia. A Review Study of Fire - Side Corrosion in Utility and Industrial Boilers. Windsor, CT, C-E Inc. Paper presented at Corrosion Seminar McMaster Univ. and Engineering Institute of Canada, Hamilton, Ontario, May 19-20, 1966.

4. Seppala, Kauko. Corrosion Studies in Finnish Reductive Recovery Boilers. Oulu, Finland. for C-E Inc. 1970.

5. Rosa, R. J. 5th International Conference on MHD, Electrical Power Generation, Munich, January 1971.

6. Lawit, R. L., P.R. Sheth and R. A. Stoudt. Specifics of Heat Exchanger Design for a 2000 Mwth Dual Cycle, MHD Topping Steam Bottoming Power Plant: Reading, PA, Gilbert Associates, Inc. 1977. ASME Pub. \#77-HT-61.

7. Babcock \& Wilcox (B \& W). Steam - Its Generation and Use. 38th Edition 1972.

8. Hochmuth, F. W. An Odor Control System for Chemical Recovery Units. Windsor, CT, C-E Inc. Paper presented at Canadian Pulp and Paper Assn., Fourth Paper Industry Air and Stream Improvement Conference, Halifax, Nova Scotia, September 16-18, 1968. 
9. Blue, J. D. Functional and Mechanical Aspects of a Modern Recovery Boiler Design. (Paper Industry Boiler Seminar). North Canton, $\mathrm{OH}$, Power Generation Group, B\&W SP-123 N.D.

10. Pollak, P., R. Oesterholm and. L. Egnell. Corrosion Resistant Composite or Stainless Clad Tubes for Chemicals Recovery Boilers.

Quebec, Canada, Sandvik Canadian L\&D and Sandvik A.B. (N.D.)

11. Taylor, Malcom L. and H. S. Gardner. Causes of Recovery Boiler Explosions. Technical Association of Pulp and Paper Industries, Vol. 57, No. 11, November, 1974 p. 76

12. Heberer, N. L. (Hamilton, . OH, Champion International Corp.) Summary Report on Activities of the Black Liquor Recovery Boiler Advisory Committee. Technical Association of Pulp and Paper Industries, Vol. 57 , No. 11 , November, 1974 p. 80

13. Lockheed Palo Alto Research Labs. Thermodynamic Phase Stability Diagrams for the Analysis of Corrosion Reactions in Coal Gasification/Combustion Atmospheres. Palo Alto, CA, for EPRI December, 1977, EPRI-FP-539.

14. Battelle Columbus Labs. Corrosion Studies in Municipal Incinerators. For National Environmental Research Center, 1972. PB 213-378

(N.D. ) = No Date Available: 
15. Schultz, J. W. and W. R. Halsiger Corrosion Resistant Nickel-Base Alloys for Gas Turbines. Metals Engineering Quarterly (N.D.)

16. Personal communications by: P. Sheth (GAI) with J. Myers, R. Callahan and B. Lee, P.H. Glatfelter Company, Spring Grove, PA. (Feb. 78).

17. Clement, J. L. The Kraft Recovery Boiler. (Paper Industry Boiler Seminar) North Canton, $\mathrm{OH}$, Power Generation Group, B\&W SP-I13 (N.D.)

18. Coulter, J. H. and J. L. Clement. Factors Affecting Recovery Boiler Spray: B\&W. (Oct. 74).

19. Darmstadt, W. S. Neutral Sulfite Recovery Process. Technical Association of Pulp and Paper Industries, Vol. 41, No. 3. March 1958. N. Y. B\&W, BuT. BR-706

20. Personal communications by $P$ a Sheth (GAI) with $P$. Nelson and J. Lynch of C.T. Main, Inc., Boston, MA, March 1978.

21. Owens, V. P. Present Developments in Chemical Recovery for the Pulping Industry Windsor, CT, Combustion Engineering Inc. Paper presented at 11th Annual Meeting Asociacion Mexicana de Tecnicos de Cas Industrias de Celulosa y del Papel, A. C. Mexico City, Mexico. May 24-26, 1971.

22. Bienstock, D. et. al. Corrosion of Heat Exchange Tubes in a Simulated Coal-Fired MHD System. Journal of Engineering for Power April, 1971 p. 249

23. Levig, Arthur and Earl L. Merryman. Sulfur Chemistry and Its Role in Corrosion and Deposits. Columbus, $\mathrm{OH}$, Battelle Memorial Inst., (1962). ASME Pub1. \#62-WA-124. 
24. Suda, Stanley. Considerations for Sodium Base Recovery Unit Design. Paper Industry Boiler Seminar, North Canton, OH, Power Generation Group, B\&W, SP-124. (N.D.)

25. Plumley, A. L. Dr. et. al. External Corrosion of Waterwall Tubes in Kraft Recovery Furnaces: A Progress Report. Windsor, CT, C-E, Inc. Paper presented at Technical Assoication of Pulp and Paper Industries, 20th Engineering Conference, Minneapolis, Minnesota, September 13-16, 1965.

26. Morre, G. F. and R. F. Ehrler. Western Coals-Laboratory Characterization and Field Evaluations of Cleaning Requirements. ASME Pub. \#73-WA/FU-1

27. Coulter, J. H. and J. L. Clement. (Barberton, $\mathrm{OH}$, Babcock and Wilcox C0.) Factors Affecting Recovery Boiler Safety, Technical Association of Pulp and Paper Industries, Vo1. 57, No. 10 October, 1974.

28. Personal Communication by:P. Sheth (GAI) with N. Eft, Babcock and Wilcox Co. 78.

29. Babcock and Wilcox Co. The Cyclone Furnace. (N.D.)

30. Personal Communication by Pravin Sheth (GAI) with W. Sage, Babcock and Wilcox Co. 78.

31. Utility Companies surveyed
a. Commonwealth Edison, Chicago, Illinois
b. TVA, Chattanooga, Tennessee
c. Illinois Power, Chicago, Illinois 

d. Otter Tail Plant, Beachston, Minnesota
e. Ohio Edison, Akron, Ohio
f. Tampa Electric, Tampa, Florida

32. Gilbert Associates/STD Research Corporation. Baseline Power Plant Open Cycle MHD - Steam Cycle Power Loop - Overall Plant Design Description. U.S. ERDA, Div. of MHD, $30 \mathrm{Dec} .1976$.

33. W. Nelson, and C. Cain, Jr. Corrosion of Superheaters and Reheaters of Pulverized-Coal-Fired Boilers, Trans. ASME 82:194 (1960).

34. TRW Defense \& Space Systems Group. TRW 25 MWt Staged MHD Coal Combustor Conceptual Design Study. Redondo Beach, CA for U.S. ERDA (DOE), 4 June 1976. TID 27145.

35. Jackson, W. E. et. al. Status of the Reference Dual Cycle MHD-Steam Power Plant, 16th Symposium Engineering Aspects of MHD. 1977.

36. Stairmand, C.J. The Design and Performance of Cyclone Separators. Trans. Instn. Chem. Engrs., 1951

37. Kock, Wolfgang $\mathrm{H}$ and William Licht. New Design Approach Boosts Cyclone Efficiency. Chemical Engineering. Nov. 1977.

38. Cyclone Manufacturers Surveyed:
a. Fisher-Klosterman, Inc., Louisville, Kentucky
b. Ducon Company, Inc., Mineola, New York
c. Aerodyne Development Corp., Cleveland, Ohio
d. AGET Manufacturing Company, Adrian, Michigan
e. Hammond Machinery Builders, Kalamazoo, Michigan . 
f. Peerless Mfg. Company, Dallas, Texas.

g. Envirotech Corporation, Houston, Texas

h. General Electric Company, Schenectady, New York

i. Enviro-Systems \& Research Inc., Roanoke, Virginia

j. W.W. Sly Manufacturing Company, Cleveland, Ohio

k. Joy Manufacturing Company, Los Angeles, California

1. Dyna-Therm Corporation, Houston, Texas

m. She11 Development Company, Houston, Texas

n. Van Tongeren, Reynoldsburg, Ohio

o. Donaldson Company, Minneapolis, Minn.

p. Dixie Manufacturing Company, Baltimore, Md.

q. W.C. Wiedenmann \& Son, Inc., Kansas City, Mo.

r. Seneca Environmental Products, Tiffin, Ohio

s. Aerex Corporation, Scottstown, Quebec

t. Environmental Elements Corporation, Baltimore, Maryland

39. AVCO Everett Research Laboratory. Engineering Test Facility Conceptual Design. Everett, MA. 1978.

40. Westinghouse. MHD Conceptual Design. 1978. 
APPENDIX A BLACK LIQUOR BOILER INSTALLATION LISTS $\quad A-2$

APPENDIX B CORROSION IN BLACK LIQUOR BOILERS B-1 
APPENDIX A

BLACK LIQUOR BOILER

INSTALLATION LISTS

A-2 
BABCOCK \& WILCOX CO.

BLACK LIQUOR UNITS WITH CYCLONE EVAPORATORS

\section{Contracts}

$5-9906$

$S-9950$

S- 9952

$P R-35$

$P R-42$

$P R-49$

$P R-55$

$P R-56$

$P R-57$

$P R-67$

$P R-67$

$\operatorname{PR}-\frac{10}{10}$

$P R-83$

$P R-84$

$P R-85$

$P R-86$

$P R-87$

$P R-88$

PR-89

$P R-90$
$P R-91$

$P R-91$
$P R-92$

PR-92

$P R-93$

$P R-94$

PR-97

$P R-105$

PR-108

$P R-112$

$P R-113$

$P R-114$

$P R-115$

$P R-116$

\section{Customer}

Hudson Pulp \& Paper Co., Palatka, Fla.

W. Va. Pulp \& Paper, Charleston, S.C.

Crown Zellerback Corp., Camas, Wash.

Packaging Corp. of America, Filer City, Mich.

W. Va. Pulp \& Paper co., Luke, Md.

Bowaters Carolina Corp., Catawba, S.C.

Continental Can Co. Nixon, Ga.

Rayonier Corp. Hoquiam, Wash.

Fibreboard Paper Products, Antioch, Cal.

Downingtown Mfg. Co. for: Seshasayee Pulp \& Paper Ltd., India

Spruce Falls Pwr. \& Paper Co., Kapuskasing, Ont.

olin Mathieson Chemical Corp., W. Monroe, La.

Crown Zellerbach Corp., Bogalusa, La.

Crown Zellerbach Corp., St. Francisville, La.

Scott Paper Co., Mobile, Ala.

Champion Papers, Inc., Canton, N.C.

Georgia Pacific Corp. Woodland,

Con, Ga.

Bowaters Carolina Corp. Catawbal.

Weyerhaeser Co. Cosmopolis, Wash.

Weyerhaeuser Co. ' Cosmopolis, Wash.

Crown Zellerbach Corp. Wauna, Ore.

Celulose Billeruds, Portugal

Alabama Kraft Co: Mahrt, Ala.

Owens-Illinois, Orange, Texas

Int. Paper Co., Bastrop, La.

Int. Paper Co., Pine Bluff, Ark.

Int. Paper Co., Georgetown, S.C.

Int. Paper Co., Camden, Ark.

\begin{tabular}{c}
$\begin{array}{c}\text { No. of } \\
\text { Units } \\
\text { Sold }\end{array}$ \\
\hline 1 \\
1 \\
1 \\
1 \\
1 \\
1 \\
1 \\
1 \\
1 \\
1 \\
1 \\
1 \\
1 \\
1 \\
1 \\
1 \\
2 \\
1 \\
1 \\
1 \\
1 \\
1 \\
1 \\
1 \\
1 \\
2 \\
1 \\
1 \\
1 \\
1 \\
1
\end{tabular}

Oper.

Press

(Psig) $\quad$ Temp. ${ }^{0} \mathrm{~F}$

460725

1525
400

.750

1525
850

$875-900$

620750

$600 \quad 715$ 
BABCOCK \& WILCOX CO

BLACK LIQUOR UNITS WITH CYCLONE EVAPORATORS

(continued)

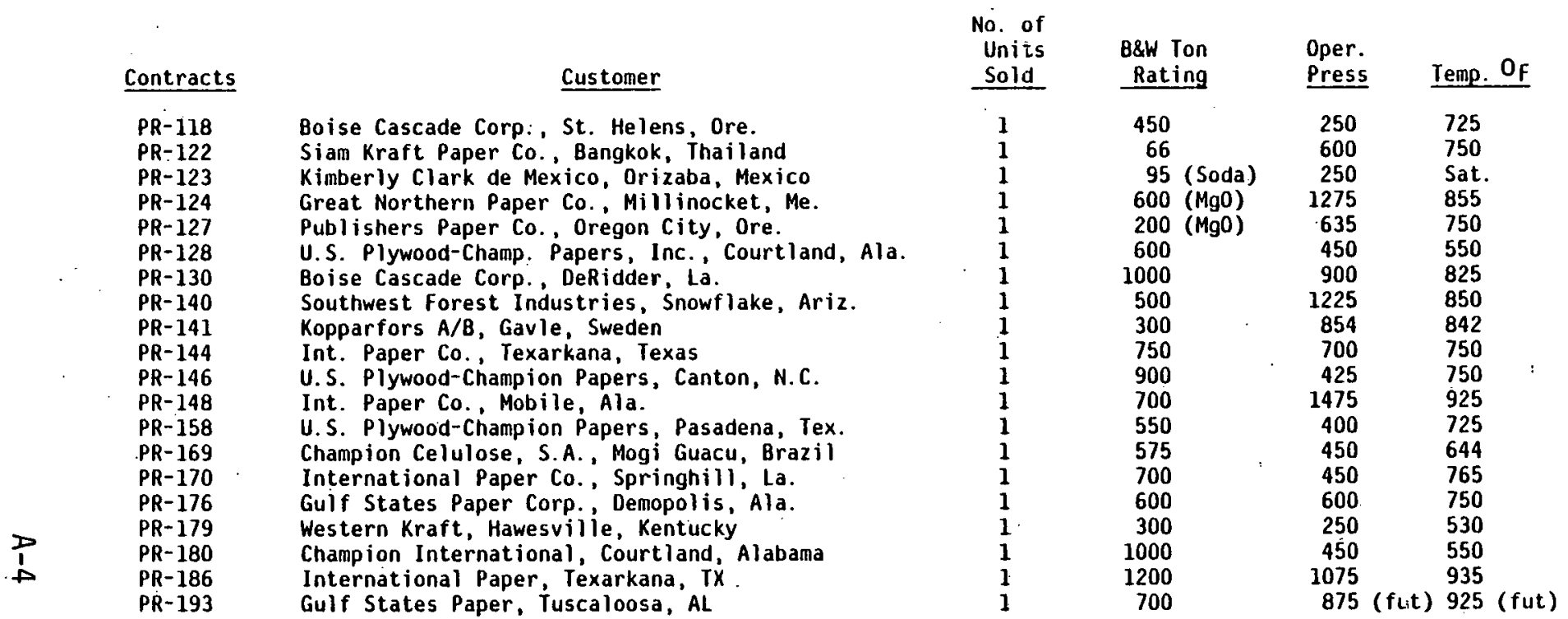

\section{Cyclone Evaporators:}

The cyclone evaporator is a vertical cylindrical vessel with a conical bottom. The strong black-liquor (45 to $50 \%$ solidsi from the storage tank The cyclone evaporator is a vertical cylindrical vessel with a conical bottom. The strong black-liquor (45 to $50 \%$ solids) from the storage tank Black liquor is sprayed from the top across the gas outlet to obtain contact of liquor with gas. 
BABCOCK \& WILCOX CO.

BLACK LIQUOR UNITS WITH CASCADE EVAPORATORS*

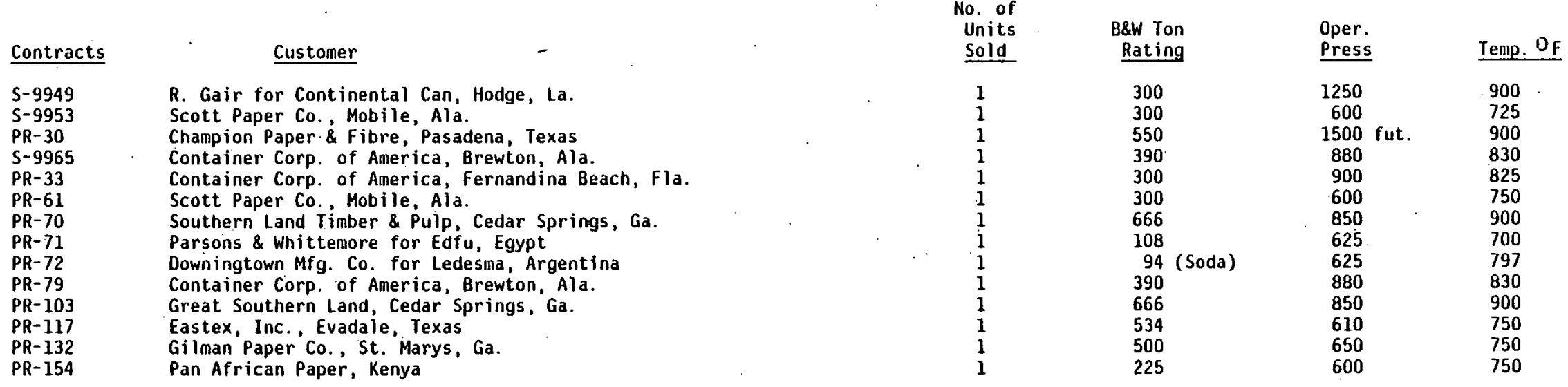

\section{Cascade Evaporators:}

In the cascade evaporator, spaced tubular elements arranged horizontally are supported between two circular side plates to form a wheel that is partially submerged in a bath of hot-liquor contained in the lower position of the evaporator housing. Slow speed rotation turns the welded tubes into the gas stream; as the tubes rise above the liquor bath, the surface coated with black liquor contacts the gas stream flowing through the wheel above the liquor level. The number and arrangement of the wheels to provide the amount of total contact surface required, depends on the weight and temperature of the gas and the weight of water that must be evaporated from the liquor. It can concentrate the black liquor up to $65 \%$ solids. 


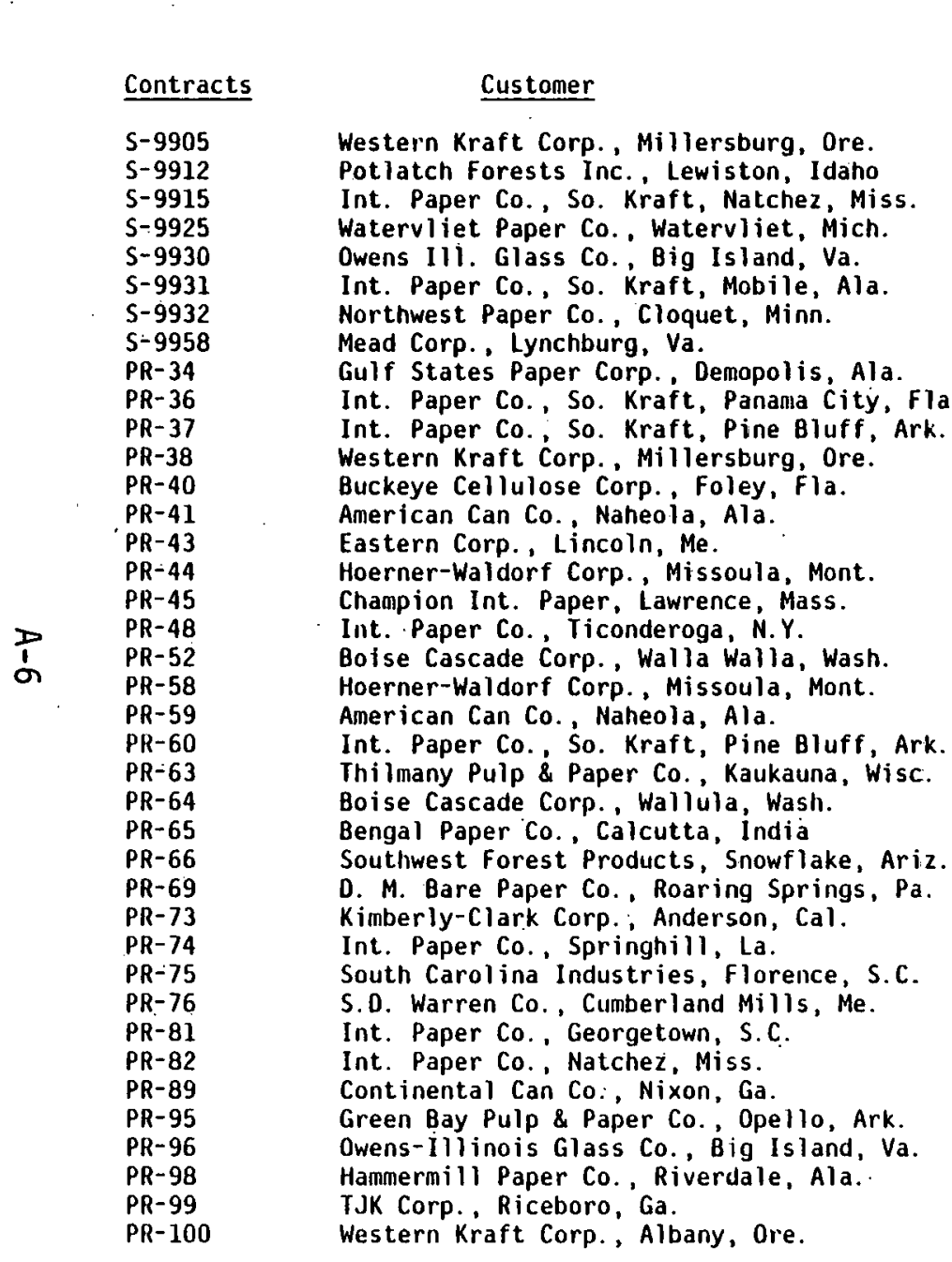

\begin{tabular}{|c|c|c|c|}
\hline $\begin{array}{l}\text { No. of } \\
\text { Units } \\
\text { Sold }\end{array}$ & $\begin{array}{r}\text { Ei\&w Ton } \\
\text { Rating }\end{array}$ & $\begin{array}{l}\text { Oper. } \\
\text { Press }\end{array}$ & Tenp. $O_{F}$ \\
\hline 1 & 117 & $250^{\circ}$ & Sat. \\
\hline 1 & 300 & 600 & 750 \\
\hline 1 & 250 & 650 & 750 \\
\hline 1 & $30 \mathrm{~T}$. Sinelter & 120 & Sat. \\
\hline 1 & 40 I. Smelter & 185 & Sat. \\
\hline 2 & $360 \mathrm{ea}$ & 450 & 725 \\
\hline 1 & 300 & 600 & 750 \\
\hline i & 108 (NSSC) & 600 & 750 \\
\hline$i$ & 330 & 600 & 750 \\
\hline$i$ & 360 & 1275 & 900 \\
\hline 2 & 390 ea. & 1275 & 900 \\
\hline 1 & 165 & 250 & 580 \\
\hline 1 & 550 & 600 & 750 \\
\hline 1 & 390 & 875 & 825 \\
\hline 1 & 165 & 635 & 650 \\
\hline 1 & 300 & 600 & 750 \\
\hline 1 & 66 & 400 & 600 \\
\hline 1 & 150 & 425 & 700 \\
\hline 1 & 165 & 250 & 580 \\
\hline 1 & 300 & 600 & .750 \\
\hline 1 & 390 & 875 & 825 \\
\hline$i$ & 390 & 1275 & 900 \\
\hline 1 & 390 & 620 & 825 \\
\hline 1 & 250 & 260 & 580 \\
\hline 1 & 94 & 475 & 725 \\
\hline$i$ & 250 & 1200 & 900 \\
\hline$i$ & 122 & 615 & 730 \\
\hline 1 & 150 & 600 & 600 \\
\hline 1 & 500 & 870 & 825 \\
\hline $\overrightarrow{1}$ & 410 & 650 & 760 \\
\hline 1 & 250 & 570 & 720 \\
\hline$i$ & 900 & 1020 & 825 \\
\hline 1 & 600 & 1250 & 925 \\
\hline 1 & 400 & 875 & 900 \\
\hline 1 & 250 & 250 & Sat. \\
\hline$i$ & 40 (NSSC) & 185 & Sat. \\
\hline 1 & 450 & 650 & $760^{\circ}$ \\
\hline$i$ & 450 & 650 & 760 \\
\hline 1 & 165 & 250 & 580 \\
\hline
\end{tabular}


BABCOCK \& WILCOX CO.

\section{BLACK LIQUOR UNITS WITH VENTURI SCRUBBER - EVAPORATORS}

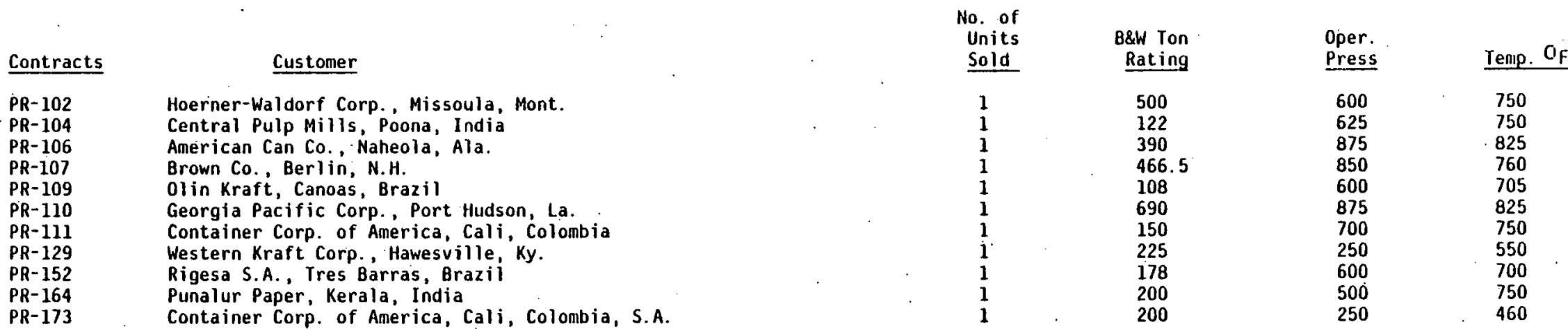

Venturi Scrubber - Evaparators:

The venturi evaporator-scrubber is a device that collects the fume from the waste gas and also provides contact of the gases with the black liquor for concentration by evaporation. This scrubber depends on the collision of fume particles with liquid droplets. The liquor is concentrated by cooling the gas to about $180 \mathrm{~F}$. The liquor is recirculated from the cyclone separator sump to the Venturi throat nozzles at a concentration of $60-70 \%$ solids. Fume collection coefficiencies of 90 to $94 \%$ are continuously maintained. 


\section{乙-E recovery unit orders}

\section{CASCADE EVAPORATOR SYSTEMS}

\begin{tabular}{|c|c|c|}
\hline $\begin{array}{l}\text { CUSTOMER NAME } \\
\text { LOCATION }\end{array}$ & $\begin{array}{l}\text { DAY SOLIDS } \\
\text { CAPACITY } \\
\text { LBSIOAY }\end{array}$ & $\begin{array}{l}\text { PRESSURE - PSI } \\
\text { S. HO. TEMP. 'F } \\
\end{array}$ \\
\hline $\begin{array}{l}\text { Allied Paper } \\
\text { Jackson. Ala. }\end{array}$ & $1,700,000$ & $400 / 700$ \\
\hline $\begin{array}{l}\text { Chesapeak Corp. of Virginia } \\
\text { West Point. Va. }\end{array}$ & 2.700 .000 & $1.225 / 900$ \\
\hline $\begin{array}{l}\text { Churchill Forest Industries } \\
\text { Maniloba. Canada }\end{array}$ & 1.450 .000 & $775 / 825$ \\
\hline $\begin{array}{l}\text { Comp. Portuguesa De Celulosa } \\
\text { Cacia. Portugal }\end{array}$ & 800,000 & $910 / 797$ \\
\hline $\begin{array}{l}\text { Consolidated Paper Co. } \\
\text { W/isconsin Rapids. Wisc. }\end{array}$ & 1.200 .000 & $1.275 / 900$ \\
\hline $\begin{array}{l}\text { Crown Zellerbach } \\
\text { Camas. Wash. }\end{array}$ & $1,980,000$ & $415 / 525$ \\
\hline $\begin{array}{l}\text { Federal Paperboard } \\
\text { Riegelwood. N C. }\end{array}$ & 2.100 .000 & $850 / 825$ \\
\hline $\begin{array}{l}\text { Westvaco Corp. } \\
\text { Cuvington. VA }\end{array}$ & $3,968,000$ & $650 / 750$ \\
\hline $\begin{array}{l}\text { Westvaco Corp. } \\
\text { Luke. MO }\end{array}$ & 3.450 .000 & $645 / 720$ \\
\hline $\begin{array}{l}\text { Georgia.Pacilic Corp. } \\
\text { Porl Hudson. LA }\end{array}$ & $3.000,000$ & $900 / 825$ \\
\hline $\begin{array}{l}\text { Great Lakes Paper Co. } \\
\text { inunder Bdy. Ontario }\end{array}$ & $3,000,000$ & $900 / 900$ \\
\hline $\begin{array}{l}\text { International Paper Co. } \\
\text { Natcitez. MIss }\end{array}$ & $2,700,000$ & $600 / 750$ \\
\hline $\begin{array}{l}\text { International Paper Co. } \\
\text { Pjuluina Cily. Fla. }\end{array}$ & 2.700 .000 & $\begin{array}{l}450 / 450 \\
(2 \text { units })\end{array}$ \\
\hline $\begin{array}{l}\text { Longuiew Fibre } \\
\text { I ongvicw. Wash.. }\end{array}$ & $3.300,000$ & $850 / 750$ \\
\hline $\begin{array}{l}\text { New Zealand Forest Products } \\
\text { Kinleith. N Z }\end{array}$ & 2.500 .000 & $350 / 490$ \\
\hline $\begin{array}{l}\text { Si. Joe Paper Co. } \\
\text { Poit St. Joe. Fla. }\end{array}$ & 3.180 .000 & 1,$300 ; 900$ \\
\hline $\begin{array}{l}\text { Union Camp Corp. } \\
\text { Savilluilı. Cia } \\
\text { EXTENDED ECONOMI }\end{array}$ & $\begin{array}{c}4.050 .000 \\
\text { ER SYSTEMS* }\end{array}$ & $\frac{1.375 / 925}{1-1.25}$ \\
\hline $\begin{array}{l}\text { CUSTOMER NAME } \\
\text { LOCATION }\end{array}$ & $\begin{array}{l}\text { DAY SOLIDS } \\
\text { CAPACITY } \\
\text { LBS/DAY } \\
\end{array}$ & $\begin{array}{l}\text { PRESSURE - PSI } \\
\text { S. HO. TEMP. OF }\end{array}$ \\
\hline $\begin{array}{l}\text { Arkansas Krall } \\
\text { Murrillon. Ark. }\end{array}$ & 2.000 .000 & $615 / 735$ \\
\hline $\begin{array}{l}\text { lish Forest Products } \\
\text { x. Felicien. Que. }\end{array}$ & 3.000 .000 & $625 / 750$ \\
\hline
\end{tabular}

\begin{tabular}{|c|c|c|}
\hline $\begin{array}{c}\text { CUSTOMER NAME } \\
\text { LOCATION }\end{array}$ & $\begin{array}{l}\text { DRY SOLIDS } \\
\text { CAPACITY } \\
\text { LBS/DAY } \\
\end{array}$ & $\begin{array}{l}\text { PRESSURE - PSI } \\
\text { S. HO. TEMP. OF }\end{array}$ \\
\hline $\begin{array}{l}\text { Canadian Cellulose } \\
\text { Prince Rupert, B.C. }\end{array}$ & $2,640,000$ & $625 / 650$ \\
\hline $\begin{array}{l}\text { Canadian International Paper } \\
\text { La Tuque, Que. }\end{array}$ & $3.000,000$ & $400 / 500$ \\
\hline $\begin{array}{l}\text { Eastex, Inc. } \\
\text { Evadale. Texas }\end{array}$ & $3,300,000$ & $625 / 750$ \\
\hline $\begin{array}{l}\text { Hudson Pulp \& Paper } \\
\text { Palataka, Fla. }\end{array}$ & $3.600,000$ & $1.300 / 900$ \\
\hline $\begin{array}{l}\text { Kimberly-Clark Corp. } \\
\text { Coosa Pines. Ala. }\end{array}$ & 2.700 .000 & 575,750 \\
\hline $\begin{array}{l}\text { Kimberly-Clark Corp. } \\
\text { of Canada } \\
\text { Terrace Bay, Ontario }\end{array}$ & $2.400,000$ & $875 / 900$ \\
\hline $\begin{array}{l}\text { Northwestern Pulp \& Paper } \\
\text { Hinton, Alberta }\end{array}$ & $2,400,000$ & $625 / 750$ \\
\hline $\begin{array}{l}\text { Proctor and Gamble } \\
\text { Grand Prairie. Alberta }\end{array}$ & $3,300,000$ & $910 / 800$ \\
\hline $\begin{array}{l}\text { Scoll Paper Co. } \\
\text { Skowhegan, Me. }\end{array}$ & $3,000,000$ & $900 / 850$ \\
\hline $\begin{array}{l}\text { Sociedade Indiustrial } \\
\text { De Cullutose } \\
\text { Selubul, Portugal }\end{array}$ & $1.186,800$ & 925,878 \\
\hline $\begin{array}{l}\text { Weyerhaeuser Co. } \\
\text { Everell, Wash. }\end{array}$ & $1,000,000$ & $620: 710$ \\
\hline $\begin{array}{l}\text { Weyerhaeuser Co. } \\
\text { Plymouth, N.C. }\end{array}$ & $4,500,000$ & 875,825 \\
\hline LAMINAIRE AIR HEATER & $\star \star$ & 、 \\
\hline $\begin{array}{c}\text { CUSTOMER NAME } \\
\text { LOCATION }\end{array}$ & $\begin{array}{l}\text { DAY SOLIDS } \\
\text { CAPACITY } \\
\text { LBS/DAY }\end{array}$ & $\begin{array}{l}\text { PRESSURE_PSI } \\
\text { S. HO. TEMP. F }\end{array}$ \\
\hline $\begin{array}{l}\text { Boise Cascade } \\
\text { St. Helens. Ore. }\end{array}$ & $2,100,000$ & $400 ; 750$ \\
\hline $\begin{array}{l}\text { Boise Cascade } \\
\text { Willulia, Ore }\end{array}$ & 2.100 .000 & $400 ; 750$ \\
\hline $\begin{array}{l}\text { Continental Can } \\
\text { Hodyi: La. }\end{array}$ & 3.700 .000 & $1.275,900$ \\
\hline $\begin{array}{l}\text { S1. Regis } \\
\text { Tacoina. Washl. }\end{array}$ & $2.590,000$ & 450,725 \\
\hline $\begin{array}{l}\text { Weyerhaeuser Co. } \\
\text { Vallianl. Okla. }\end{array}$ & 4.500 .000 & $1300: 925$ \\
\hline
\end{tabular}

See following page for note.

** See following page for note. 
* EXTENDED ECONOMIZER SYSTEMS:

The types of extended surfaces are cast iron or aluminum gill rings, spiral fins and small metal studs welded to the tubes. The extended surface economizers have economic advantages over bare tube surface in lower first cost and smaller space required for installation. Extended surface tubes are normally installed horizontally in a staggered pattern. They are suited for units without air heaters.

** LAMINAIRE AIR HEATER:

This regenerative type air heater is of two types:. (1) rotating plate and (2) rotating duct connections. In the rotating plate type regenerative air heater, heat storage plate elements are heated progressively in a flowing gas stream, and then progressively rotated by mechanical means into a flowing air stream where the stored heat is released to the air before the plates are returned to the gas stream. In the rotating duct connections plates are stationary. Depending upon the gas and air inlet and outlet temperatures, two or three types of heating surface metals with ceramic coating are used. 


\begin{tabular}{l} 
COPELAND SYSTEMS INCORPORATED \\
(SUBSIDIARY OF FOSTER WHEELER DEVELOPMENT CORPORATION) \\
BLACK LIQUOR UNITS WITH DIRECT CONTACT \\
EVAPORATORS \\
\hline
\end{tabular}

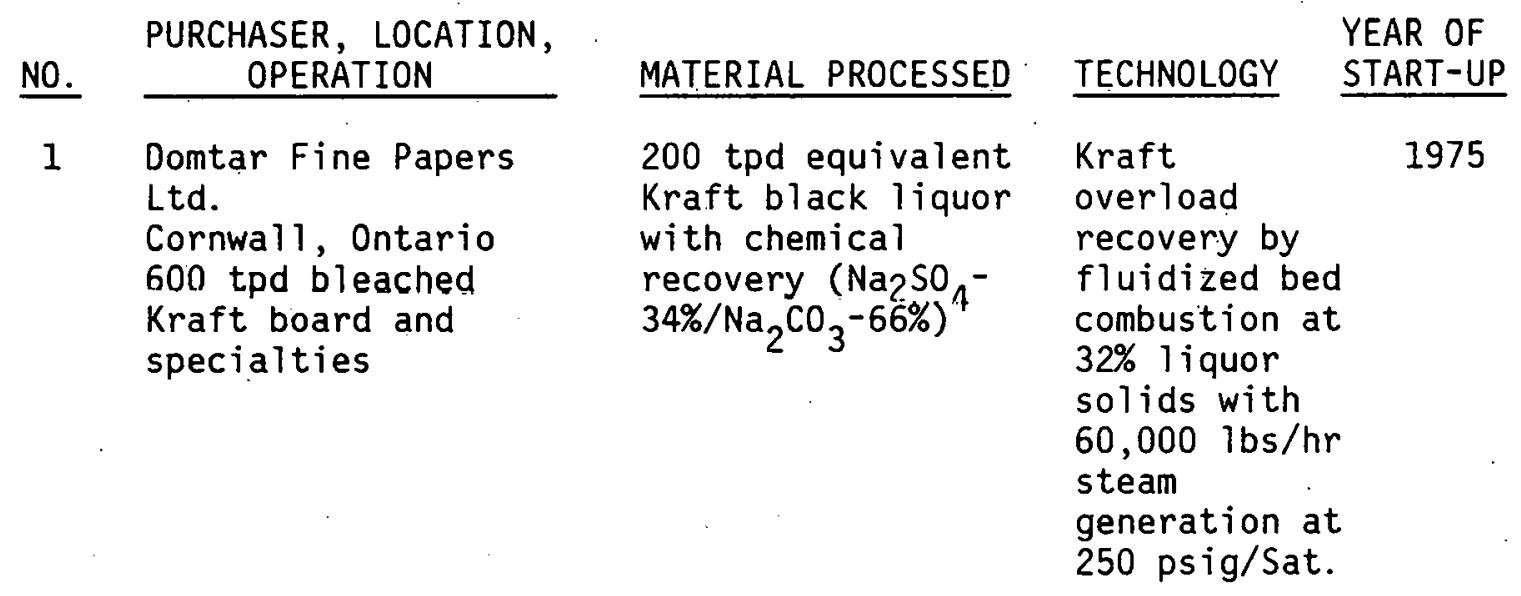

\section{DIRECT CONTACT EVAPORATORS:}

In the direct contact evaporator, the liquor and flue gas are brought into intimate physical contact, and there is a mass transfer of water vapor from the liquor to the gas across the liquor-gas interface.

The direct contact evaporator used in the recovery unit is of the cyclone, cascade or Venturi type which were described previously. 


\section{APPENDIX B \\ CORROSION IN BLACK LIQUOR BOILERS}

The corrosion rate is strongly affected by skin metal temperature, type of atmosphere (reducing or oxidizing), gas constituents, and tube metal composition. It is further complicated by operating pressures, high velocities, and erosive particle impingement. Cyclic operation also increases the potential for corrosion, due to accelerated exfoliation of semiprotected scale. Corrosion follows a parabolic relationship with time, i.e. corrosion tends to "drown" in its own waste products unless they are removed by spalling due to thermal cycling or other causes.

Knowledge of the action of the gas constituents on the principal and minor elements of the tube metal, along with the relative thermodynamic stability of the various metal compounds that could be formed, are necessary to determine corrosion. The gas constituents may be oxidizing $\left(\mathrm{H}_{2} \mathrm{O}, \mathrm{CO}, \mathrm{CO}_{2}\right)$, carburizing $\left(\mathrm{CO}, \mathrm{CO}_{2}, \mathrm{CH}_{4}\right)$, sulfidizing $\left(\mathrm{SO}_{2}\right.$, $\left.\mathrm{H}_{2} \mathrm{~S}, \mathrm{COS}\right)$, or nitriding $\left(\mathrm{N}_{2}, \mathrm{NH}_{3}\right)$. The tube metal is principally composed of $\mathrm{Fe}, \mathrm{Ni}$, or $\mathrm{Cr}$, with minor additions of $\mathrm{Si}, \mathrm{Mn}, \mathrm{Cu}, \mathrm{Ti}, \mathrm{Al}$, Mo, etc. The metal compounds that could be formed are oxides, sulfides, carbides, and nitrides, simple or complex. As a result of chemical reactions, new species, including $\mathrm{S}_{2}, \mathrm{O}_{2}, \mathrm{C}, \mathrm{HS}, \mathrm{COS}$, and $\mathrm{SO}_{3}$, will be formed. At any given pressure and temperature, the gas will shift composition to approach equilibrium. The radiant furnace zone, especially at the hearth area, incurs extensive corrosion compared to the convection surface zones (superheater and boiler bank). (Ref. 13)

At higher operating pressures, sulfur and oxygen partial pressures are similar, but carbon activity increases significantly. Depending upon changes in sulfur and oxygen activity through the predominant scale, other reaction products may form. If the sulfur activity at the interface of a chromium oxide $\left(\mathrm{Cr}_{2} \mathrm{O}_{3}\right)$ scale surface falls below the value at which the sulfide is in equilibrium with the metal, only the 
oxide will form, and the sulfides will not grow beneath the scale. The penetration of any protective oxide scale system by sulfur is inevitable, and, eventually, that scale will be destroyed by the undergrowth or internal formation of sulfides.

The equilibrium mixture changes significantly when the pressure is changed. As for example, when the pressure is changed from one atm. to 68 atm., sulfur and oxygen pressures are similar, but carbon activity is increased by a factor of over 50. A shift toward equilibrium for $\mathrm{CO} / \mathrm{CO}_{2}$ may be established in seconds, where as the $\mathrm{CH}_{4} / \mathrm{H}_{2}$ equilibrium shift has a half life of over seven minutes. That is, the methane content will be reduced to half its initial value in this time span. Nickel-NiS slags are liquid above $1193^{\circ} \mathrm{F}$ (918 K) while Fe-FeS-Feo slags are liquid above $1697^{\circ} \mathrm{F}$ (1198 K). Melting of $\mathrm{Fe}-\mathrm{FeS}-\mathrm{FeO}$ slags on $\mathrm{Fe}-\mathrm{Al}-\mathrm{Cr}$ is at temperatures as low as $1650^{\circ} \mathrm{F}(1172 \mathrm{~K})$. Sulfide melting temperature is of major importance in determining the use of stainless steels and high temperature alloys. (Ref. 13)

In black liquor boilers, the phenomenon of corrosion has been observed at the following locations:

- The window face of the furnace wall tubes. The attack is limited to an area between the primary air ports from six to eight inches above and below the ports. This high heat relase area (since the heat absorption rate is nearly twice $(40,000 \mathrm{Btu} / \mathrm{hr} / \mathrm{sq} . \mathrm{ft}$.$) as$ high as the average rate for (containing localized concentrations of $\mathrm{CO}_{2}, \mathrm{O}_{2}$ and $\mathrm{S}$ compounds) are major reasons for attack. Under the furnace conditions, the gases always generate sodium hydroxide $(\mathrm{NaOH})$ vapor by the following reaction:

$$
2 \mathrm{Na}_{2} \mathrm{~S}+\mathrm{H}_{2} \mathrm{O}+2 \mathrm{O}_{2} \rightarrow \mathrm{Na}_{2} \mathrm{~S}_{2} \mathrm{O}_{3}+2 \mathrm{NaOH}
$$

This $\mathrm{NaOH}$ vapor penetrates the porous wall structure into the small closed space. Here, the vapor condenses due to the 
considerably cooler tube surface. This causes a vacuum which draws additional $\mathrm{NaOH}$ vapor. The additional components such as $\mathrm{Na}_{2} \mathrm{CO}_{3}$ and $\mathrm{Na}_{2} \mathrm{SO}_{4}$, lower the melting point of $\mathrm{NaOH}$ still further. Thus, the $\mathrm{NaOH}$ appears as a smelt at higher boiler pressure. This molten $\mathrm{NaOH}$ reacts with oxidized steel (ferric oxide- $\mathrm{Fe}_{2} \mathrm{O}_{3}$ ) forming sodium hypoferrite $\left(\mathrm{NaFeO}_{2}\right)$ as follows:

$$
2 \mathrm{NaOH}+\mathrm{Fe}_{2} \mathrm{O}_{3} \rightarrow 2 \mathrm{NaFeO}_{2}+\mathrm{H}_{2} \mathrm{O}
$$

If removed, the generated $\mathrm{NaFeO}_{2}$ exposes the unattacked tube metal (Fe) for further corrosion attack by concentrated $\mathrm{NaOH} . \mathrm{NaFeO}_{2}$ in the presence of $\mathrm{O}_{2}$ transforms to sodium ferrate $\left(\mathrm{Na}_{2} \mathrm{FeO}_{4}\right)$.

- In the reducing atmosphere in which sodium sulfide $\left(\mathrm{Na}_{2} \mathrm{~S}\right)$ along with high metal temperatures results in a fire side corrosion of the flat studs (corrosion starts at $570^{\circ} \mathrm{F}$ and maximizes above the $750^{\circ} \mathrm{F}$ ). Burn-through of the flat stud barrier above and below the primary air ports accelerates the penetration and deposit of alkaline salts in back of the furnace wall tubes.

- At the upper parts of the furnace (above the furnace zone), due to the following reactions, elemental $S$ is generated:

$$
\begin{aligned}
& \mathrm{H}_{2} \mathrm{~S}+1 / 2 \mathrm{O}_{2} \rightarrow \mathrm{H}_{2} \mathrm{O}+\mathrm{S} \\
& \text { (known as "sulfide" corrosion) } \\
& \mathrm{Na}_{2} \mathrm{~S}+2 \mathrm{CO}_{2} \rightarrow \mathrm{Na}_{2} \mathrm{CO}_{3}+\mathrm{S}+\mathrm{CO} \\
& 2 \mathrm{Na}_{2} \mathrm{~S}+3 \mathrm{SO}_{2} \rightarrow 2 \mathrm{Na}_{2} \mathrm{SO}_{3}+3 \mathrm{~S}
\end{aligned}
$$

The principal corrosion product is formed by the reaction:

$$
\mathrm{Fe}+\mathrm{S} \rightarrow \mathrm{FeS}
$$


The formation of iron sulfide (FeS) in the corrosion scale suggests that the oxygen pressure beneath the scale may be in the order of $10^{-14}$ atmospheres. At higher $\mathrm{SO}_{2}$ or $\mathrm{O}_{2}$ pressures, iron oxides form, and, in the presence of oxides on iron surfaces, higher sulfur pressures and moistures are needed to form iron sulfide (FeS). (Ref. 14)

The corrosion caused by the furnace gases is dependent on the varying ratio between $\mathrm{H}_{2} \mathrm{~S}$ and $\mathrm{O}_{2}$ due to lack of combustion air, overloading of the boiler, high sulfidity, and sulfur losses. The corrosion is diminished by proportional increase of oxygen as well as by an increase of water vapor and $\mathrm{SO}_{2}$. In the area near the tube walls below the primary air ports, the furnace gas analysis in recovery units show large amounts of carbon dioxide ( 7 to 9 percent) and small amounts of sulfur dioxide ( 0.05 percent or less). The effect of concentrations of $\mathrm{CO}_{2}$ on the corrosion rate is shown in Figure 12.

- At the smelt level, the corrosiveness of the smelt depends primarily the amount of sodium suifate $\left(\mathrm{Na}_{2} \mathrm{SO}_{4}\right)$ and sodium chloride $(\mathrm{NaCl})$ present. The resulting corrosion can be so severe that a bare stainless steel tube cannot stand a steam pressure higher than 1200 psig.

As shown in Figure 13, the melting point of the smelt (mostly $\mathrm{Na}_{2} \mathrm{~S}$ ) decreases as the concentration of sodium chloride ( $\mathrm{NaCl}$ ) increases. Based on hot corrosion screening tests for two mixtures of $\mathrm{NaCl}$ and $\mathrm{Na}_{2} \mathrm{SO}_{4}$, corrosion rates on $\mathrm{IN}-738$ and UDIMET-500 are plotted in Figures 14 and 15 . Chloride stress corrosion has cracked the solid stainless steel tubing. It is advisable to retain a carbon steel tube as the pressure-bearing tube. Chloride stress corrosion conditions may arise in the furnace during shutdown and waterwash operation in the boiler. The origin of chlorides may be either sea water or bleach plant 


\section{FIGURE 12}

EFFECT OF FURNACE GAS COMPOSITION ON CORROSION (REF. 8)

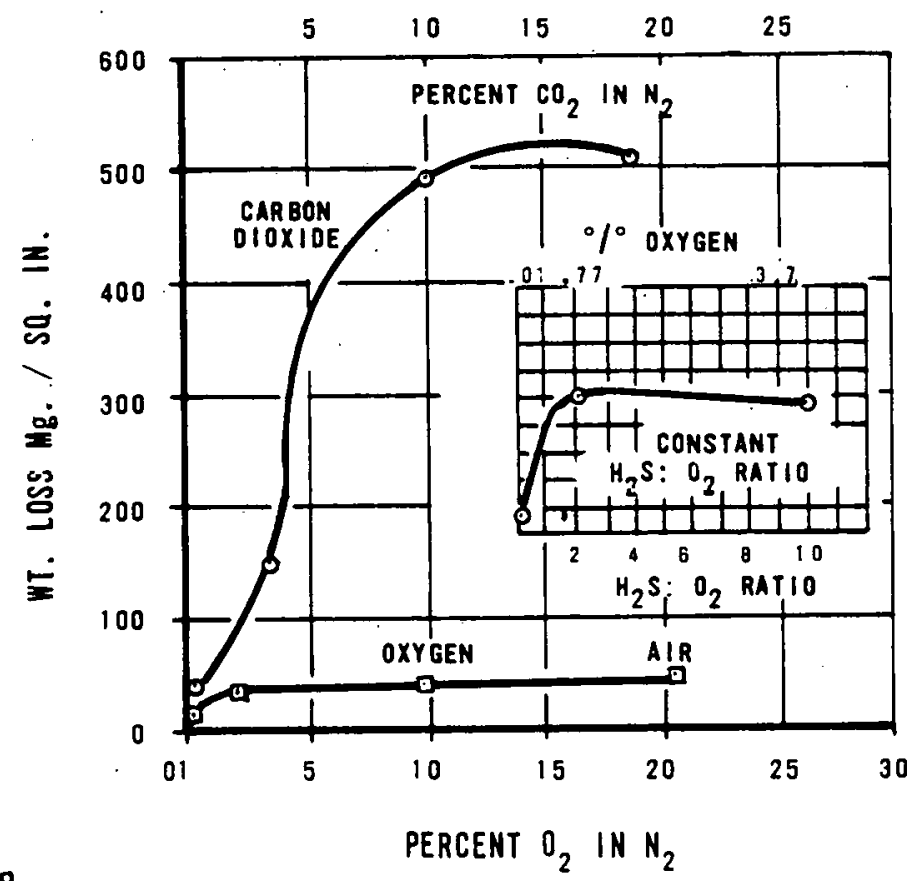

AESD-79-0228

FIGURE 13

EFFECT OF SODIUM CHLORIDE ON THE MELTING POINT OF SMELT (REF. 8)

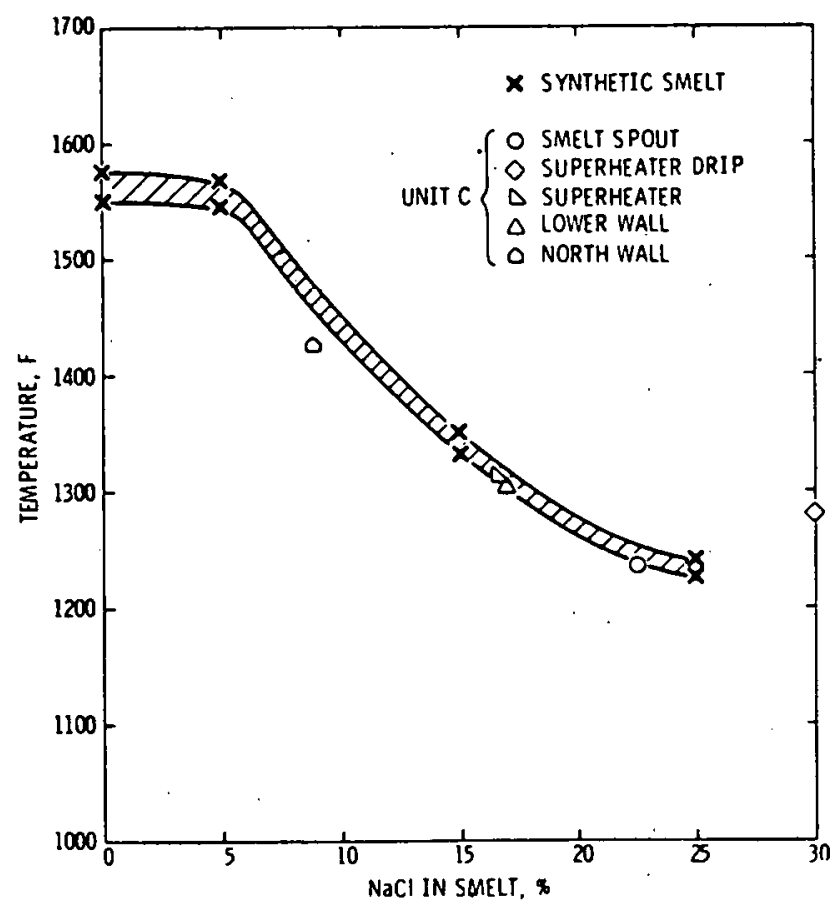

AESD-79-0229 


\section{FIGURE 14}

COMPARISON OF SUPERALLOY PERFORMANCE IN 90 PERCENT $\mathrm{Na}_{2} \mathrm{SO}_{4}$ -1.0 PERCENT NaC1 CRUCIBLE TEST AT $927^{\circ}$ C. (REF. 15)

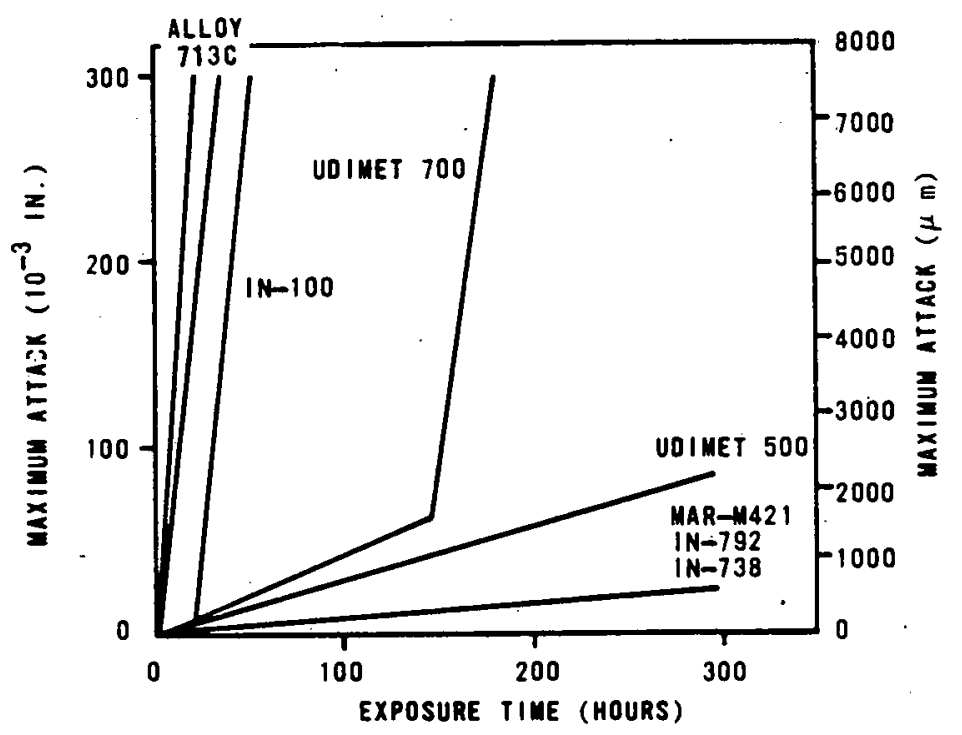

\section{FIGURE 15}

COMPARISON OF SUPERALLOY PERFORMANCE IN

75 PERCENT $\mathrm{Na}_{2} \mathrm{SO}_{4}-25$ PERCENT NaC1 SALT SHOWER TEST AT $900^{\circ} \mathrm{C}$ (REF. 15)

AESD-79-0231

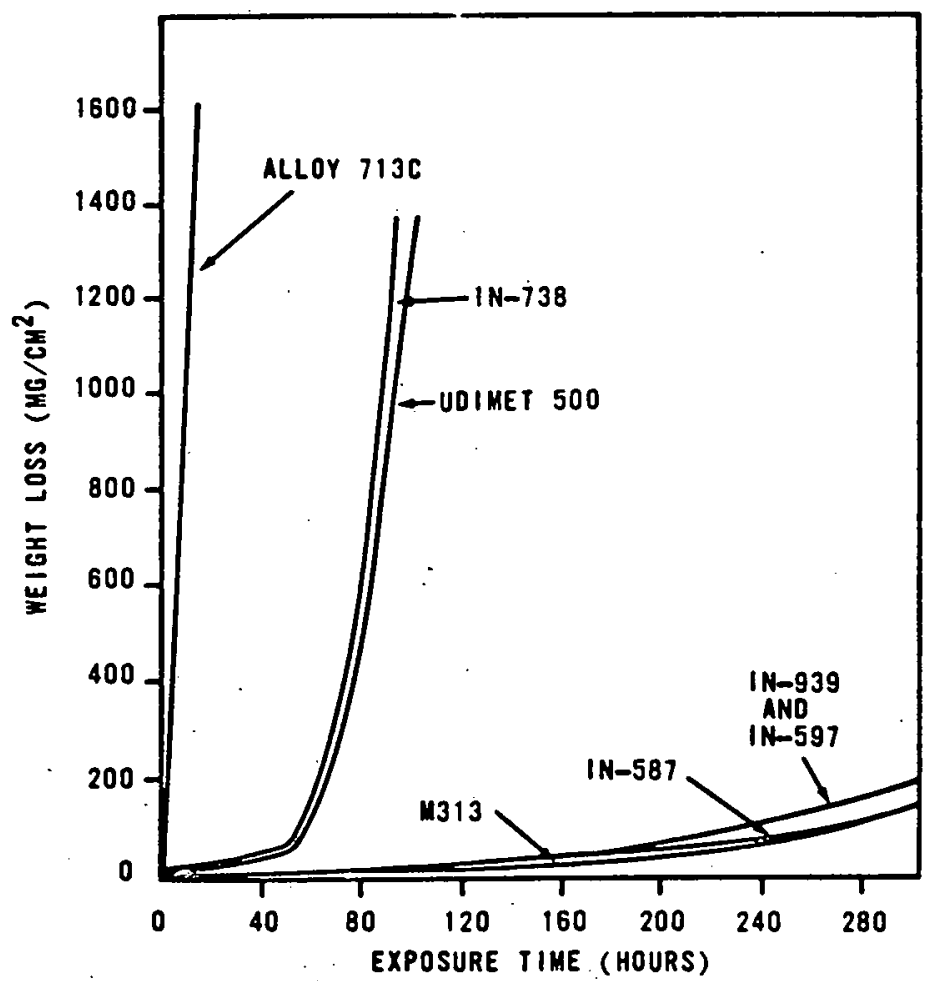


recycle water. Relatively lower melting points of sodium thiosulphate $\left(\mathrm{Na}_{2} \mathrm{SO}_{3}\right)$ and sodium pyrosulphate $\left(\mathrm{Na}_{2} \mathrm{~S}_{2} \mathrm{O}_{7}\right)$ result in high corrosion rates. The expected reaction is:

$$
\mathrm{Fe}_{2} \mathrm{O}_{3}+3 \mathrm{Na}_{2} \mathrm{~S}_{2} \mathrm{O}_{7} \rightarrow 2 \mathrm{Na}_{3} \mathrm{Fe}\left(\mathrm{SO}_{4}\right)_{3}
$$

Sodium sulfide $\left(\mathrm{Na}_{2} S\right)$ is corrosive in air, and sodium thiosulfate $\left(\mathrm{Na}_{2} \mathrm{SO}_{3}\right)$ is extremely corrosive in nitrogen. The sodium sulfide is much more corrosive than the thiosulfate in the furnace gas atmosphere. Above $950^{\circ} \mathrm{F}(738 \mathrm{~K})$, corrosion of studs has been recorded due to polysulfides and chlorides in the smelt. 


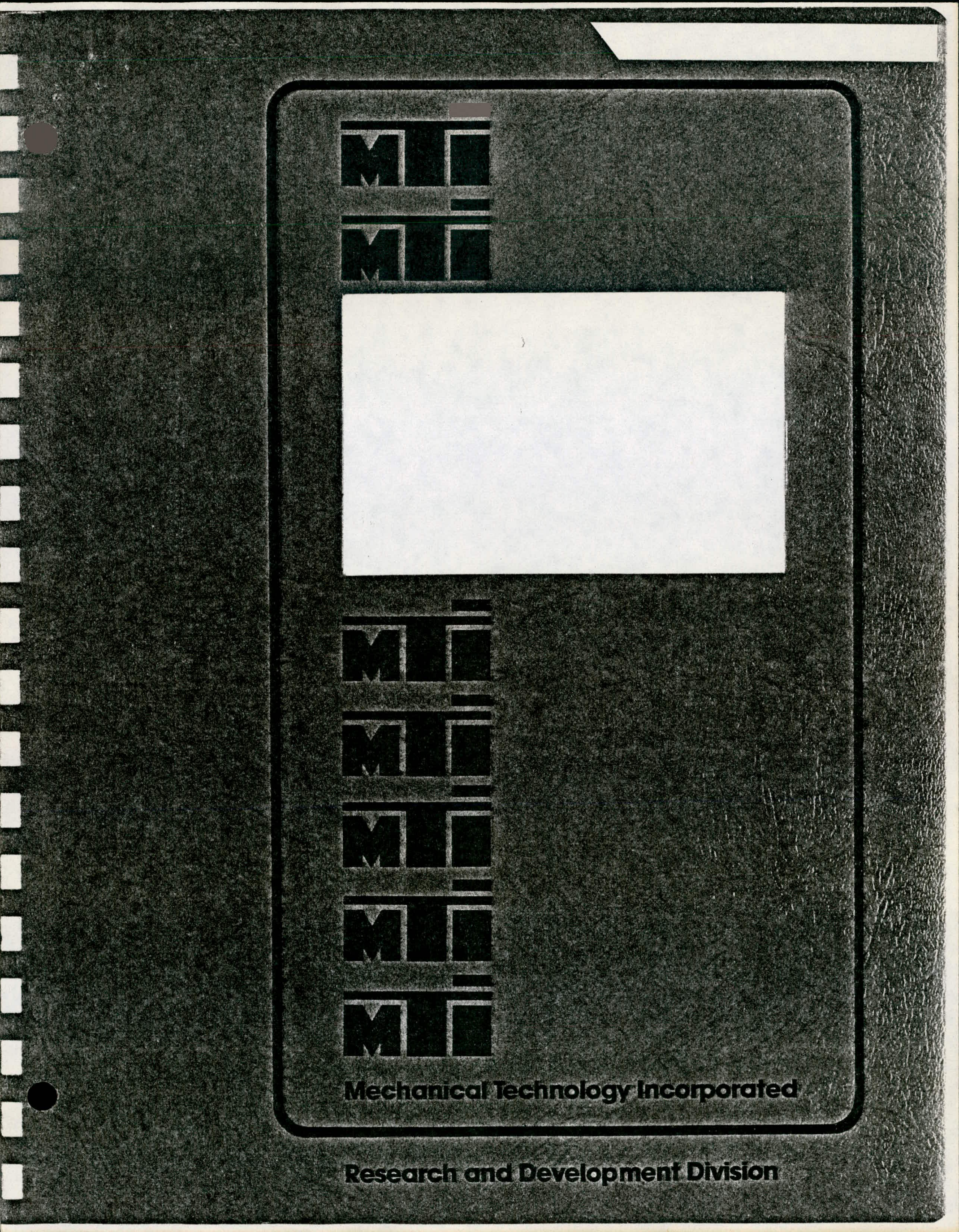


MTI $78 T R 112$

COMMERCIAL BOILER SYSTEM AND CYCLONE SEPARATOR TFCHNOLOGY FOR MHD

\author{
Prepared For: \\ Department of Energy
}

Növember, 1978

MECHANICAL TECHNOLOGY INCORPORATED

968 Albany-Shaker Road

Latham, New York 12110 
MTI 78TRI12

COMMERCIAL BOILER SYSTEM AND CYCLONE SEPARATOR TECHNOLOGY FOR MHD

Prepared For:

Department of Energy

Prepared Under:

Contract No. ET-78-C-01-2688

November, 1978

MECHANICAL TECHNOLOGY INCORPORATED

968 Albany-Shaker Road

Latham, New York 12110 


\section{ABSTRACT}

Current conceptual designs of Magnetohydrodynamic (MHD) Electrical Power Generating Stations are open cycle systems which include the use of a Rankine cycle bottoming system in combination with the MHD loop. The high temperatures and presence of significant amounts of alkali metal compounds are items of concern for the Rankine cycle equipment. In this report, currently available commercial boiler systems and cyclone separations are reviewed. The applicability of. this technology to an MHD system is assessed, and development requirements identified. This report is divided into three sections: 1.0 Black Liquor Boilers, 2.0 Slag Tap Boilers, and 3.0 Cyclone Separators. 
ABSTRACT. . . . . . . . . . . . . . . . . . . iii

LIST OF FIGURES . . . . . . . . . . . . . . . . . . . . v

1.0 BLACK LIQUOR RECOVERY BOILERS . . . . . . . . . . . . . . 1-1

1.1 Introduction . . . . . . . . . . . . . . . . . . . . . 1-1

1.2 Summary and Conclusions. . . . . . . . . . . . . $1-1$

1.3 Discussion . . . . . . . . . . . . . . . . . 1-3

1.3.1 Black Liqunr Prnress Description. . . . . . . . 1-3

1.3.2 Design Features .. . . . . . . . . . . . . . 1-3

1.3.3 Field Operation and Experience. . . . . . . . . . 1-8

1.3.4 MHD Requirements. . . . . . . . . . . . . . . . . 1-9

1.3.5 Technology, Voids and Development Requirements . . 1-10

REFERENCES FOR SECTION 1.0. . . . . . . . . . . . . . . . 1-12

2.0 SLAG TAP BOLlERS. . . . . . . . . . . . . . . . . . 2-1

2.1 Introduction . . . . . . . . . . . . . . 2-1

2.2 Summary and Conclusions. . . . . . . . . . . . . 2-1

2.3 Discussion . . . . . . . . . . . . . . . . 2-1

2.3.1 Furnace Design. . . . . . . . . . . . . . . . 2-1

2.3.2 MHD Requirements. . . . . . . . . . . . . 2-5

2.3.3 Technology Voids and Development Requirements . . 2-5

REFERENCES FOR SECTION 2.0................. . 2-7

3.0 CYCLONE SEPARATORS. . . . . . . . . . . . . . . . 3-1

3.1 Introduction . . . . . . . . . . . . . . . . . 3-1

3.2 Summary and Conclusions. . . . . . . . . . . . 3-1

3.3 General Cyclone Theory . . . . . . . . . . . . . . . 3-1

3.4 Cyclone Applications in the MHD System . . . . . . 3-6

3.4.1 Summary . . . . . . . . . . . . . 3-6

3.5 Existing Cyclone Capability. . . . . . . . . . . 3-9

3.5.1 Cyclones and Multi-Clones . . . . . . . . 3-9

3.5.2 Modified Cyclones . . . . . . . . . . . . 3-10

3.6 Technology Voids and Development Requirements. . . . . 3-17

REFERENCES FOR SECTION 3.0................ . 3-18 


\section{LIST OF FICURES}

Number

$\underline{\text { Page }}$

1-1 Kraft Recovery Process. . . . . . . . . . . . . . . . 1-4

1-2 Typical Recovery Unit Showing Reactions and Where They

Occur . . . . . . . . . . . . . . . . . . 1-5

2-1 Cyclone Furnace Design. . . . . . . . . . . . . . 2-3

3-1 Typical Cyclone Configuration . . . . . . . . . . . . 3-2

3-2 Cyclone Spin Speed. . . . . . . . . . . . . . . . . 3-3

3-3 Cyclone Fractional Collection Efficiency. . . . . . . . . 3-5

3-4 Percent Slag Carryover as Vapor as a Function of .

Temperature ................... . 3-7

3-5 Cyclone Performance Comparison. . . . . . . . . . . . . 3-11

3-6 Modified Cyclone Performance. . . . . . . . . . . . 3-12

3-7 Aerodyne Dust Collector . . . . . . . . . . . . . 3-13

3-8 Cyclocentrifuge, General Arrangement. . . . . . . . . . 3-15

3-9 Dynatherm Solids Separator. . . . . . . . . . . . 3-16 


\subsection{BLACK LIQUOR RECOVERY BOILERS}

\subsection{Introduction}

Black liquor recovery boilers utilized in the paper. industry operate with significant quantities of sodium sulfate $\left(\mathrm{Na}_{2} \mathrm{SO}_{4}\right)$, which is chemically similar to potassium sulfate compounds that will be encountered in the MHD system. Fouling and corrosion problems encountered in the Black Liquor System are indicators of the problems to be expected in the MHD system. Techniques to minimize these problems in black liquor boilers and their applicability to MHD are examined in this section.

\subsection{Summary and Conclusions}

There are certain features employed in black liquur boilers which have merit regarding applicability to the MHD steam tube banks. Designs by major manufacturers incorporate wide lateral spacing in the tube banks to minimize plugging due to fouling. Spacings similar to black liquor recovery boiler practices are desirable for the MHD system. The technique of tangent tube construction in the superheater region to minimize the projected surface area perpendicular to the gas flow should reduce fouling and corrosion/erosion problems. Tube rows in the black liquor superheaters are in line (not staggered), to similarly minimize projected area perpendicular to the gas flow. This technique should be considered for the MHD system. Parallel flow superheaters are used in black liquor units to ensure that the hottest gases encounter the coolest metal tube temperatures: This practice should also be considered for the MHD system.

Corrosion of water-wall tubes is typically encountered in the furnace hearth area. The severity is apparently little affected by application of refractory coating in this area, but rather is minimized by maintaining low tube wall temperatures.

One manufacturer's design, Combustion Engineering, (CE) permits superheater screen inlet temperatures in the range of $1900^{\circ} \mathrm{F}\left(1040^{\circ} \mathrm{C}\right)$. At these temperatures, molten sodium compounds would be present on the tubes at the front. 
of the superheater, and "sticky" deposits would occur further into the tube banks. Operation under these conditions apparently does not markedly effect either tube corrosion or fouling problems. The Babcock and Willcox design on the other hand, is based on a $1700^{\circ} \mathrm{F}$ superheater screen inlet temperature to minimize liquid/sticky deposits. Similar operating conditions are contemplated for the MHD superheater/reheater components.

The most critical concerns of the MHD system relative to the black liquor boiler are:

- Higher gas side and steam temperatures as envisioned in the ECAS and ETF studies. The possibility for corrosion, especially during transient periods of unbalanced steam/gas flow operation, is increased.

- The presence of coal slag constituencies also increases corrosion potential.

- Increased particulate loading. Fouline problems will be more severe due to loading on the order of 5 times higher in the MHD system.

- Presence of molten and sticky seed on the superheater tubes. Corrosion potential is enhanced with liquid seed, and fouling problems become more severe with "sticky" seed.

The following recommendations are made to increase the probability of success of the superheater-reheater-low temperature MHD component designs.

- Conduct small scale tests in a simulated MHD atmosphere.

- Continue the search for improved materials.

- Investigate the feature of gas quenching to eliminate either molten seed, or "sticky" seed problems as an alternative approach to current conceptual designs.

- Consider alternate means of secd removal, other than deposition on heat exchanger surfaces.

- Consider steam temperatures and pressures lower than WCAS and ETF levels for initial test train evaluation. 
These recommendations point to the need for a greatly expanded data base for the MHD heat recovery equipment. Testing conducted to date has not duplicated the actual MHD operating conditions; hence, very little materials data and essentially no fouling information is available. It is important that such information be obtained as soon as practical, utilizing such facilities as Argonne National Laboratory's TCTDF [12] test facility, UTSI and Mississippi State University Test Programs, and the coal combustor development facility at Pittsburgh Research Center.

\subsection{Discussion}

\subsubsection{Black Liquor Process Description ${ }^{[1]}$}

Black liquor is the solution resulting in the sulfate pulping process from dissolving the lignin binder which molds the cellulose fibers together in wood chips. The wood chips are "cooked" under pressure with steam, sodium hydroxide, and sodium sulfide. During this cooking process, the lignin is dissolved in the cooking solution, which is then known as black liquor. The black liquor is then recycled for repeat use as a cooking liquor through several processes shown in the schematic in Figure 1-1. The boiler serves to burn of $f$ the organic compounds in the black liquor and convert the sodium sulfate ( $\mathrm{Na}_{2} \mathrm{SO}_{4}$ ) to sodium carbonate $\left(\mathrm{Na}_{2} \mathrm{CO}_{3}\right)$ and sodium sulfide $\left(\mathrm{Na}_{2} \mathrm{~S}\right)$.

The basic principles of operation of a typical boiler are depicted in Figure 1-2. [2] Black liquor ( 65 percent solids) is sprayed on the furnace wall for drying to evaporate the water remaining in the solution. The dried solids fall to the hearth area of the furnace for combustion. A reducing atmosphere is maintained in the hearth area to accomplish conversion to sodium sulfide. Additional air is added in other sections above the hearth in different locations to complete combustion and promote drying of the black liquor sprayed onto the furnace walls. The chemical reactions that occur in given areas are also shown in Figure 1-2.

\subsubsection{Design Features}

1.3.2.1 Furnace. There are several different philosophies utilized for the recovery boiler furnace design. The "oster-Wheeler Copeland Systems design [3] 


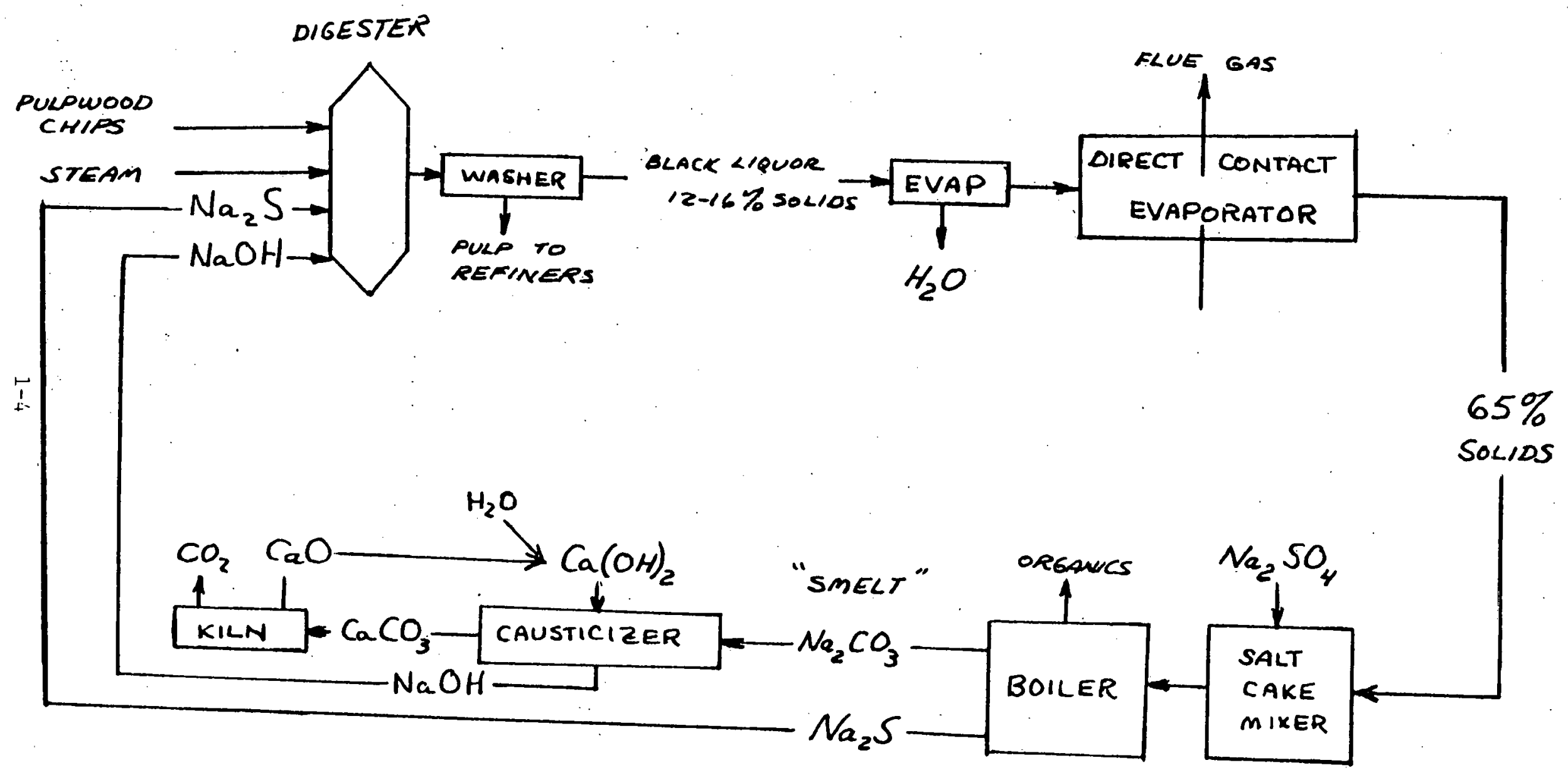

Fig. 1-1 Kraft Recovery Process 


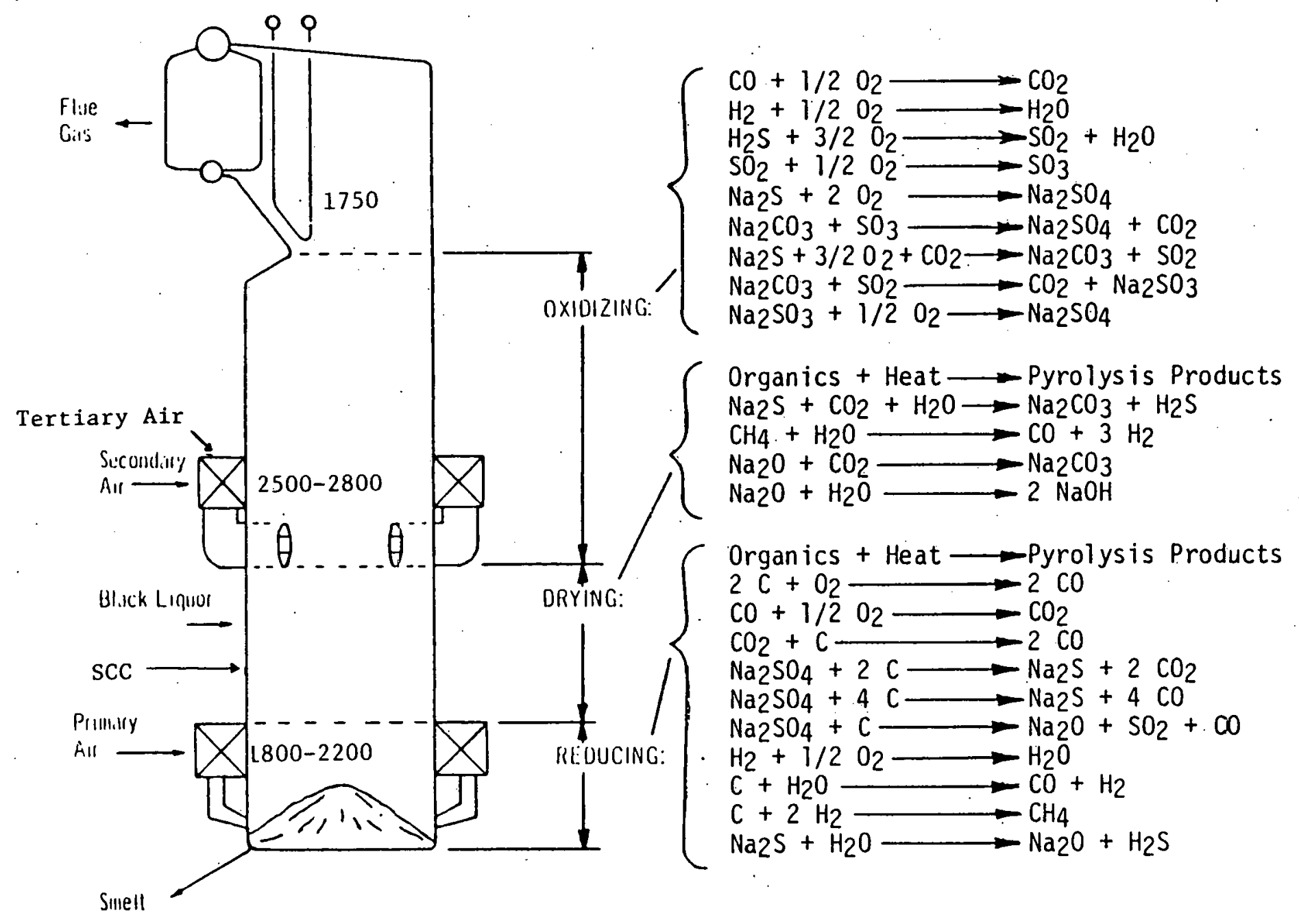

Fig. 1-2 Typical Recovery Unit Showing Reactions and Where They Occur, Reference [13] 
THIS PAGE

\section{WAS INTENTIONALLY LEFT BLANK}


All designs incorporate a sloping floor to minimize smelt pool formalion.

1.3.2.2 Tube Banks. The different design features are shown below in Table 2-2.

TABLE I-2

\begin{tabular}{|c|c|c|}
\hline & $\underline{B} \& W^{[5,6]}$ & $\underline{C E}^{[4]}$ \\
\hline $\begin{array}{l}\text { S/H } \\
\text { (Spacing, Lateral/Fore } \& \text { Aft })\end{array}$ & $12^{\prime \prime} / 3^{\prime \prime}$ & $\begin{array}{l}12^{\prime \prime} / 0 \\
\text { (tangent tube) }\end{array}$ \\
\hline Boiler Bank & 6"/4" & $9^{\prime \prime} / 5 \quad 1 / 2 " 1$ \\
\hline Economizer & $8^{\prime \prime} / 4^{\prime \prime}$ & $4^{\prime \prime} / 71 / 2^{\prime \prime}$ finned \\
\hline Steam Flow & Parallel & Parallel \\
\hline Temperature in: & & . \\
\hline Superheater (Slag Screen) & 1700 & 1900 \\
\hline Boiler Bank & 1300 & 1200 \\
\hline Economizer & 750 & $700-750$ \\
\hline
\end{tabular}

Similar wide lateral spacings are used in the superheater designs by both manufacturers to minimize the possibility of fuuling when ash deposits build up. The CE superheacer design incorporates a tangent tube construction (tube wall surfaces in contact in the direction of gas flow) to minimize projected surface area perpendicular to the gas flow. This philosophy was chosen because the most severe ash deposition usually occurs on surfaces perpendicular to the gas flow due to impingement. Gas velocities through the superheater are on the order of $10 \mathrm{ft} / \mathrm{sec}$ for all designs. The most significant design feature of the $C E$ unit is the superheater inlet temperature level. At the $1900^{\circ} \mathrm{F}$ inlet temperature, deposits on the initial rows of the superheater slag screen tubes are liquid. (The tube wall temperatures are on the order of $700-800^{\circ} \mathrm{F}$ so that, later, a solid ash is maintained adjacent to the tube surface.) Further into the superheater bank, the gas temperature passes through the ash solidification temperature of $\sim 1600^{\circ} \mathrm{F}$. For several rows thereafter, sticky ash deposits result. The deposits apparently do tend to fall off (with soot blower assistance) before fouling occurs. The soot blowers actually blow upstream to enhance removal of the deposits. In the economizer bank, the CE design incorporates finned tubes (in the gas flow direction) to direct the flow and minimize ash deposition. The gap between fins is approximately $1 / 2$ inch. [4] 


\subsubsection{Field Operation and Experience}

Several paper companies were contacted (see References 13-18) to determine user experience in the field. The major problem areas were corrosion of the waterwall tubes in the lower part of the furnace and fouling in the superheater sections. The possibility of explosions occurring, due to smelt/water reactions caused by tube leakage in the lower furnace, dictates that frequent boiler inspections be made. The majority of users inspect boilers twice annually, with Crown-Zellerbach inspecting thrice annually on major holidays. Inspection shutdowns require three to four days (minimum) for inspection alone. All water/steam tubes are inspected during the shutdown, utilizing ultrasonic and radiographic techniques. Occasionally the front ruws of superheater tubes require cleaning during shutdown due to buildup of hard deposits formed by molten/sticky salts during load fluctuations. Most users attempt to keep superheater slag screen entrance temperatures in the $1400-1600^{\circ} \mathrm{F}$ range to avoid such problems but occasional load fluctuations cause higher inlet temperatures and occasional shutdowns are required due to fouling. (It should be noted that the inlet temperatures to the superheater are not monitored, but settings are established via monitoring superheater exit temperatures.)

In the contrast to the practice followed by most users, the Hudson Pulp \& Paper Company (Palatka, Florida) has a relatively new CE boiler (1250 psi, $900^{\circ} \mathrm{F}$ steam) that is operated at rated load continually. At rated load conditions, slag screen entrance temperature is $1900^{\circ} \mathrm{F}$, and superheater entrance temperature is $1650^{\circ} \mathrm{F}$ (CE design values). The boiler was operated from December 1976 to December 1977 with no shutdowns. During the inspection period, hard deposit layers were removed from the slag screen and initial bank of superheater tubes, which would indicate that liquid smelt had been present on the tubes during operation. No fouling problems were encountered during the one year operational period.

The reason for the difference in fouling experience with this boiler, relative to other boilers, could not be determined from the users or from the manufacturer. The superheater and soot blower design does not differ markedly from older designs that reportedly have fouling problems. A more detailed investigation into specific boiler and soot blower operational procedures would be required to ferret out the differences. 
Insofar as furnace water-wall tube corrosion is concerned, the industry feels that duplex tube configurations are necessary for stcam pressures in excess of $850 \mathrm{psi}$. The Sandivik tube would be selected by the industry for these conditions. It consists of a carbon steel inside tube for pressure carrying and a 316 stainless steel outside shell for corrosion resistance.

\section{$\underline{1.3 .4 \mathrm{MHD} \text { Requirements }}$}

The principal differences between the Black Liquor Recovery Boiler Systems and the contemplated MHD designs are listed in Table 1-3 below and discussed in the following paragraphs.

$\underline{\text { TABLE } 1-3}$

\begin{tabular}{|c|c|c|}
\hline Item & Black Liquor & MHD Steam Cycle (ETF/ECES) \\
\hline Steam Temperature/Pressure & to $925^{\circ} \mathrm{F} / 1500 \mathrm{psi}$ & $1000^{\circ} \mathrm{F} / 3700 \mathrm{psi}$ \\
\hline $\begin{array}{l}\text { Primary Ash/Coristituents } \\
\text { Slag }\end{array}$ & $\mathrm{Na}$ Compounds & $\begin{array}{l}\mathrm{K} \text { compounds and } \\
\text { coal slag }\end{array}$ \\
\hline Maximum Gas Temperature & $2800^{\circ} \mathrm{F}$ & $3650^{\circ} \mathrm{F}$ \\
\hline $\begin{array}{l}\text { Gas Temperature to Steam } \\
\text { Tubes }\end{array}$ & $1900-2000^{\circ} \mathrm{F}$ & to $3000^{\circ} \mathrm{F}$ (ETF/ECAS) \\
\hline $\begin{array}{l}\text { Particulate Loading into } \mathrm{S} / \mathrm{H} \\
\text { Grains } / \mathrm{ft}^{2} / \mathrm{sec}\end{array}$ & 18 & 77 \\
\hline Melting Point ${ }^{\circ} \mathrm{F}$ & $\begin{array}{l}\mathrm{Na}_{2} \mathrm{CO}_{3}-1563 \\
\mathrm{Na} \mathrm{SO}_{4}-1625\end{array}$ & $\begin{array}{l}\mathrm{K}_{2} \mathrm{CO}_{3}-1645 \\
\mathrm{~K}_{2} \mathrm{SO}_{4}-1955\end{array}$ \\
\hline
\end{tabular}

The increased steam requirements for the MHD system create concern for steam tube corrosion in the superheater region. The limited available data indicate that corrosion of tube materials at metal temperatures in excess of $1100^{\circ} \mathrm{F}$ in the presence of smelt, similar to that anticipated in the MHD system, could be extremely severe $[7,8,9,10,11]$. Any transient unbalances which either increase the heat load to the steam tubes, or decrease the heat transfer rate on the steam side, will increase corrosion potential. The higher gas temperature also increases the potential for corrosion during temporary steam side imbalances.

The presence of coal slag in the MHD system, in addition to the potassium compounds, adds further complexity to the corrosion problems due to several factors such as effects on the potassium compound melting temperatures and presence of 
additional trace elements in the system. There is a meiger data base available to understand and predict the reaction of tube materials in the MHD environnent for lengthy exposures and with cyclic effects caused by startup and shutdown that would be expected in the operation of the system.

Superheater fouling problems in the MHD system can be expected to be more severe than those encountered in black liquor boiler operation. The particulate loading in the MHD system is anticipated to be much higher than the black liquor boiler, as noted in Table 1-3. Although the fouling tendencies of $\mathrm{K}_{2} \mathrm{SO}_{4}-\mathrm{K}_{2} \mathrm{CO}_{3}$ are not clearly defined, again due to lack of data, it is expected that it will exhibit tendencies similar to the deposits in the Black Liquor Systems. Experiences in the Russian MHD effort and at the Pittsburgh Energy. Research Center have indicated that severe fouling problems can be anticipated. [7] In addition to the quantity of ash, the temperature range of the gas in the superheater/reheater banks will result in formation of molten and "sticky" deposits as the gas temperature falls through the $\mathrm{K}_{2} \mathrm{SO}_{4}-\mathrm{K}_{2} \mathrm{CO}_{3}$ solidification temperature.

\subsubsection{Technology Voids and Development Requirements}

There are several areas where technology advancements or alternate approaches may be required for the MHD system, namely: (1) new materials, (2) deposit removal techniques, (3) recycle gas mixing systems, and (4) development of alternate seed removal techniques other than by deposition on steam tube surfaces. It would appear that scaled tests should be conducted at the earliest possible time to confirm or deny the need for these development items.

From the standpoint of materials corrosion in the steam tube banks, the data can be accumulated, prior to the testing of a full steam train system, by utilizing facilities at the Pittsburgh Energy Research Center (PERC) currently being used for the development of an MHD coal combustor. Tube material sample tests have been conducted in the past in this facility, and could again be conducted as an add-on item to the current program. The test component and teclinology development facility at Argonne National Laboratory ANL, currently under construction, is targeted to conduct tests of tube type heat exchangers in simulated MHD atmosphere in the near future. Early sample testing in the PERC facility could provide guidance to the ANL program. 
As an alternate to the current conceptual design approach with liquid and sticky seed deposits in the steam tube banks, it is recommended that the concept of recycle gas mixing be pursued. In the event that corrosion and. deposit removal in the sticky form are severe problems, gas quenching temperatures on the order of $1700^{\circ} \mathrm{F}$ could provide relief. Conceptual development of a quenching process utilizing recycled stack gas should include an economic assessment to evaluate additional power requirements, increase in heat exchanger surface requirements, and overall cycle effects.

An additional alternate approach to the seed deposition problem would be via removal of seed by techniques that do not involve the use of heat exchanger tube materials. Conceptual designs could be developed to utilize devices such as cyclones, expansion wave techniques, or moving bed filters. The applicability of any of these approaches is dependent on characterization of the deposit and again emphasizes the need for testing at an early date. The economics of the alternate removal techniques, as in the case of gas quenching, must also be assessed. 


\section{REFERENCES FOR SECTION 1.0}

1. Steam - "Its Generation And Use", Babcock and Willcox, 38th Edition.

2. Assessment of "Black-Liquor", Boilers Gilbert Associates, Inc. March, 1978.

3. Personal Communication, William: Kelly, Foster Wheeler Corporation.

4. Personal Communication, George Prohaska, Combustion Engineering.

5. "Functional and Mechanical Aspects of a Modern Recovery Boiler Design", J.D. Blue, Babcock and Willcox.

6. Personal Communication, Neil Eft, Babcock and Willcox.

7. "Corrosion of Heat-Exchange Tubes in a Simulated Coal-Fired MHD System" D. Bienstock, et. al., ASME No. 70-WA/CD-3 (1.970).

8. Personal Communication, Dr. Donald Muzyka, Mgr. - Carpenter Technology, R\&D Division.

9. 'Corrosion of Superheaters and Reheaters of Pulverized Coal-Fired Boilers", W. Nelson and C. Cain Jr.; Trans. ASME, 82:194 (1960).

10. Personal Communication, Arthur P. Fraas, MTI Consultant.

11. Personal Communication, James McGee, MTI Consultant.

12. "Program Plan for Development of MHD.Balance of Plant Components", Argonne National Laboratory, September 1977.

13. Personal. Communication, Frank Moulton, Crown Zellerbach.

14. Personal Communication, Ralph Mason, Weierhauser.

15. Personal Communication, Gerald Drotter and Tom Condon, International Paper, Ticonderoga, N.Y.

16. Personal Communication, George Nelson, International Paper, Natchez, Miss.

17. Personal Communication, Sheldon Mader, Westvaco.

18. Personal Communication, Robert Millikan and Joseph Conner, Hudson Pulp and Paper, Palatka, Florida. 


\subsection{SLAG TAP BOILERS}

\subsection{Introduction}

Slag tap boilers are coal-fired systems which operate with liquid slag in the furnace. Liquid coal slag will also be present in the radiant boiler section of the MHD Downstream Heat Recovery System. A review of existing slag tap boilers was conducted to define current problem areas, and identify technology requirements for the MHD radiant boiler.

\subsection{Summary and Conclusions}

Slag tap boilers operate successfully in utility atmospheres with a one-year. operational period between shutdowns. The combustion gas in the MHD System, however, is expected to be more corrosive and may require more frequent shutdowns. Based on industry experience and materials testing, it is anticipated that corrosion problems can be minimized by control of waterwall tube temperatures through steam cycle selection. Experimental testing should be conducted to ascertain the magnitude of the corrosion problem. Slag tap boil.er construction/design techniques that should be retained for the MHD system are sloping furnace floor and studded wall construction.

\subsection{Discussion}

\subsubsection{Furnace Design}

There are two basic types of slag tap boilers - pulverized-coal-fired and cyclone furnaces. These two designs are discussed in the following paragraphs.

2.3.1.1 Pulverized-Coal-Fired Boilers. [1,2] The concept of coal pulverization was initiated with the desire to promote a more rapid, fully mixed combustion process than that normally obtained in grate-fired, crushed-coal furnaces. The coal is pulverized to a fine "dust" and pneumatically injected into the furnace, with the finer coal particle size and turbulence created by injection, enhancing the combustion process. The formation of a liquid slag pool in the furnace occurred as an incidental result of this clesign, due to the higher combustion temperatures obtained. It was discovered that the liquid slag pool was desirable as a result of reduction of ash carry-over to 
the exhaust stack (40-50 percent for the pulverized coal furnace cuilipared to 80 percent for typical dry-ash boilers). New furnace problems arose, however, with the formation of a liquid slag pool: 1) increased corrosion resulted in the hearth area, and 2) techniques had to be developed to achieve effective liquid slag removal. The problem of corrosion still exists but is minimized through use of sacrificial stud walls, refractory coatings and maintenance of tube wall temperatures in the area of $600^{\circ} \mathrm{F}$. Slag removal problems have been decreased by the use of a sloping floor in the furnace, enlarged slag taps, and location of the pulverized-coal injectors so that the coal is fired directly at the slag tap hole. This last technique ensures that the maximum furnace temperature uccurg at the tap to provide the lowest possible slag viscosity for removal purposes. Even with these precautions, occasional tap hole plugging occurs with high-slagging coals. In the final analysis, the pulverized-coal-fired furnace suffered from two undesirable features - tap hole plugging and use of a substantial amount of power required to pulverize the coal, thereby degrading overall station efficiency. These two drawbacks led to the development of the cyclone furnace discussed in the following paragraph. With the cyclone furnace successfully developed, production of pulverized-coal furnaces was terminated. Several of these furnaces are still in service at present.

\subsubsection{Cyclone Furnace. [1,2,3] The cyclone furnace was conceived to over-} come two deficits of the pulverized coal furnace: 1) to eliminate the need for pulverization, and 2) to provide better slag removal. The cyclone furnace operates with crushed coal, thereby reducing the coal, sizing power requirements. Increased fan power is required, however, with the resultant auxiliary net power about equal to that of pulverized-coal furnaces. The design of the cyclone furnace is illustrated conceptually in Figure 2-1. Coal is injected tangentially at the head of the furnace, along with combustion air. Swirl and turbulence in the cyclone furnace promote effective mixing and result in higher combustion temperatures than those obtained in the pulverized-coal furnaces. A liquid slag pool is formed in the cyclone and runs off into the main boiler, as shown in Figure 2-1. The cyclone is constructed with watercooled walls, and utilizes a ceramic wear liner for protection. Both corrosion, due to liquid slag, and erosion, due to coal particle abrasion, are experienced 


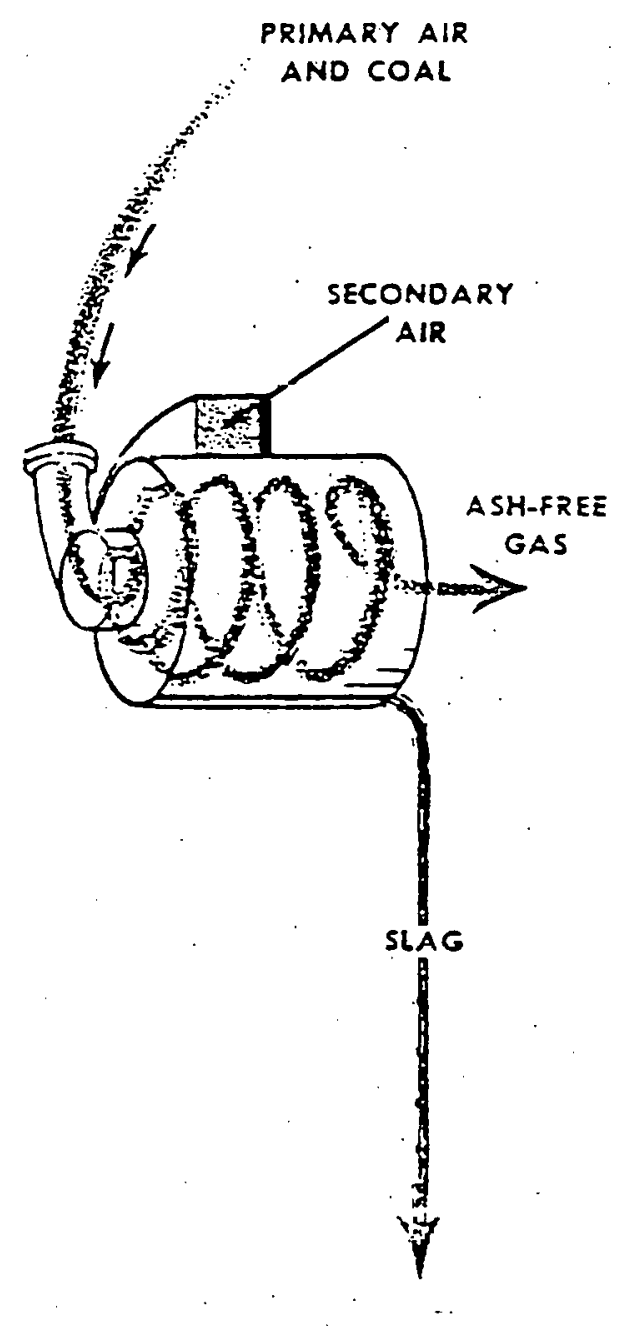

Fig. 2-1 Cyclone Furnace Design 
in the cyclone. The wear liner is designed for a continuous one-year furnace operational period. During the annual shutdown/maintenance interval, the liner is simply replaced. The main boiler section experiences corrosion problems similar to those encountered with the pulverized-coal furnaces. Here again, studded wall construction is used and refractory linings are applied. The cyclone furnace operates with approximately 10 percent excess air overall. Locally, however, under the slag layer, the atmosphere is reducing. [4] Several utility companies have experimented with various refractory coatings to enhance corrosion resistance, but all have found that the lining is completely consumed in the one-year operating period. Regardless of lining consumption, the unit does normally operate for one year without shutdowns. The waterwall tube corrosion is mainly controlled by sacrificial studs and maintenance of $-600^{\circ} \mathrm{F}$ maximum tubewall temperatures, as for the pulverized-coal furnaces. [5]

The temperatures encountered in the cyclone furnace are usually on the order of $3200^{\circ} \mathrm{F}$ in the cyclone and $3000^{\circ} \mathrm{F}+$ in the boiler furnace. It should be noted here that, although these temperatures are somewhat higher than those encountered in the pulverized-coal furnaces, the overall corrosion effects are similar. The materials of construction for both furnaces are the same, and both inits operate for one year between shutdowns.

2.3.1.3 Convection Passage Design Philosophy. In coal-fired furnaces of all types, the ground rule used for the boiler design is to lower the radiant (waterwalled) furnace gas temperature to a level below the initial deformation temperature of the particular coal being burned. There are two reasons for this approach. First is the concern for heat exchanger surface fouling. Reduction of the gas temperature below the initial deformation temperature of the coal ash is desirable, so that the ash deposited on the tube banks will be non-sticky and, hence, easier to remove. Secondly, there is concern for corrosion with the presence of fluid ash on heat exchanger surfaces at elevated temperatures. $[5,7,8]$ Experience has indicated that presence of liquid slag on heat exchanger metallic surfaces, at temperatures in excess of $1000^{\circ} \mathrm{F}$, causes corrosion severe enough that this practice is avoided in commercial installations. 


\subsubsection{MHU Requirements}

Current conceptual designs for the MHD Heat Recovery System call for a radiant boiler section immediately downstream of the MHD Channel-Diffuser Exit. The conditions of the combustion stream at this point are more severe than normally encountered in existing commercial coal-fired boiler systems. The major concerns are: 1) higher temperatures, and 2) a more complex and corrosive slag. The MHD radiant boiler entrance temperatures are expected to be on the order of $3700^{\circ} \mathrm{F}, 600-700^{\circ} \mathrm{F}$ hotter than cyclone boiler furnace temperatures. The atmosphere in the boiler will be reducing, similar to conditions under the slag layer in the cyclone furnace. However, the increased potassium salt content of the gas stream is of concern from the corrosion standpoint. The planned MHD steam conditions of $3800 \mathrm{psia}$ and $1005^{\circ} \mathrm{F}$ will require steam temperatures of $800^{\circ} \mathrm{F}$ at exit from the radiant boiler. [6] This will result in waterwall tube metal surface temperatures in excess of $800^{\circ} \mathrm{F}$. Experience has indicated that corrosion of carbon steel tubes at this temperature will be a problem, and raises concerns relative to life characteristics of the MHD System.

Based on industry experience with existing systems, it seems advisable to adopt techniques which have been proven successful commercially. The concept of studded wall construction should be maintained to minimize the amount of corrosion experienced on tube waterwalls, utilizing the studs as sacrificial material. The sloping floor cuncept should also be maintained to enhance slag drainage and prevent slag-pool buildup. Finally, industry waterwall tube corrosion experience as a function of steam cycle selection should be reviewed, and the MHD desired conditions as envisioned in the ECAS studies should be revised as necessary, as development progresses to ensure successful MHD System commercial life.

\subsubsection{Technology Voids and Development Requirements}

The technology voids identifiable for the MHD radiant boiler section, compared to current coal-fired boilers, are corrosion oriented. Materials and coatings with increased corrosion resistance are desirable for the MHD System. As noted earlier in this report, the corrosion anticipated for the MHD radiant boiler is expected to be essentially a function of the selected steam conditions. To ascertain this, it is recommended that tests be conducted as early as possible 
to guide the overall MHD program. Tests planned at UTSI, Mississippi State, and Argonne National Laboratory are expected to provide this needed information. Additional data could be obtained utilizing the coal combustor development facility at the Pittsburgh Energy Technology Center.

There are additional, unique requirements for the MHD radiant boiler that are not addressed in current boilers. High $\mathrm{NO}_{x}$ concentrations are antictpated in the MHD System, and current conceptual designs utilize the radiant boiler to decompose $\mathrm{NO}_{x}$ through controlled cooling rates. Preliminary data from tests at UTSI indicate that NO $_{x}$ emissions are controllable in this manner; however, additional testing would be helpful to determine the effect of variables such as scaling, stoichiometry, and combustion temperatures. The attainment of slag removal and seed separation in the boiler through temperature control is also a concern. Economic studies have indicated that on the order of 95 percent of the seed material must be recovered for recycling purposes. Testing must be conducted to verify that this separation can be achieved. 
1. "Steam - Its Generation and Use", Babcock and Willcox, 38th Edition.

2. Personal Communication, Neil Eft, Babcock and Willcox.

3. "The Cyclone Furnace", Babcock and Willcox.

4. Personal Communication, Warner Sage, Babcock and Willcox.

5. Utility Companies Surveyed
a. Commonwealth Edison, Chicago, Illinois
b. TVA, Chat tanooga, Tennessee
c. Illinois Power, Chicago, I11inois
d. Otter Teal Plant, Beachston, Minnesota
e. Ohio Edison, Akilor, Ohio
f. Tampa Electric, Tampa, Florida

6. "Overall Plant Design Description, Baseline Plant Open Cycle MHD-Steam Cycle Power Loop", Gilbert Associates/STD Research Corporation.

7. "Corrosion of Superheaters and Reheaters of Pulverized-Coal-Fired Boilers", W. Nelson and C. Cain jr., Trans. ASME 82:194 (1960).

8. "Corrosion of Heat Exchange Tubes in a Simulated Coal-Fired MHD System", D. Bienstock et al., Trans. ASME Paper 70-WA/CD-3, 1971. 


\subsection{CYCLONE SEPARATORS}

\subsection{Introduction}

This report is a survey of cyclone equipment feasibility for liquid and solids removal in the MHD steam bottoming plant. Cyclone theory is reviewed, potential uses for cyclones are discussed, the capabilities of currenily available equipment are assessed, and recommendations for development are presented.

\subsection{Summary and Conclusions}

Standard cyclones lack capability to effectively separate particulate matter with particle sizes of five microns or less. Development of modified cyclones that utilize aerodynamic or mechanical means of separation enhancement could be of interest to the MHD system in two areas, (1) seed separation prior to superheater entrance, and (2) flyash/seed separation at the econometer exit. Seed separation at the superheater entrance could be attractive to decrease superheater tube plugging. However, the elevated temperatures, corrosive atmosphere, and small particulate sizes anticipated would indicate that extensive development would be required. Development of improved efficiency collectors for flyash/seed collection at the economizer outlet could be helpful in reducing the load on electrostatic precipitators. The economic impact of these devices should be assessed if development is contemplated.

\subsection{General Cyclone Theory $[3,4]$}

The basic principle of operation of cyclones is to impart a spin to the gas stream, creating a vortex to separate solids by centrifugal force. A sketch of a typical cyclone is shown in Figure 3-1.

Air enters through the tangential inlet, spirals downward, and exits upward through the discharge duct in a strong vortex. Particle separation that can be achieved in a cyclone is dependent primarily on the following factors:

- Particle size

- Particle density

- Gas viscosity

- Vortex spin speed 


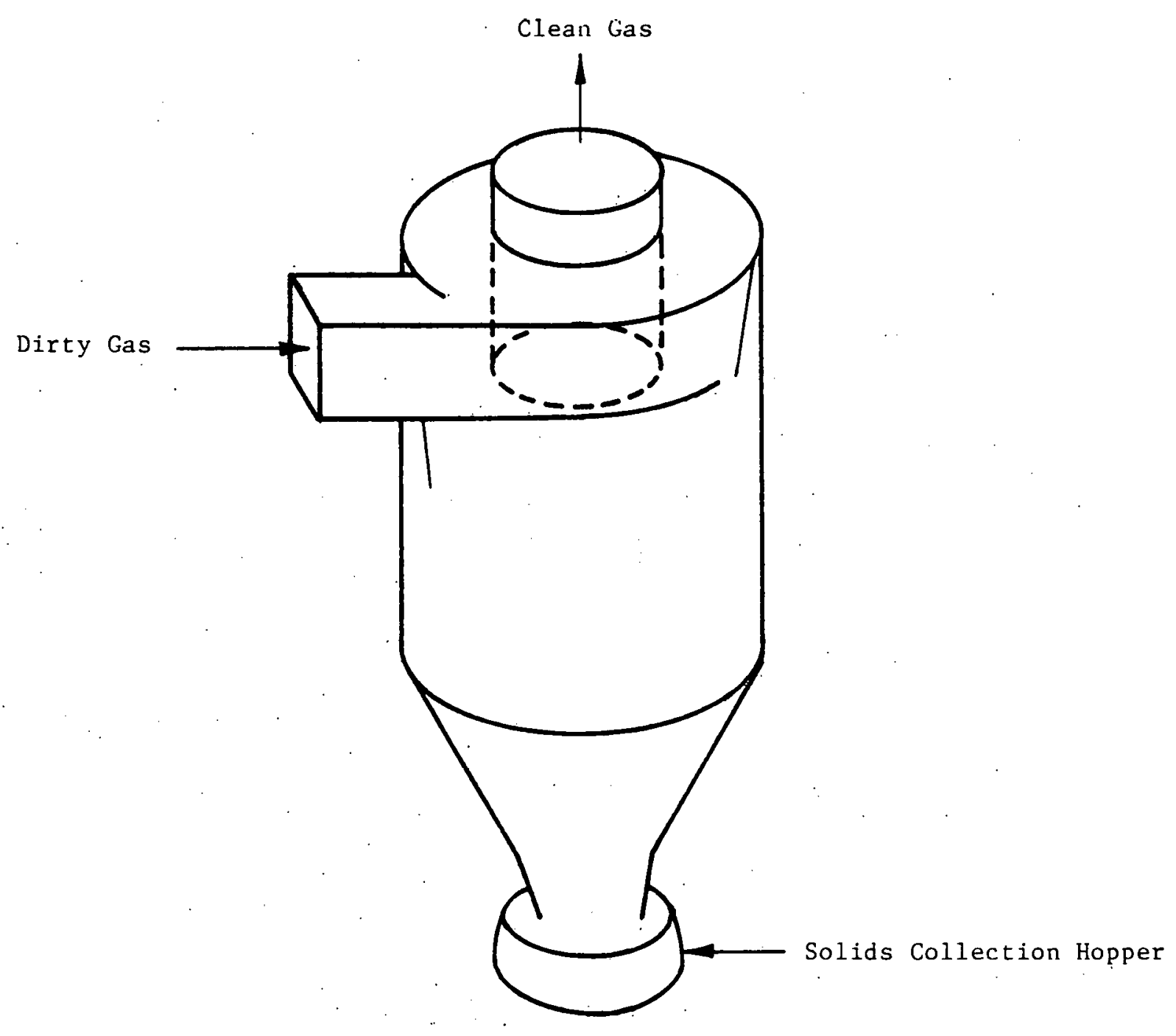

Fig. 3-1 Typical Cyclone Configuration 
Theoretically, for a given cyclone design with a fixed particle density, gas density, and gas viscosity, there is a minimum particle size (referred to as the "cut" size) that can be collected. The "cut" size is determined by calculating viscous drag and centrifugal forces acting on the particles, and determining the particle size at which these forces are equal. All smaller particles will drift inward with the gas flow and will escape, whereas all larger particles will be separated. The "cut" size calculation is illustrated below:

Spin Speed: The centrifugal force generated in a cyclone is a function of the spin speed, which is in turn a function of throughput mass flow, and cyclone geometry. For a selected geometry, and flow rate, the cyclone spin speed has been experimentally determined to be represented by two different relationships as shown in Figure 3-2.

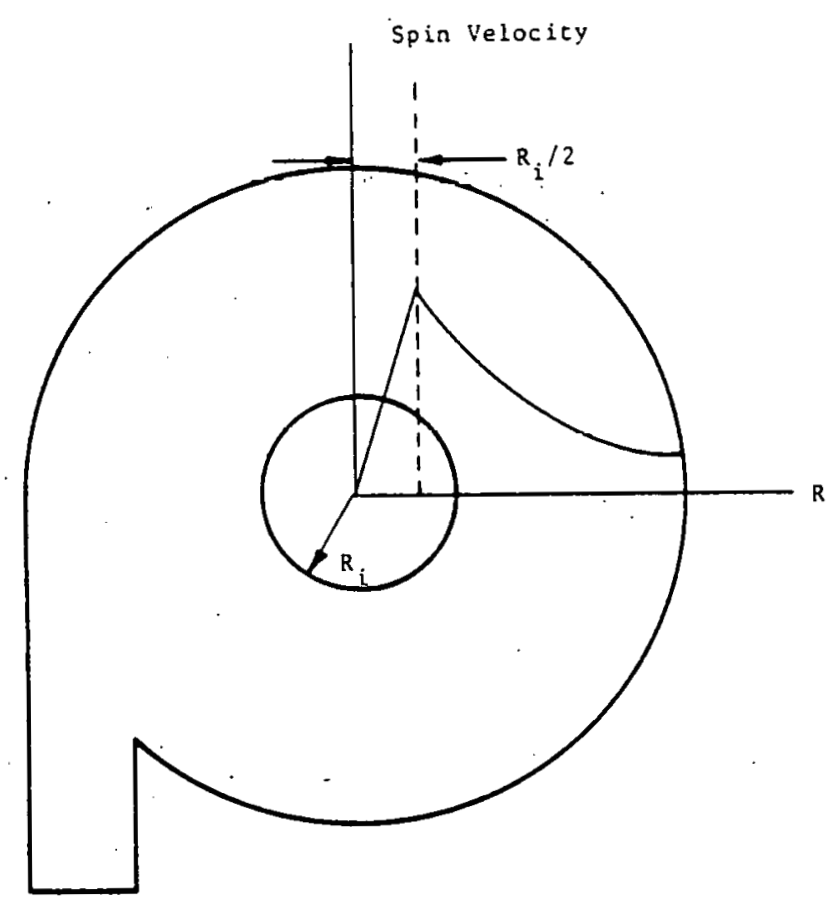

79654

Fig. 3-2 Cyclone Spin Speed 
The inner core gas spins at constant angular velocity, and the outer gas according to the relationship $U^{2} R=$ Constant.

Centrifugal Force - The centrifugal force generated $=\frac{U_{T}}{R}$, and is a maximum at $R / 2$.

Inward Drift Velocity - The inward drift velocity is a function of mass-flow rate and cyclone geometry, and is calculated as follows:

$$
\begin{aligned}
& W=\rho^{A V} \\
& V=\frac{W}{\rho A}=\frac{\dot{\mathrm{m}}}{2 \frac{\mathrm{R} \cdot \mathrm{h}}{2}}
\end{aligned}
$$

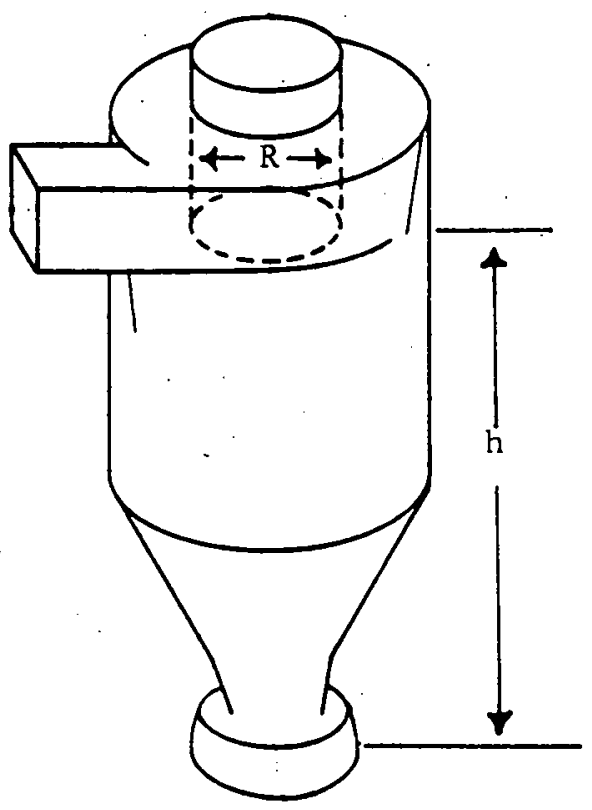

Cut Size Calculation - At the location where maximum centrifugal force is generated, ( $R / 2$ in the preceding figure) the drag force on the "cut" size particle, due to the inward drift, will be exactly equal and opposite to the centrifugal force. The situation is analogous to one wherein a drag force counterbalances a gravitational field of magnitude equivalent to the centrifugal force. The cut size particle, then, in 19 field would free fall at the velocity $V_{F F}=\frac{V_{\text {Inward }}}{\text { Cent Force }(g s)}$ 


$$
\begin{aligned}
& \text { At free fall conditions }(V=K) \\
& \text { Drag }=\text { Gravitational Force } \\
& 6 \pi \mu r_{p}=m a=\rho \frac{4}{3} \pi r_{p}^{3} a
\end{aligned}
$$

Therefore, for a given particular density, the "cut" size is. determined. The theoretical separation should then be 100 percent for all larger particles and 0 percent for all smaller particles. Due to particle collisions and agglomerations, however, some smaller particles will be collected, and conversely, due to secondary flow fields and wall bounce effects, some larger particles will escape. The resultant collection efficiency curve, then, is shown typically in Figure 3-3.

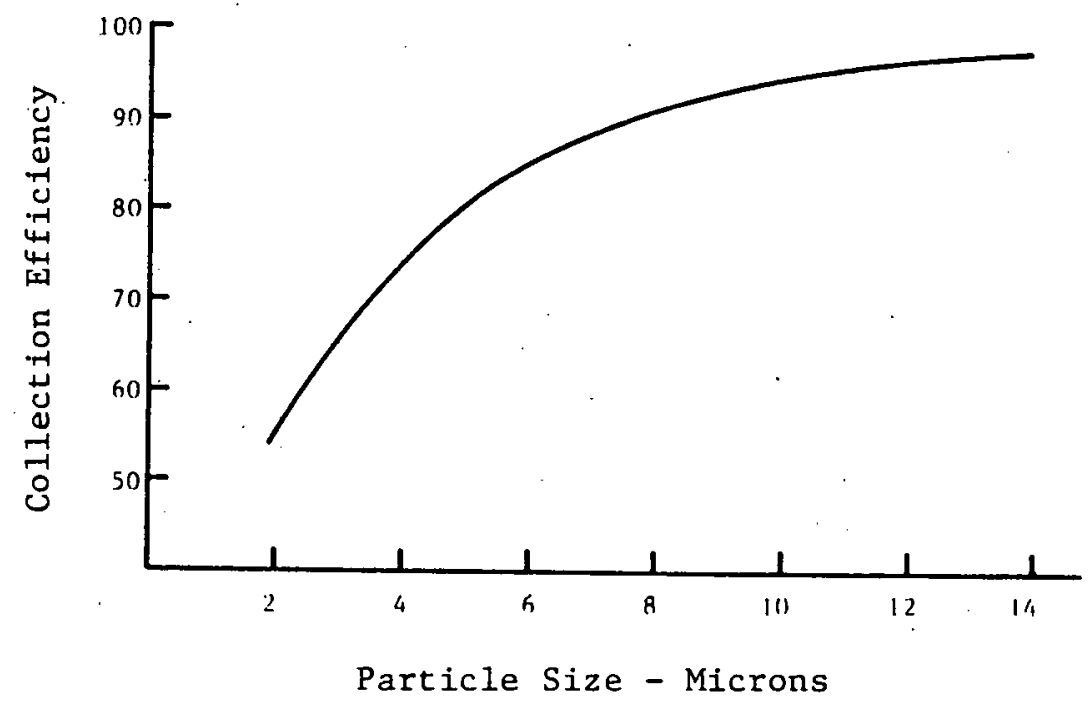

i9655

Fig. 3-3 Cyclone Fractional Collection Efficiency

The effect of various design parameters on the collection efficiency curve is presented qualitatively in Table $3-1$.

\section{TABLE 3-1}

\author{
Parameter Increase \\ Particle Density \\ Cyclone Diameter \\ Gas Viscosity \\ Inlet Velocity
}

\section{Efficiency \\ Increases \\ Decreases \\ Decreases}

Increase then Decrease 


\subsection{Cyclone Applications in the MHU System}

\section{$\underline{3.4 .1 \quad \text { Summary }}$}

There are several requirements for liquid and solid material separation in the MHD System. These requirements and the probable application of cyclones are summarized in Table 3-2 and are discussed. in detail in the following sections.

$\underline{\text { TABLE } 3-2}$

MHD SEPARATION REQUIREMENTS

\begin{tabular}{|c|c|c|c|}
\hline $\begin{array}{l}\text { Separation } \\
\text { Requirement }\end{array}$ & Temperature Range & Cyclone Potential & Problem Areas \\
\hline Slag (liquid) & $3000-3700$ & No & $\begin{array}{l}\text { No cyclones available } \\
\text { for this temperature. }\end{array}$ \\
\hline Seed (1iquid) & $2060-3200$ & No & $\begin{array}{l}\text { No cyclones available } \\
\text { for this temperature. }\end{array}$ \\
\hline Seed (solid) & $-1700^{\circ} \mathrm{F}$ & Yes & Particle size \\
\hline $\begin{array}{l}\text { Emission } \\
\text { Control }\end{array}$ & $200-400^{\circ} \mathrm{F}$ & Yes & Particle size \\
\hline Coai & $200^{\circ} \mathrm{F}$ & Yes & Particle size \\
\hline
\end{tabular}

\subsubsection{Slag Separation - The criteria of separate slag and seed recovery} dictates that slag removal must be accomplished at temperatures above the point where the seed vapors begin to condense. Current MHD system conceptual designs utilize a radiant boiler at the MHD channel exhaust to condense and remove the coal slag carried over from the combustor.

Use of a cyclone to achieve slag separation at this location presents several problems. First, the MHD channel exhaust temperatures currently contemplated are in the order of $3600-3800^{\circ} \mathrm{F}$. At this temperature, as much as 20 percent of the coal slag carried over into the radiant boiler [1] could still be vaporized (Figure 3-4) and would not be separated; therefore, this approach is considered impractical. Alternatively, the gas temperature could be reduced to $\sim 3000^{\circ} \mathrm{F}$, by quenching, to achieve slag condensation while leaving the seed in the vapor state. 


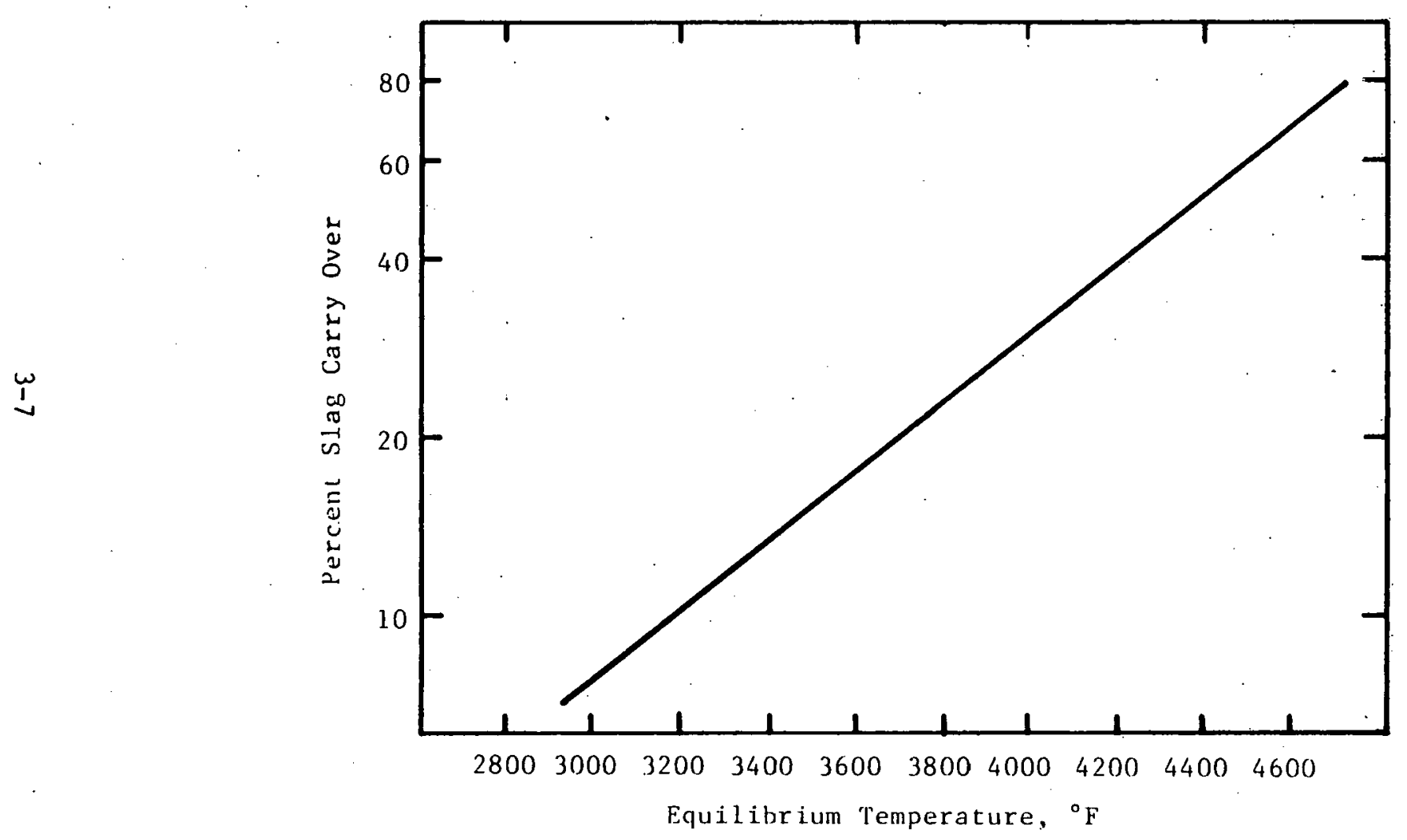

Fig. 3-4 Percent S1 ag Carryover as Vapor as a Function of Temperature

79656 
However, $\mathrm{NO}_{\mathrm{x}}$ control is achieved in current design concepts phrough decomposition with residence times of 2-3 seconds at temperatures in excess of $3000^{\circ} \mathrm{F}$. Quenching to $3000^{\circ} \mathrm{F}$ would not allow the required residence times and would result in $\mathrm{NO}_{\mathrm{x}}$ control problems.

If $\mathrm{NO}_{x}$ control could be achieved by other means, such as utilization of a decomposition chamber prior to radiant boiler entry, then quenching to $3000^{\circ} \mathrm{F}$ could be accomplished to promote slag condensation. However, there are no state-of-the art cyclones capable of operating at $3000^{\circ} \mathrm{F}$. Development would be required in the event that this approach is used.

It is concluded that the use of cyclones for slag separation in MHD systems is not practical for currently contemplated MHD systems. Alternate methods of ${ }^{N O} x$ control and cyclone development for temperatures of $3000^{\circ} \mathrm{F}$ would be required.

3.4.1.2 Seed Separation - Seed separation/removal from the gas stream is currently contemplated in both liquid and solid forms in the downstream sections of the stream bottoming plant (superheater, reheater, and low temperature air heater units). It is anticipated that removal of the deposited seed from the heat exchanger surfaces may be difficult and that corrosion may be a concern. Removal of seed by use of cylcones would reduce potential heat exchanger fouling problems and provide potentially easier-to-clean surfaces.

With base line plant operation at radiant boiler exit temperatures in the range of $2500-3000^{\circ} \mathrm{F}$, the combustion gas exiting the boiler will be essentially slag-free but will contain seed in the vapor state. The gas then must be quenched to get the seed into a liquid or solid form for separation. A temperature of $\sim 2000^{\circ} \mathrm{F}$ would be required to condense the seed vapor in a liquid form, and a temperature of $-1700^{\circ} \mathrm{F}$ would be required to sub-cool the particles in a solid state to the point where tackiness would not be a problem. Rapid gas quenching, however, may produce sub-micron, fume-like particles which would be difficult to separate. In addition, with quenching, the heat exchanger surface requirements are increased, but this approach may be attractive if heat exchanger seed removal is a serious problem.

The use of cyclones in this temperature range appears to be feasible. Several manufacturers have built cyclones for unique applications at temperatures 1800- 
$1900^{\circ} \mathrm{F}$. However, it is predictcd that seed particles will be small and collection will be difficult.

3.4.1.3 Exhaust Stack Cleanup - For some plant designs, ${ }^{[6,7]}$ the flue gas exiting the economizer section of the boiler is exhausted directly to the atmosphere. The flue gas will contain both flyash and seed particles which must be removed from the gas stream to enable effective seed recovery and reduce exhaust stack emissions. Here again, as in the case of seed removal further upstream, the particulate size and loading is as yet undetermined, but it is thought that the loading will be quite heavy, with smal1-to-medium size particles $(50 \text { percent } 12-15 \mu)^{[1]}$ or (50 percent $\left.3-10 \mu\right)^{[5]}$. With EPA standards permitting a maximum of .1 lb particulate emissions per $1 \mathrm{~m}$ Btu fuel input, collection efficiencies on the order of 99 percent will be required. A cyclone alone cannot provide sufficient removal to meet the standards, but it could be used to reduce the load on the prime collection mechanism (ESP or baghouse).

Other designs $[2,6,7]$ utilize the stack gas exiting the economizer for coal drying and transport. In this case, flyasi:/seed must be removed at the economizer exit, and coal particles must be separated from the flue gas after drying. The flyash/seed separation problem remains unchanged in this concept. The separation of coal particles presents an additional process requirement. The particulte loading will be very heavy and particle sizes relatively large. 'To separate as much of the coal as possible, a cyclone in series with a baghouse will most likely be used. This approach is attractive because most of the coal is removed in the cyclone, minimizing maintenance requirements associated with baghouse operations.

\subsection{Existing Cyclone Capability}

\subsubsection{Cyclones and Multi-Clones}

The principle of cyclone separation is dependent overwhelmingly on the balance between viscous and centrifugal. iorces. Conventional cyclone designs that utilize tangential entry, reverse flow, and center tube discharge do not vary markedly in collection efficiency, regardless of design details such as tailored inlet scroll passages, cone angles, etc. For throughput 
sizes on the order of 20,000 ACFM, collection efficiencies on the order of 80-90 percent can be achieved for particles sizes of five microns. Several manufacturers utilize a multi-clone design to enhance separation of finer particles. This concept consists of clustering several small cyclones (tube diameters generally less than one foot) in a common enclosure. Both tangential and vertical inflow with swirler vanes are utilized. Units of this size are prone to plugging in the collection vessel area with sticky and/or large particles. Generally, the collection efficiency improvements with these configurations (relative to standard cyclones), at particle sizes of 2 microns or less, is minimal. Illustrated on Figure 3-5 are fractional collection efficiencies from several sources. A general assessment of collection efficiency is provided by "typical" curves from references 3 and 4. Also presented on the curve are manufacturers' quotes for a range of throughput sizes. As would be anticipated, the smallest unit has the highest collection efficiency. The efficiency differences between units is probably due to pressure drop allowances and minor design differences. For all units, however, the effectiveness drops off rapidly below 5 micron particle size. It can be concluded that standard cyclones are effective for stack cleanup only when particle sizes are expected to be in excess of 5 microns.

\subsubsection{Modified Cyclones}

Four modified cyclones were identified in the industry survey conducted. Both aerodynamic and mechanical enhancement techniques have been utilized. The performance quoted for these units is presented in Figure 3-6, compared to the range of standard cyclone performance presented on Figure 3-5. In all cases, the quoted efficiencies exceed that of the standard cyclones. The four units are discussed in the following subsections.

3.5.2.1 Aerodyne "SV" Collector - The SV collector utilizes a secondary gas flow to augment the inlet (dirty) gas flow as indicated in Figure 3-7. The manufacturer claims collection efficiencies of 100 percent at 6 microns and 92 percent at 2 microns. Westinghouse has tested the unit under cold flow conditions and hals been unable to verify these claims; measuring collection efficiencies on the order of 50 percent at five microns. General Electric has planned to utilize an aerodyne unit in a combined gas turbine/fluidized bed combustor unit, using part of the bed exit gas for the secondary inlet. Tests at one atmosphere and low 


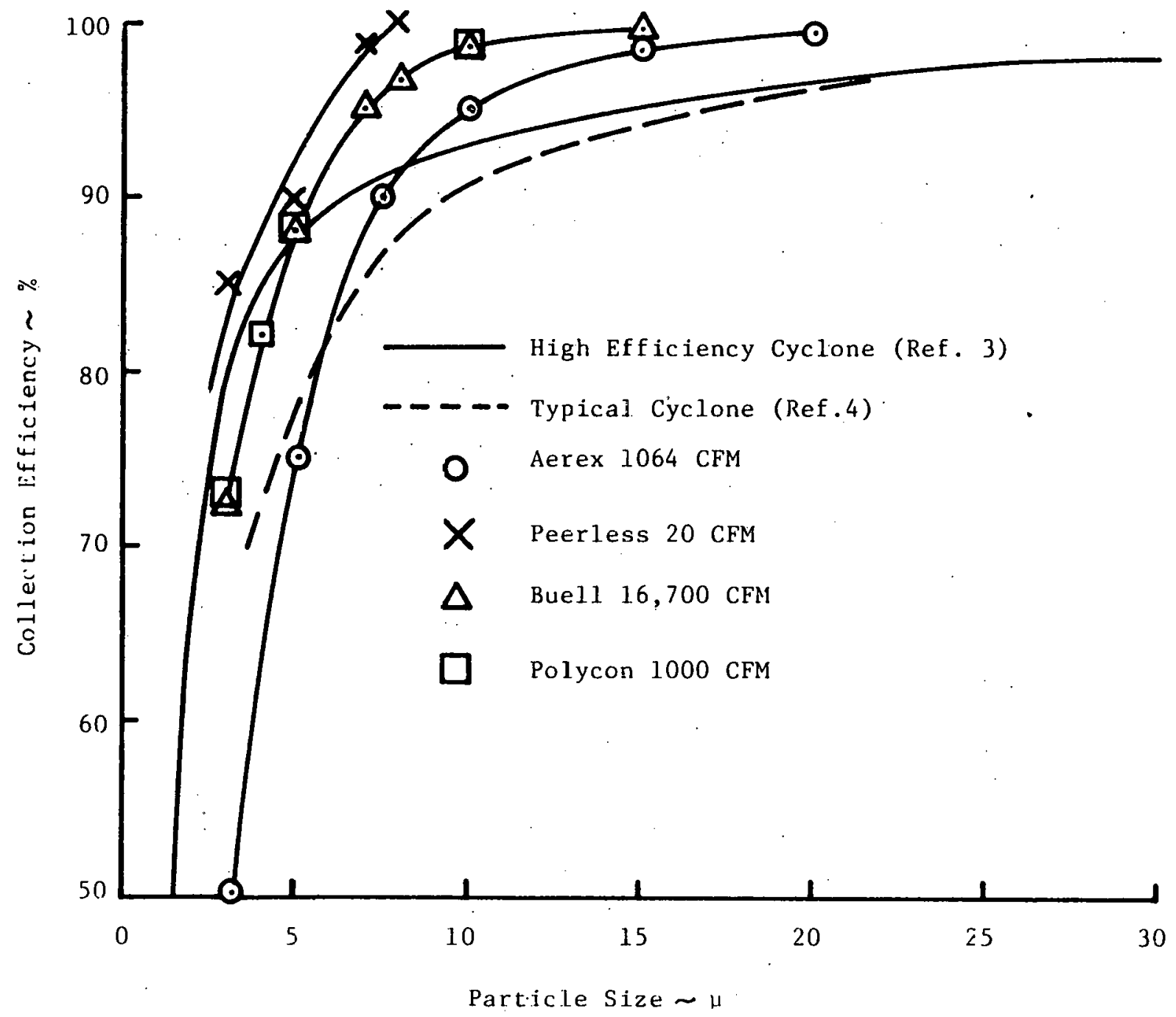

Fig. 3-5 Cyclone Performance Comparison 


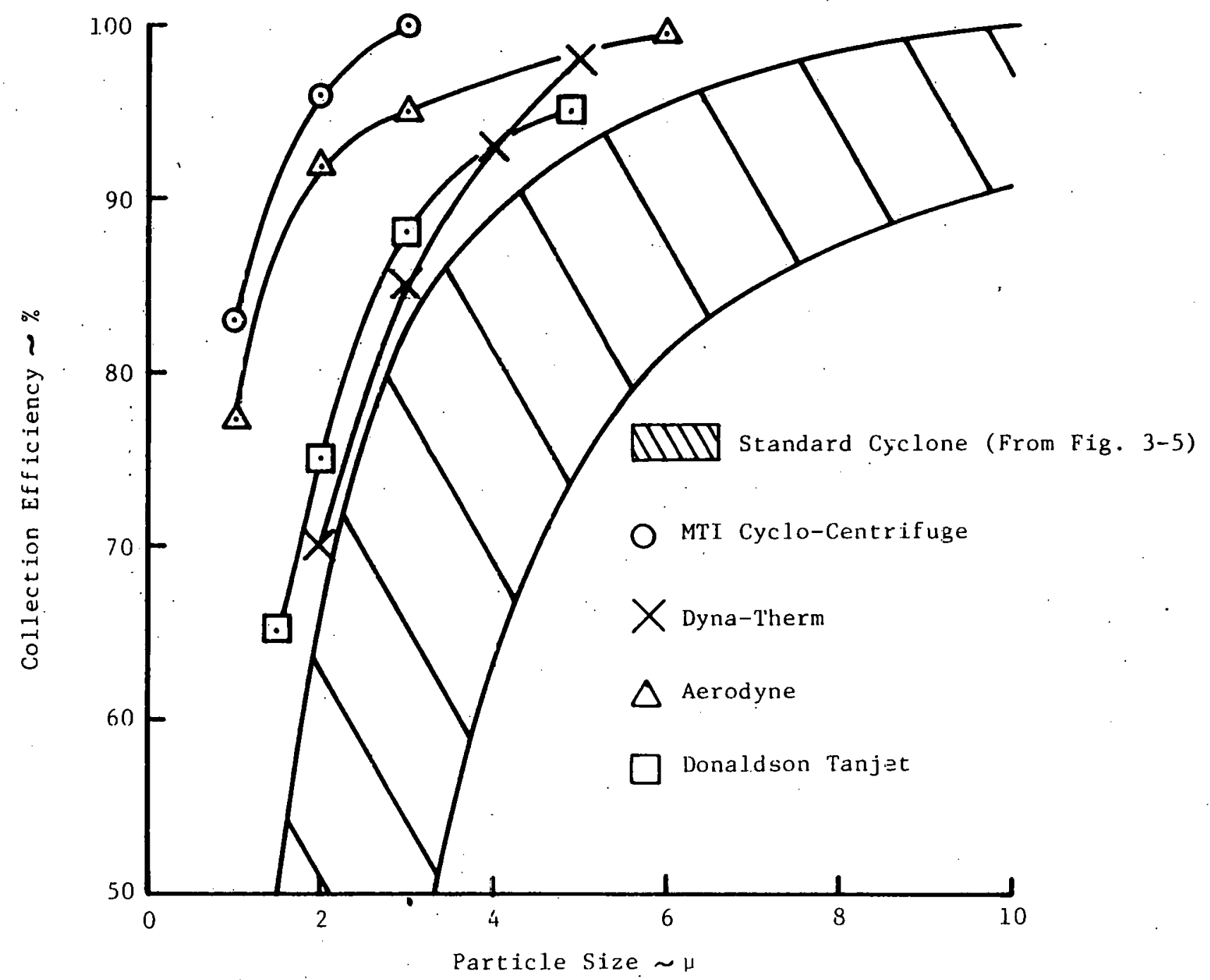

Fig. 3-6 Modified Cyclone Performance 


\section{Clean Gas}

$\uparrow$

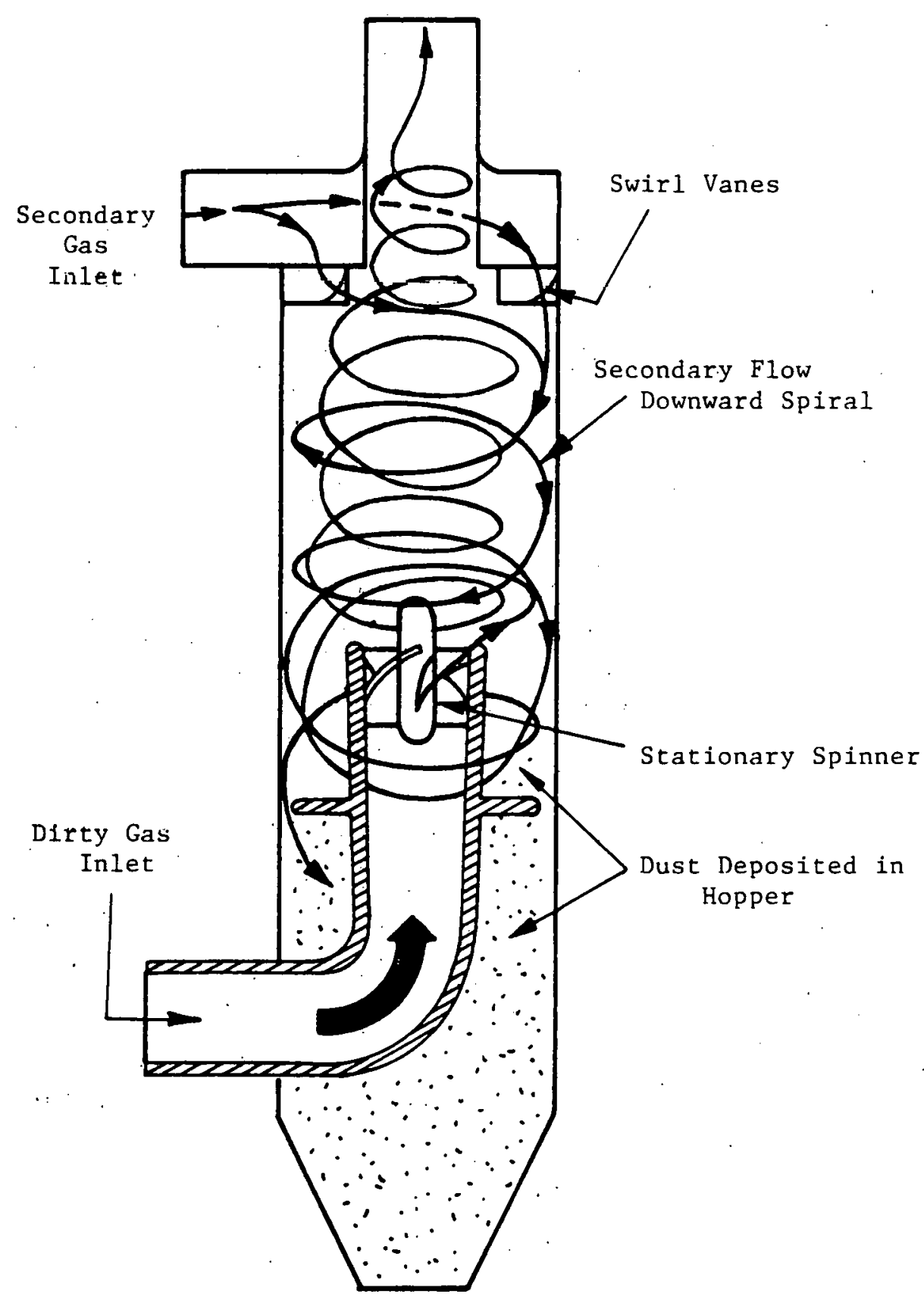

Fig. 3-7 Aerodyne Dust Collector 
temperature have indicated poor collection efficiencies (60 percent). Particle size distribution of 0-100 microns, with a mean particle size of 30-35 microns, was utilized in this test. It has been noted that many large particles escape from the collector and that no measurable improvement is evident at the smaller particle diameters.

\subsubsection{Donaldson Tanjet - The tanjet utilizes a high energy tangential} injection system on the O.D. of the inner collector tube. This tangential injection enhances the vortex strength and, in theory should improve separation capability. The vortex thus created is strong enough so that tangential inflow is not required. Development work on the tanjet was suspended due to a lack of market potential, resulting from the power requirements associated with the secondary air source supply. Also, problems were encountered with re-entrainment of particles due to the vortex strength. It is currently planned to continue the development program started in August 1978.

\subsubsection{MTI Cyclocentrifuge - The cyclocentrifuge utilizes a rotating,} bladed center tube to enhance vortex strength (Figure 3-8). The predicted collection efficiency is approximately 94 percent at 2 microns for 125,260 SCFM at 250 psia and $1000^{\circ} \mathrm{F}$ inlet temperature. This device is in the development stage with initial cold flow tests scheduled to begin in July 1978, with subsequent follow-on hot testing at Morgantown Energy Research Center:

\subsubsection{Dynatherm Solids Separator - The Dynatherm Solids Separator,} Figure 3-9, incorporates several design features that are a departure from the standard cyclone design. The initial flow is upward, a separator element is added to the center tube, and a third tube is added for clean gas exit. Efficiency claims state that 100 percent collection will be achieved at particle sizes of five microns and larger, and that 90 to 95 percent of particles, 1 micron in size or larger would be removed. Several units are currently in operation at catalytic cracking facilities at temperatures up to $950^{\circ} \mathrm{F}$. A visit was made to the Dyna-Therm Corporation to examine the design and investigate the collection efficiency claims. The "Whir1Away" separation element is typically a stamped louver unit claimed to 


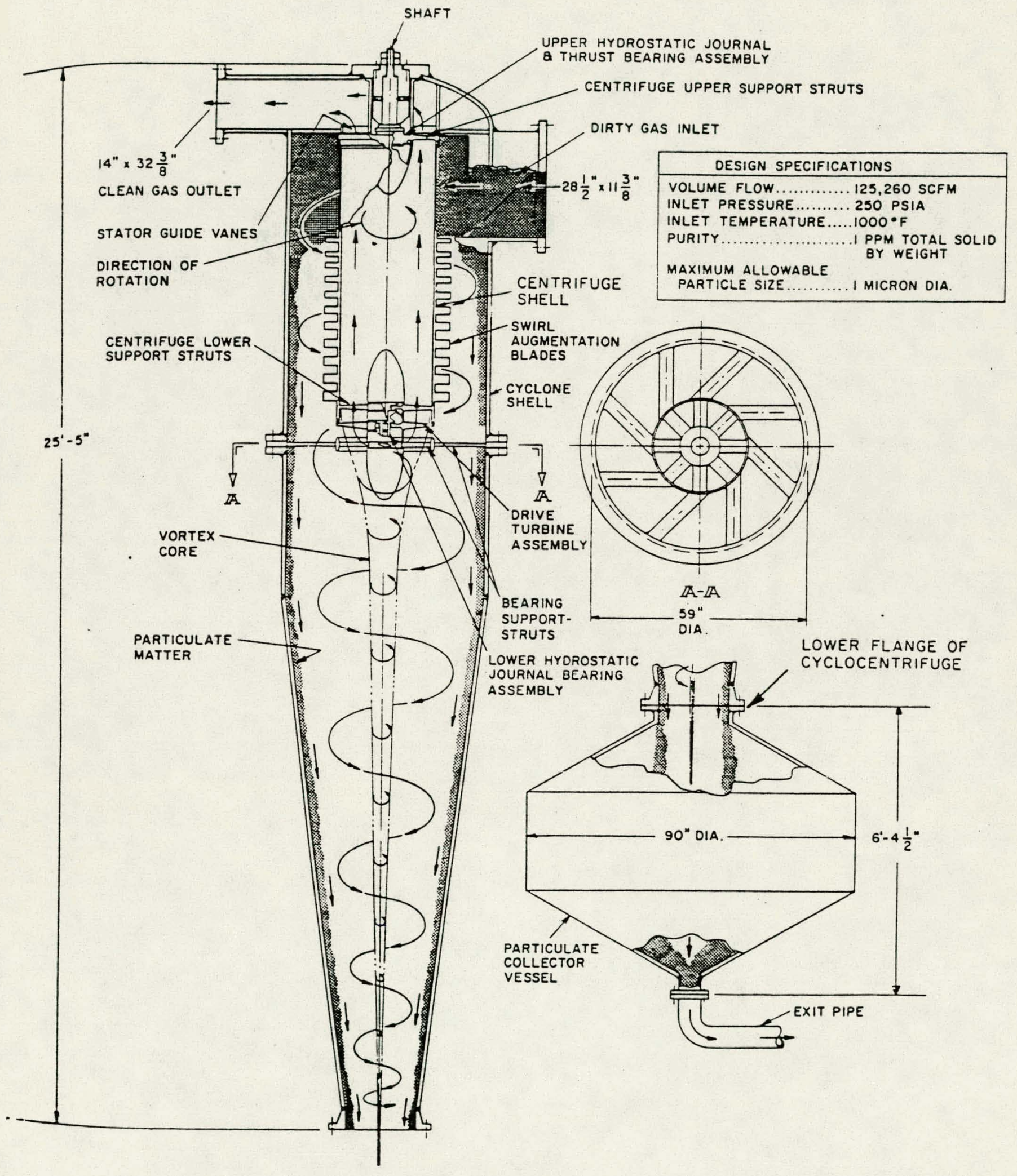

Fig. 3-8 Cyclocentrifuge, General Arrangement 


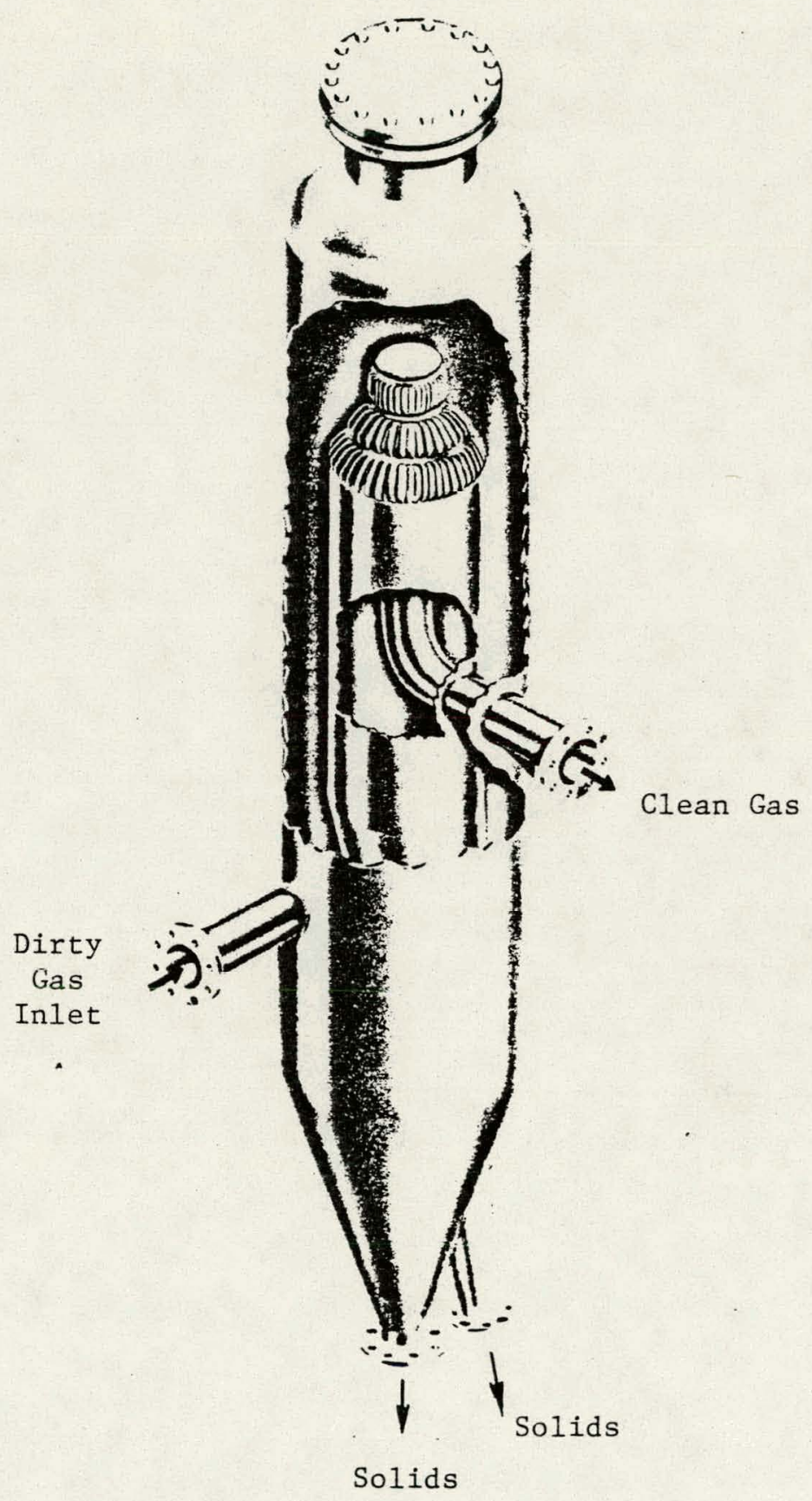

Fig. 3-9 Dynatherm Solids Separator 
direct the incoming gas flow along the inner collector tube outer wall. Collection efficiency claims could not be documented by the Dyna-Therm Corporation, although it is claimed that University of Florida tests were used to determine collection efficiency levels. The Dyna-Therm Corporation does not build hardware nor do they have facilities to test their product. It is recommended that this device be tested to verify or dispute the efficiency claims.

\subsection{Technology Voids and Development Requirements}

Current standard cyclone devices lack the potential to achieve effective particulate separation for particle sizes of less than five microns. It is conceivable that modified cyclone devices could be developed and used to reduce fouling tendencies in the superheater/reheater sections and also to reduce particulate loading on the exhaust cleanup system prior to coal dyring. There are two prime areas which must be addressed. First, in the superheater region, corrosion problems can be anticipated. Materials development (metals and refractory coatings) would be required to achieve successful sustained operation. Second, for stack cleanup or for removal of flyash and seed material, pirior to coal drying, the prime development requirement is to enhance collection efficiency of small particles. For the separation of pulverized coal after the coal drying process, standard cyclones would appear to provide sufficient collection capability due to the expected large particle size. 
REFERENCES FUR SECTION 3.0

1. "TRW 25MW Staged MHD Coal Combustor Conceptual Design Study", US ERDA Report TID-27145, June 4, 1976.

2. "Status of the Reference Dual Cycle MHD-Steam Power Plant", W.D. Jackson, et.al., 16th Symposium Engineering aspects of MHD.

3. "The Design and Performance of Cyclone Separators", C.J. Stairmand, Trans. Instn. Chem. Engrs., 1951.

4. "New Design Approach Boosts Cyclone Efficiency", Wolfgang H. Koch and William Licht, Chemical Engineering, November 1977.

5. Cyclone Manufacturers Surveyed:
a. Fisher-Klosterman, Inc., Louisville, Kentucky
b. Ducon Company, Inc.; Mineola, New York
c. Aerodyne Development Corp:, Cleveland, Ohio
d. AGET Manufacturing Company, Adrian, Michigan
e. Hammond Machinery Builders, Kalamazoo, Michigan
f. Peerless Mfg. Company, Dallas, Texas
g. Envirotech Corporation, Houston, Texas
h. General Electric Company, Schenectady, New York
i. Enviro-Systems \& Research Inc., Roanoke, Virginia
j. W.W. Sly Manufacturing Company, Cleveland, Ohio
k. Joy Manufacturing Company, Los Angeles, California
1. Dyna-Therm Corporation, Houston, Texas
m. She11 Development Company, Houston Texas (No Reply)
n. Van Tongeren, Reynoldsburg, Ohio (No Reply)
o. Donaldson Company, Minneapolis, Minn.
p. Dixie Manufacturing Company, Baltimore, Md. (No Reply)
q. W.C. Wiedenmann \& Son Inc., Kansas City, Mo (No Reply)
r. Seneca Environmental Products, Tiffin, Ohio (No Reply)
s. Aerex Corporation Scottstown, Quebec
t. Enviromental Elements Corporation Baltimore, Maryland

6. "Engineering Test Facility Conceptual Design", Preliminary Draft, AVCO Everett Research Laboratory.

7. "MHD EFT Conceptual Design", Draft Copy, Westinghouse. 